NBER WORKING PAPER SERIES

\title{
WHAT GETS MEASURED GETS MANAGED: INVESTMENT AND THE COST OF CAPITAL
}

\author{
Zhiguo He \\ Guanmin Liao \\ Baolian Wang \\ Working Paper 29775 \\ http://www.nber.org/papers/w29775 \\ NATIONAL BUREAU OF ECONOMIC RESEARCH \\ 1050 Massachusetts Avenue \\ Cambridge, MA 02138 \\ February 2022
}

We thank Chong-en Bai, Allen Berger, Loren Brandt, Hui Chen, Chang-Tai Hsieh, Jay Ritter, Zheng Michael Song, Bernard Yeung, and seminar participants at the Macroeconomy and Finance in China Conference, Hong Kong Polytechnic University, University of Florida, University of Nevada, Las Vegas, University of South Carolina, and Fanhai International School of Finance at Fudan University for valuable comments. We also thank Xin Wang for his input on the group company level data. Zhiguo He acknowledges financial support from the John E. Jeuck Endowment at the University of Chicago Booth School of Business. Guanmin Liao acknowledges financial support from the National Natural Science Foundation of China (grant \#71972180). All errors are our own. The views expressed herein are those of the authors and do not necessarily reflect the views of the National Bureau of Economic Research.

NBER working papers are circulated for discussion and comment purposes. They have not been peer-reviewed or been subject to the review by the NBER Board of Directors that accompanies official NBER publications.

(C) 2022 by Zhiguo He, Guanmin Liao, and Baolian Wang. All rights reserved. Short sections of text, not to exceed two paragraphs, may be quoted without explicit permission provided that full credit, including $\odot$ notice, is given to the source. 
What Gets Measured Gets Managed: Investment and the Cost of Capital

Zhiguo He, Guanmin Liao, and Baolian Wang

NBER Working Paper No. 29775

February 2022

JEL No. G31,G38

\begin{abstract}
$\underline{\text { ABSTRACT }}$
We study the impact of government-led incentive systems by examining a staggered reform in the Chinese state-owned enterprise (SOE) performance evaluation policy. To improve capital allocative efficiency, in 2010, regulators switched from using return on equity (ROE) to economic value added (EVA) when evaluating SOE performance. This EVA policy adopts a onesize-fits-all approach by stipulating a fixed cost of capital for virtually all SOEs, ignoring the potential heterogeneity of firm-specific costs of capital. We show that SOEs did respond to the performance evaluation reform by altering their investment decisions, more so when the actual borrowing rate was further away from the stipulated cost of capital. Our paper provides causal evidence that incentive schemes affect real investment and sheds new light on challenges faced by economic reforms in China.

\author{
Zhiguo He \\ University of Chicago \\ Booth School of Business \\ 5807 S. Woodlawn Avenue \\ Chicago, IL 60637 \\ and NBER \\ zhiguo.he@chicagobooth.edu \\ Guanmin Liao \\ School of Business \\ Renmin University of China \\ liaoguanmin@rmbs.ruc.edu.cn
}

\author{
Baolian Wang \\ Warrington College of Business \\ University of Florida \\ 314 Stuzin Hall \\ Gainesville, FL 32611 \\ Baolian.Wang@warrington.ufl.edu
}




\section{Introduction}

Incentives are everywhere, whether they are productive or counter-productive. As pointed out in "On the Folly of Rewarding A, while Hoping for B" by Kerr (1975), which is an Academy of Management Classic reprinted in 1995, "numerous examples exist of reward systems that are fouled up in that the types of behavior rewarded are those which the rewarder is trying to discourage, while the behavior desired is not being rewarded at all." Though widely acknowledged as the potential pitfalls of poorly designed incentive systems, empirical researchers face mounting challenges to study this issue in a rigorous way. To name one of these obstacles, because incentive arrangements are arguably the endogenous outcome of a complex process, comparing behaviors between firms with different managerial incentive arrangements may not necessarily reflect managerial incentives themselves.

By exploiting a staggered policy adoption experiment in China, this paper conducts an empirical analysis that directly speaks to the relationship between managerial incentives and firm behaviors, shedding light on Kerr (1975). Since 2004, the Chinese government, through State-Owned Assets Supervision and Administration Commissions (SASACs), has been using formula-based schemes to evaluate state-owned enterprises (SOEs). These schemes are based on four accounting measures. One of them was return on equity (ROE) initially, and later was replaced by economic value added (EVA) starting 2010. Because it includes a charge for the cost of all capital employed by a firm, EVA has been applauded as a measure of economic profit and is fundamentally more sound than ROE that captures accounting profit only (Rogerson, 1997).

More importantly, this EVA reform was launched with the goal to improve capital allocative efficiency in the Chinese economy (Stern, 2011). It is well-known that Chinese SOEs have access to cheaper credit and hence overinvest relative to their private peers (e.g., Song, Storesletten, and Zilibotti (2011); Brandt, Tombe, and Zhu (2013)), and this policy distortion is the root cause of China's capital allocative inefficiency. The EVA reform, with the primary motivation of urging SOEs to manage their capital more efficiently, has the potential to correct this policy distortion without touching the root cause itself. In other words, by modifying the performance evaluation metric, the 
EVA reform could discourage SOEs from overinvestment without changing their preferential credit access.

However, as has been typical in reforms conducted in any transition economy around the world, the devil is always in the details. Instead of using firm-specific costs of capital as a full-blown risk-based theory would suggest, the Chinese central SASAC — which lacks knowledge of local information a la Hayek (1945) and Huang, Li, Ma, and Xu (2017) — set the after-tax cost of capital at $5.5 \%$ for virtually all the SOEs under its control. ${ }^{1}$ Most local SASACs, if they decided to adopt the EVA policy, also chose to follow, albeit in different years. In other words, the implementation of EVA reform ignores the potential heterogeneity of firm-specific cost of capital.

During our sample period, listed firms faced tight regulations on external equity financing in China. Our theoretical framework in Section 3 hence assumes that firms adjust their financing margin through debt at their firm-specific borrowing interest rates. ${ }^{2}$ Before the EVA policy, a firm invests until its marginal operating profit equals its actual marginal cost of debt, while after the EVA policy, the firm invests until it hits the stipulated 5.5\% cost of capital. Assuming a decreasing return to scale, we expect that the higher the marginal cost of debt a firm had before the EVA adoption, the more the firm investment will increase in the post-EVA period.

Our empirical analysis, which directly speaks to the question "Do incentives matter?", starts by studying how the EVA policy adoption affected the investment of firms with different interest rates, using a panel of 638 SOEs listed on either the Shanghai or the Shenzhen Stock Exchanges. From 2010 to 2015, the central SASAC and fourteen provincial SASACs adopted the same EVA policy. To tease out the sole effect of the EVA policy, we not only rely on the staggered adoption of the EVA policy but also exploit an important institutional feature to address the potential endogeneity issue regarding the EVA adoption decisions.

The following example illustrates our identification strategy, which is essentially a differencein-differences-in-differences (DDD) approach. The Beijing SASAC (treatment group) adopted the EVA policy in 2010, after which firms under the Beijing SASAC with high interest rates increased

\footnotetext{
${ }^{1}$ The reason that the central SASAC chose $5.5 \%$ as the cost of capital was never disclosed. In 2009, the benchmark interest rates for bank loans with maturity between one to three years (the most popular maturity range) were from $5.31 \%$ to $5.40 \%$. Vice Director of the SASAC Shuhe Huang said, "The capital returns have to be higher than the bank loan interest rate." (Adfaith, 2005). This seems to suggest that 5.5\% was chosen to equal the bank loan interest rate. However, the $5.5 \%$ stipulated cost of capital is after-tax, while the bank loan interest rate is before tax.

${ }^{2}$ We provide more discussion on the external equity financing regulations in Section 4.6.3.
} 
their investment more than firms under the Beijing SASAC but with low interest rates. This gives us a difference-in-differences (DD) estimation, but there is a concern: Firms with different interest rates were not the same, and investment opportunities might have changed in 2010 in a way that affected Beijing SOEs with high interest rates differently from those with low interest rates, regardless of the EVA policy adoption. To address this concern, we compare the DD estimation of the SOEs under the Beijing SASAC with a similarly calculated DD estimation of the SOEs controlled by other SASACs without an EVA adoption in 2010, say Shanghai (control group). If the investment difference between firms with high and low interest rates was affected by the similar investment opportunity change in 2010 regardless of their SASAC affiliations, the DD estimation of Shanghai provides a counterfactual of Beijing's DD, yielding the desired estimate of the effect of the EVA policy.

Following the above DDD methodology, we show that firms with a higher interest rate increased their investment more than firms with a lower interest rate in the post-EVA period, consistent with our prediction. A standard deviation (3.3 percentage points) increase in the interest rate leads to about a 0.6 percentage point increase in a firm's investment, measured as capital expenditure divided by lagged total assets. The effect is economically sizable as the median firm investment was 4.6\%. We also confirm the parallel trends assumption for both the treatment and control groups in the pre-EVA period, lending support to a causal interpretation of our results.

One remaining concern about the DDD strategy is the potential endogeneity of the EVA policy adoption, as there may be business cycle factors that coincided with or even led to the EVA policy's adoption, giving rise to changing economic conditions specific to the EVA-passing SASACs. Although empirically, the EVA policy adoption's timing does not seem to be correlated with many provincial-level factors, we address this concern by exploiting a unique feature of the EVA policy adoption. EVA adoption by a SASAC affects all the firms under its control, independent of the firms' locations. For instance, central SOEs are located all over the country; for local SOEs, while most of them and their SASACs are located in the same province, some are in other provinces. This allows us to include province-year fixed effects to control for time-varying provincial-level factors. Our estimation is essentially unchanged under this specification. ${ }^{3}$

\footnotetext{
${ }^{3}$ We exploit another variation in the data that can address this concern by treating non-SOEs as placebos since they were not subject to the EVA policy. In the placebo test, we assign a provincial SASAC's EVA adoption year to the non-SOEs located in that province. Among the non-SOEs, we find no significant change in the investment
} 
The EVA policy has implications on firm performance from the shareholders' perspective; we will discuss the welfare implication from the planner's perspective shortly. The EVA policy leads firms to deviate from using their actual borrowing cost toward the stipulated cost of capital. For firms with an interest rate higher (lower) than the stipulated one, the EVA policy encouraged them to raise (cut) their investment, giving rise to overinvestment (underinvestment) that is detrimental to shareholder value. More specifically, our theory in Section 3 predicts that the EVA policy lowers a firm's ROE as long as its actual interest rate differs from the stipulated cost of capital and that ROE decreases more when the interest rate is further away from - either above or below - this threshold. Our empirical results lend strong support for this prediction; for instance, firms with an interest rate below $3.5 \%$ or higher than $9.5 \%$ had a ROE reduction of about 4-6 percentage points.

We conduct our main analysis based on the listed SOE firms for data quality issues, but we show that our results are robust to using group-level data. We further explore the underlying economic mechanisms at work in the EVA reform, by first showing that the adoption of the EVA policy strengthens the relationship between a firm's EVA performance and its forced executive turnover (i.e., demotions), but not executive compensation. This result points to a unique feature of managerial incentives in Chinese SOEs wherein managers are more like government officials. On potential heterogeneous effects concerning manager characteristics, we find that managers with little equity ownership or managers with government experience were more likely to comply with the EVA rules.

In the last part of the paper, we study whether the EVA policy improves the capital allocative efficiency from a social perspective, both theoretically and empirically, under the premise that the EVA rules are implemented at their full scale. Returning to the opening quote in Kerr (1975), Chinese authorities are hoping for "capital allocative efficiency" by "EVA-based rewarding" that uses a uniformly stipulated cost of capital. Although the EVA policy hurts individual firms' performances (from the shareholders' perspective), it may improve aggregate capital productivity by mitigating capital misallocation, either within SOEs (say, moving the capital from less efficient SOEs to more efficient ones), or from SOEs to more productive non-SOEs. ${ }^{4}$

We base our welfare discussion with a framework where risk plays an important role in determin-

difference between the low and high interest rate firms.

${ }^{4}$ There is an extensive literature on capital allocative efficiency; see Restuccia and Rogerson (2013) and Syverson (2011) for more details. 
ing the firm's cost of capital and hence the economy-wide capital allocative efficiency. Risk is not highlighted in the literature pioneered by Hsieh and Klenow (2009), but is central to the finance literature (say, the classic capital asset pricing model (CAPM) by Sharpe (1964) and Lintner (1965)). The EVA's welfare implication crucially depends on whether the true cost of capital, which reflects the fair market-based risk compensation, is equal across firms. Intuitively, the observed dispersion in interest rates could be either driven by policy distortions and such dispersion represents a "bad" one. The observed dispersion in interest rates could also be driven by heterogeneous risk premia, and such a dispersion represent a "good" one. A "one-size-fits-all" EVA policy could kill both bad and good dispersions, and, therefore, potentially do more harm than good to the social welfare.

In our empirical investigation, we first study the capital allocative efficiency within the SOE sector. We construct a measure of the true cost of capital based on the pre-EVA data and document that, in response to the EVA policy, industries with a higher true cost of capital increased their investment more than industries with a lower true cost of capital. Under the assumption that SOE firms in the same industry share the same cost of capital, ${ }^{5}$ this hints at a negative welfare impact of the one-size-fits-all EVA policy. A further variance decomposition exercise shows that, in our data, only about half of the cross-SOE variations in their actual costs of capital (i.e., including policy distortions) are within-industry variations, which represent "bad" dispersion under the premise of equal cost of capital within any industry. Although this result points to considerable scope for the EVA policy to eliminate the "bad" dispersion, it also warns that the EVA policy may kill a significant portion of good dispersion as well. Overall, we offer preliminary but mixed evidence as to whether the EVA reform improves the overall allocative efficiency within SOEs, and we await future research that can offer more evidence on this important question.

On the second question of capital reallocation from SOEs to non-SOEs, we find no evidence that non-SOEs increased their investment more than SOEs after the EVA policy, suggesting no improvement on this front. This is consistent with the criticism that the stipulated cost of capital was not high enough (Stern, 2011). ${ }^{6}$

\footnotetext{
${ }^{5}$ As we explain in Section 5.2, this is a common assumption in the finance literature (e.g., Krüger, Landier, and Thesmar (2015)) and has been widely used among industry practitioners (Berk and DeMarzo (2017)). We classify firms into 60 industries based on three-digit industry classification codes provided by the Guidelines for the Industry Classification of Listed Companies (2012) of the Chinese Securities Regulatory Commission.

${ }^{6}$ Based on our estimation, the average after-tax interest rate of our sampled publicly listed SOEs was $4.4 \%$, which is $1.1 \%$ below the $5.5 \%$ stipulated cost of capital. Our study suggests that a margin of $1.1 \%$ is not significant enough to push capital flow from SOEs to non-SOEs. Of course, there exists another caveat for interpreting this result to
} 
Although we cannot reach a conclusion as to whether the EVA policy improved capital allocative efficiency, our evidence shows that the current EVA policy has room for improvement. For instance, Chinese authorities who are "hoping" for capital allocative efficiency could at least fine-tune the "rewarding" system to account for the industry heterogeneity. Perhaps because they are aware of potential pitfalls of the fixed stipulation in the cost of capital, the Chinese central SASAC changed to use the firm-specific cost of capital for their EVA evaluation in 2016. However, how the cost of capital has been calculated is not disclosed, and we await future research to study this reform.

Literature Review. This paper contributes to the literature studying whether and how manager incentives affect firm operation and performance, both in China and beyond. Although an extensive literature exists on the relation between manager incentives and firm behaviors, the endogenous nature of managerial incentives poses significant challenges for studies on this issue (e.g., Frydman and Jenter, 2010; Edmans, Gabaix, and Jenter, 2017). ${ }^{7}$ For clean identification, this literature then exploits certain intriguing institutional details on arguably "exogenous" compensation arrangements (e.g., restricted stocks or stock options vesting). ${ }^{8}$ By exploiting a Chinese policy reform aimed directly at managerial performance evaluations, we present clean causal evidence on the role of incentives by utilizing the EVA policy as a "natural experiment."

The EVA policy is directly aimed at improving the capital allocative efficiency in China. Capital misallocation can lower aggregate productivity (Restuccia and Rogerson, 2008; Hsieh and Klenow, 2009; Midrigan and Xu, 2014). Regulations, property rights, trade and competition, and financial and informational frictions are all causes of capital misallocation (Restuccia and Rogerson, 2017). Studies on policy distortion caused by SOEs' cheaper credit access are most relevant to ours. Brandt and Li (2003) show that private firms face discrimination from banks in China, but that

compare SOEs and non-SOEs: SOEs and non-SOEs exhibit different investment patterns (e.g., Brandt and Zhu, 2000; Li, Liu, and Wang, 2015). In other words, the parallel trends assumption might not hold. In particular, in our sample period, to mitigate the effect of the 2007--2008 financial crisis, the Chinese government encouraged SOEs to invest (Deng, Morck, Wu, and Yeung, 2015; Cong, Gao, Ponticelli, and Yang, 2019). Hence, it is possible that an average SOE would have decreased its investment due to the EVA policy, had the 2007-09 financial crisis never happened.

${ }^{7}$ Most studies in the United States have focused on how CEO pay structure (e.g., pay-performance sensitivity, option grants, deferred compensation) correlates with firm policy and performance. However, as compensation arrangements are endogenous, it is hard to interpret these correlations as causal. Murphy (1999, 2013), Frydman and Jenter (2010), and Edmans, Gabaix, and Jenter (2017) provide extensive surveys of this literature.

${ }^{8}$ For instance, Edmans, Fang, and Lewellen (2017) study how CEOs' equity vesting affects their firms' real investment decisions, and Shue and Townsend (2017) study how exogenous CEO option grants affect firm risk-taking. Based on a regression discontinuity framework, Flammer and Bansal (2017) find that narrowly passed shareholder proposals granting executives long-term incentives increase firm value. 
this discrimination diminishes with proper managerial incentives in banks. In Song, Storesletten, and Zilibotti (2011), the misallocation of resources between SOEs and non-SOEs is a key source of productivity loss, which has gained increasing attention over the years after China's four-trillion RMB stimulus package in 2009 (Bai, Hsieh, and Song, 2016; Chen, He, and Liu, 2020). Dollar and Wei (2007) find that SOEs have significantly lower returns to capital than non-SOEs. ${ }^{9}$ More recently, Geng and Pan (2021) study the time-variation of implicit guarantee and discrimination against non-SOEs in China's fast-growing corporate bond market. ${ }^{10}$ In contrast, our study takes a more reduced-form approach and provides direct evidence that policy regulation of the cost of capital has a first-order impact on capital allocation.

Our study is closely related to the literature on SOE reforms in China. ${ }^{11}$ By the early 2000s, most small SOEs had been privatized. SASACs were established in 2003 to monitor the remaining big SOEs (Naughton, 2008, 2015; Li and Zhang, 2021). Instead of continuing to privatize SOEs, SASACs focused their monitoring on setting up manager evaluation rules, and the EVA reform was one of the most significant reforms since then. We show that the EVA policy reform did manage to influence the real activities of SOEs by changing the hurdle rates for capital budgeting. ${ }^{12}$ However, it should not be taken for granted that economic incentives matter for the business operation of SOEs; our findings on the importance of these incentives could serve as a positive sign for the future of economic reform, as many researchers consider SOEs - especially central SOEs - to be run like political bureaucracies, with a significant number of them operating beyond the control of SASACs. What is more, our analysis shows that if the EVA policy can be implemented based on firm-specific "local knowledge" a la Hayek (1945), such a reform could potentially bring a significant welfare improvement.

Our paper is also useful for thinking about policy distorted credit activities. SOEs or organiza-

\footnotetext{
${ }^{9}$ Brandt, Tombe, and Zhu (2013) find that resource misallocation between SOEs and non-SOEs in China reduces non-agricultural productivity by an average of 20\%, and Bai, Lu, and Tian (2018) incorporate savings in a model with financial frictions and find the aggregate TFP loss to be about 12\%. Finally, Li, Wang, and Zhou (2021) study the effect of the anti-corruption campaign on credit reallocation between SOEs and non-SOEs.

${ }^{10} \mathrm{Amstad}$ and He (2019) provide an overview of the institutional background of the Chinese corporate bond market. For the most recent studies on this market, see Chen, Chen, He, Liu, and Xie (2020) and Ding, Xiong, and Zhang (2020), among others.

${ }^{11}$ The Chinese government has adopted several methods to reform the SOE sector, including shifting the responsibility for firm decisions to firms in the 1980s (Groves, Hong, McMillan, and Naughton, 1994), delegating firm monitoring to lower-level governments (Huang, Li, Ma, and Xu, 2017), and privatization in the 1990s (Hsieh and Song, 2015).

${ }^{12}$ This echos Brandt and Li (2003), who show that bank managers' economic incentives in China's state-owned financial institutions alleviated their discrimination against private firms.
} 
tions with similar natures exist around the world, as governments often provide implicit or explicit guarantees to too-big-to-fail financial institutions and nonfinancial firms (Lucas, 2014). While we do not advocate a simple EVA policy for all these institutions, such an approach may help them recognize any cost of government guarantees in their decision making, especially when removing such guarantees is not an option.

This paper proceeds as follows. Section 2 describes the regulations of Chinese SOEs and the details of the EVA policy. In Section 3, we develop a simple framework and develop our predictions. Section 4 describes the data, explains our methodology, and reports the main empirical results. Analysis on the capital allocative efficiency is presented in Section 5, and Section 6 concludes.

\section{Chinese SOEs and the EVA Reform}

We provide institutional background in this section.

\subsection{The SOE System in China and the SASAC}

The SOE system in China has undergone significant reforms in the last four decades. Before 1978, SOEs were directly under the management of the Chinese government. Reforms gave them increasing autonomy (Groves, Hong, McMillan, and Naughton, 1994; Mengistae and Xu, 2004) so that, by the 1990s, many SOEs had become independent production and management entities.

To monitor these SOEs, the Chinese government established the SASAC system in March 2003. The SASACs were set up simultaneously at the central and local government levels. The SASACs represent the government authority as the legal owner of the SOEs and is designed to monitor the SOEs and ensure that they advance the government's interests. The SASACs accomplishe this by appointing auditors and boards of directors, establishing procedures for appointing managers, approving major decisions including mergers, bankruptcies, the issuance of stocks, and major new strategic initiatives, and reporting SOEs' performance to the appropriate level of government. Most relevant to our study, the SASACs conduct annual performance evaluations of SOE managers. ${ }^{13}$ The SASACs make their reward or punishment and personnel decisions concerning SOE managers

\footnotetext{
${ }^{13}$ Besides annual performance, the SASACs also consider performance over the past three years. For the threeyear performance evaluation, they mainly consider average sales growth and average growth of firm equity (after considering external equity financing and dividend payments).
} 
based on these evaluations. ${ }^{14}$

SOEs are controlled by different levels of the Chinese government. Some are controlled by the central government, and others are controlled by provincial or lower-level governments. An SOE is under the watch of the SASAC at the appropriate level of government that controls it. The majority of local SASACs adopt monitoring rules similar to the central SASAC. Next, we discuss the rules adopted by the central SASAC.

\subsection{Performance Evaluation Procedures}

The SASAC bases its performance score on a formula that uses several objective performance measures. Two of these measures are mandatory across all SOEs. The SASAC also chooses other supplementary measures based on industry and firm characteristics. Common measures include inventory turnover, accounts receivable turnover, and sales growth. From 2004 to 2009, the two mandatory measures were earnings before tax and extraordinary items (EBT) and return on equity (ROE). Starting from 2010, ROE was replaced by economic value added (EVA). EBT has base points of 30, ROE (and later EVA) has 40, and the supplementary measures have 30 in total.

The formula assigns points to SOEs based on whether they exceed or fall short of performance targets. Achieving above-target performance increases the points earned, and below-target performance decreases the points earned (capped and floored at $\pm 20 \%$ ). For example, every $0.4 \%$ increase in an SOE's realized ROE leads to an extra point, capped at 8.

Performance targets are negotiated with SOE managers at the end of the previous performance period and are subject to stringent guidelines. For example, they generally cannot be lower than the average of the last three years' performance and are heavily influenced by a firm's industry performance and the Chinese government's GDP growth objectives. ${ }^{15}$ Based on interviews with SASAC officials, Du, Erkens, Young, and Tang (2018) conclude that subjectivity does not play a significant role in setting target levels.

\footnotetext{
${ }^{14}$ In some cases, the Organizational Department of the Chinese Communist Party makes the personnel decisions. Based on our conversations with officials from both the SASACs and the Organizational Department, even for these cases, the SASAC evaluations are important factors that the Organizational Department considers in making their decisions.

${ }^{15}$ One concern about the effectiveness of a target-based performance evaluation scheme is the ratchet effect (Weitzman, 1980; Freixas, Guesnerie, and Tirole, 1985). A firm's industry performance and the Chinese government's GDP growth objectives are largely out of any individual firm's control. Linking the target to the past three years' performance also mitigates the ratchet effect, as the average manager tenure is 2.5 years.
} 
If one performance measure of an SOE is higher than the target, the SASAC will adjust the raw score by a factor (between 1 and 1.15) that reflects the degree of operational difficulty. The degree of operational difficulty is a subjectively determined parameter based on assets, revenue, total profit, return on equity, number of employees, and the ratio of retired employees to total employees. The SASAC indicates that they deduct punishment points if an SOE has severe safety incidents or has been involved in financial fraud or other scandals. They get extra points if they have acquired financially distressed SOEs. These adjustments cannot be more than 2 points.

After collecting all the data, the SASAC determines cutoff scores so that each SOE can be assigned to one of five rating categories, $A$ to $E$. A score of " $C$ " or above is considered acceptable, and SOE executives in $D$ - and $E$-ranked firms may be asked to step down. According to the publicly disclosed rules, executive incentive pay and promotion/demotion decisions are a direct function of the rating they get.

\subsection{The EVA Reform}

In 2010, the central SASAC replaced return on equity (net income divided by equity), or ROE, with EVA in the performance evaluation system. EVA is a measure of operating income that, by including a charge for the cost of all capital employed by a firm, provides a measure of economic profit. EVA measures value creation for shareholders, and theoretically, it is a better performance measure than ROE, which measures accounting profit (Rogerson, 1997). More specifically, define Adjusted Capital to be $\mathrm{b}^{16}$

Adjusted Capital $=$ Equity + Liabilities - Adjustment,

and Net Operating Profits after Tax (NOPAT) to be

NOPAT $=$ Net Income $+0.75 \times\left(\right.$ Interest Expenses + R\&D Expenses $\left.-\frac{\text { Nonrecurring Income }}{2}\right)$,

\footnotetext{
${ }^{16}$ Here, the "Adjustment" includes interest-free current liabilities and construction in process.
} 
and then Economic Value Added (EVA) is calculated as

$$
\text { EVA }=\text { NOPAT }- \text { Adjusted Capital } \times \text { Cost of Capital. }
$$

The EVA formula adds after-tax interest expenses back to net income and fixes the "Cost of Capital" in Eq. (2) at 5.5\%. The factor of 0.75 is to adjust for tax, as the running tax rate at that time in China was 25\%. As a result, it is as if the new policy stipulates a $5.5 \%$ after-tax cost of capital on the firm or $7.3 \%(5.5 \% / 0.75)$ on a pre-tax basis. In Section 3, we develop our hypotheses on how the EVA policy affects firm investment and valuation. ${ }^{17}$

The stipulated cost of capital of $5.5 \%$ applies to virtually all SOEs, though with a few exceptions. One such exception is for firms that are too levered; specifically, industrial firms with debt/asset ratios higher than $75 \%$ or non-industrial firms with debt/asset ratios higher than $80 \%$ have a cost of capital at $6 \%$. These firms account for about $8 \%$ of our sample. We exclude them from our analysis. Our empirical results are robust to whether we include them or not. ${ }^{18}$

Although the majority of the local SASACs adopted the same rules as the central SASAC, some provincial SASACs adopted different rules for calculating the cost of capital. In Hebei and Gansu, the actual cost of debt is considered in EVA calculations. Hebei also uses the actual cost of equity (however, it did not disclose how the cost of equity is calculated). Gansu sets the cost of equity at $7 \%$. Anhui sets the cost of capital at $4.5 \%$ instead of $5.5 \%$. Shaanxi sets a firm's cost of capital as the average return on assets of its industry peers. These four SASACs account for about $9 \%$ of our final sample. We exclude these four provincial SASACs from our analysis. We also exclude Tibet SASAC because its information is missing.

\footnotetext{
${ }^{17}$ Besides the above change, the EVA policy adds back R\&D expenses and half of the nonrecurring income. These adjustments may have changed firms' policies. For example, they may have increased firms' incentive to invest in R\&D (this was one of the SASAC's motivations). However, these two adjustments are unrelated to a firm's interest rate. In Section 4.6.3, we confirm that the EVA policy did increase firms' R\&D expenses, providing additional evidence that the EVA policy had affected SOEs' behaviors.

${ }^{18}$ Other exceptions are firms with significant policy burdens and high asset specificity, say military service-related firms. Their cost of capital is stipulated to be $4.1 \%$. Most of these firms are not publicly listed and therefore not in our sample.
} 


\subsection{The Staggered Adoption of the EVA Policy}

We manually collected information on the details of the EVA policy for each province. ${ }^{19}$ We primarily rely on the performance evaluation reports or announcements available on the SASAC websites and occasionally on our direct contact with SASAC officials. We end our sample in 2015 because the central SASAC revised the EVA policy but did not disclose the details of the new performance evaluation policy.

In our final sample, besides the central SASAC, we have fourteen provincial SASACs that also adopted the EVA policy, in a staggered fashion. Figure 1 presents the year of the EVA policy adoption for each SASAC. Figure 1 does not reveal any clear pattern on the timing of the EVA policy. For example, the Beijing SASAC adopted the EVA in 2010, while Tianjin and Shanghai did not adopt it by the end of our sample period. In Table 1, we conduct a more formal test. Table 1 presents the results on how province-level characteristics affect the timing of the EVA policy adoption. The unit of analysis is province-year. The dependent variable is one if a province adopted the EVA policy in that year and zero otherwise. Province-year observations after a province adopted the EVA are excluded. All the independent variables are lagged by one year.

We consider both economic and political factors: GDP growth, GDP per capita, age and tenure of Party secretary, the proportion of SOE assets among all industrial enterprises (\% of SOE Assets), and an index measuring the province's marketization level. Data on province marketization level are from Fan, Wang, and Zhu (2010) and Wang, Fan, and Hu (2019) and data on province Party secretaries are from the Chinese Research Data Services Platform (CNRDS). All other data are from the China Stock Market \& Accounting Research (CSMAR) Database. The results show that the only variable significant at the $5 \%$ level is \% of SOE Assets, suggesting that provinces with a higher fraction of assets under SOEs' control are more likely to adopt the EVA policy than other provinces. However, when we put all the variables into one regression, its statistical significance disappears. Broadly speaking, the EVA policy adoption timing is not strongly correlated with any of these variables. Later in the paper, we design tests to mitigate further the concern that the EVA policy adoption may be endogenous.

\footnotetext{
${ }^{19}$ Different levels (provincial, prefectural, or county) of the Chinese government have their own SASACs. In this paper, we focus on the provincial-level SASACs. First, a majority of the SOEs in our sample (firms listed on the Shanghai and Shenzhen Stock Exchanges) are controlled either by the central SASAC or the provincial SASACs. Second, information on local EVA policy adoption for lower-level governments is very difficult to collect.
} 
Finally, before the formal adoption of the EVA policy in 2010, the central SASAC had encouraged central SOEs to use the EVA formula to calculate their performance, and some SOEs had started to report their EVA to the SASAC. However, EVA was never used in actual evaluation until 2010. We argue that the partial anticipation of the EVA policy should not have affected our estimation because firms did not have incentives to maximize their EVA until it became effective (Hennessy and Strebulaev, 2020).

\section{A Theoretical Framework}

\subsection{The Setting}

Consider a model where an SOE firm chooses the capital scale of $K=D+E$, where $D$ denotes debt and $E$ denotes equity. We assume a standard production function $F(K)=F(D+E)$ with usual regularity conditions $F^{\prime}(K)>0$ and $F^{\prime \prime}(K)<0$. We assume that this SOE firm receives the following cash flows from its production

$$
\Pi(K)=\Pi(D+E)=\left(1-\tau_{Y}\right) F(D+E) .
$$

Here, $\tau_{Y}$, which could be firm specific, captures the so-called output wedge following the capital allocative efficiency literature (e.g., Hsieh and Klenow, 2009) and includes the standard corporate taxes (with a rate of $\pi$ ) as well as government subsidies (excluding indirect subsidies via lower interest rates, which will be discussed soon). ${ }^{20}$ We allow for any general $\pi_{Y}$ to ensure that our main empirical prediction, which relies on a difference-in-differences methodology, is robust to this dimension of heterogeneity in the data.

Following Hsieh and Klenow (2009) we implicitly define the capital cost wedge $\tau_{K}$, which captures the difference between the SOE's actual rate and the economy-wide equilibrium discount rate $r$ :

$$
r_{D}=\left(1+\tau_{K}\right) r
$$

The capital cost wedge $\tau_{K}$ can also be firm specific, which, similar to $\tau_{Y}$, distorts the firm's

\footnotetext{
${ }^{20}$ Note that in the standard corporate finance literature, when $\tau_{Y}=\pi, F(K)$ represents the earnings before interest and taxes (EBIT) of the firm, and $\Pi(K)$ is the earnings before interest after tax (EBIAT).
} 
investment decision as well. It could capture the government's cost of capital subsidy; the cheaper the credit access, the smaller (more negative) the $\tau_{K}$ is and hence the lower the expected financial cost. Importantly, in our data, we observe $r_{D}$ directly.

We highlight two conceptual points of our framework. We do not analyze risk in the main model; this is quite straightforward if all the risks associated with project cash flows are idiosyncratic, so only expected cash flows matter. We do offer a simple model with aggregate risk in Appendix A.1; there, we illustrate that the key empirical predictions in Section 3.3 are robust to the presence of aggregate risk. ${ }^{21}$

However, risk premia do play a role in our welfare discussion in Section 5, as we highlight that in our framework, the "right" discount rate $r$ could be firm specific. This possibility is implicitly assumed away by the standard capital allocative efficiency literature (e.g., Hsieh and Klenow, 2009), but it is widely acknowledged by the finance literature dated back to Modigliani and Miller (1958), which says that the appropriate discount rate should include the "risk premium" based on the risk profile of the firm's cash flows. This important conceptual difference matters little in most parts of our paper, which is mainly concerned with the positive implications of the EVA policy reform. However, it plays a key role when we discuss the normative implications later in Section 5 .

\subsection{Assumptions and Discussions}

Throughout the paper, we assume that debt, rather than equity, is the financing margin to adjust for the firm's investment. Section 4.6.3 provides empirical evidence for this premise, which is driven by the unique regulatory environment in China. During our sample period, external equity financing activities of Chinese listed firms were strictly regulated ${ }^{22}$ Table A.1 in the Appendix shows that less than $0.5 \%$ of listed firms conducted public seasoned equity offerings; dividend payments were low and strongly persistent, and repurchases were almost nonexistent. Since 2006, virtually all external equity was issued via private equity placements; however, these private placements could serve a different purpose than financing investment. ${ }^{23} \mathrm{We}$, therefore, assume that equity adjustment cost

\footnotetext{
${ }^{21}$ For most analyses, we can place the model in a risk-neutral setting and treat $F(K)$ and $r_{D}$ as expected cash flows and interest rate under the risk-neutral measure (as opposed to the physical measure).

${ }^{22}$ For instance, concerning poor corporate governance, the China Securities Regulatory Commission (CSRC) required a firm to have positive earnings and at least $20 \%$ dividend payout ratio over the past three years to qualify for public seasoned equity offerings.

${ }^{23}$ Private equity placements, which require neither positive earnings nor a certain dividend payout, typically involve either a change of controlling shareholders or the addition of new large shareholders. Consistent with this view, we
} 
is prohibitive and debt is the margin to adjust for investment financing. ${ }^{24}$ Our results are robust to the sample excluding firms that conducted external equity financing around the EVA policy adoption, as shown in Section 4.6.3.

There is another assumption behind the borrowing rate $r_{D}$ in Eq. (4), which is independent of the firm's leverage $D$. This is theoretically sound as the interest rate $r_{D}$ in Eq. (4) is expected interest expense per unit of borrowing. If default is driven by idiosyncratic risk, then the expected interest rate $r_{D}$ should equal the risk-free rate, which should be independent of firm leverage. The presence of aggregate risk would bring about a positive relationship between the expected borrowing cost $r_{D}$ and leverage $D$, but it really depends on the nature of aggregate risk. In the simple setting with aggregate risk given in Appendix A.1, default is driven by an aggregate disaster state, leading to an equilibrium borrowing rate that is independent of firm leverage again. ${ }^{25}$ Finally, in the data, observed $r_{D}$ and leverage are uncorrelated in our SOE sample (Panel B in Table 2); partly this is because SOE default is extremely rare during our sample period 2009-2015. ${ }^{26}$

\subsection{Model Implications}

This section provides empirical predictions regarding the firm's investment responses to the EVA policy adoption. Before the EVA policy, the SOE manager maximizes the firm's ROE:

$$
\begin{aligned}
\max _{D} R O E=\frac{\text { Net Income }}{E} & =\frac{\Pi(D+E)-\text { After-tax Interest Expense }}{E}, \\
& =\frac{\left(1-\tau_{Y}\right) F(D+E)-(1-\pi) r_{D} D}{E}
\end{aligned}
$$

find that the average private placement's issuance amount is large (conditional on conducting a private placement, the new issuance was $42.6 \%$ of the existing equity base), and about $70 \%$ of investors are either enterprises or private equities during our sample period.

${ }^{24}$ Table A.1 in the Appendix reports the summary statistics on our sample firms' external financing activities. In Table A.2, we report results if we exclude firms that conducted external equity issuance.

${ }^{25}$ In Appendix A.1, we modify the setting slightly in Section 3.1 to incorporate aggregate risk. There, the probability of project failure is driven by an aggregate event in which the project yields zero cash flows and triggers default. We derive the equilibrium interest rate, which is independent of firm leverage.

${ }^{26}$ In fact, as we explain later, in response to the EVA policy, firms changed their investment and debt financing significantly. Although the changes are economically large, they are not large enough to have a major impact on $r_{D}$ : empirically, the annual changes in leverage and $r_{D}$ have a mere correlation of $2.5 \%$, which is insignificant at the $5 \%$ level. 
where $\pi$ denotes the corporate tax rate. (Note that $\tau_{Y}$ includes the corporate tax rate $\pi$.) The first-order condition with respect to $D$ (and equivalently, with respect to $K$ ) reads

$$
F^{\prime}\left(K_{R O E}\right)=\frac{1-\pi}{1-\tau_{Y}} r_{D}
$$

Under the EVA policy, the SOE manager maximizes its EVA, which is given by ${ }^{27}$

$$
\mathrm{EVA}=\text { Net Income }+0.75 \times r_{D} D-5.5 \% \times(D+E)
$$

Plugging Net Income from Eq. (5), which equals to $\left(1-\tau_{Y}\right) F(D+E)-(1-\pi) r_{D} D$, the SOE manager now solves

$$
\max _{D}\left(1-\tau_{Y}\right) F(D+E)-(0.25-\pi) r_{D} D-5.5 \%(D+E)
$$

The optimal capital level under the EVA policy satisfies the following first-order condition:

$$
F^{\prime}\left(K_{E V A}\right)=\frac{(0.25-\pi) r_{D}+5.5 \%}{1-\tau_{Y}}
$$

Denote by $R O E^{*}$ and $R O E_{E V A}$ the ROE before and after the EVA adoption, respectively. We have the following proposition, which forms the basis of our empirical analysis.

Proposition 1. Suppose that $\pi=0.25$, which is the running corporate tax rate in China. All else equal, we have:

1. $K_{E V A}-K_{R O E}$ increases with $r_{D}$; that is to say, relative to the ROE policy, the change in an SOE's investment under the EVA policy is greater when its borrowing cost $r_{D}$ is higher.

2. $R O E_{E V A}-R O E^{*}$ is hump shaped in $r_{D}$, and reaches its maximum when $r_{D}=7.3 \%$.

Proof. When $\pi=0.25, F^{\prime}\left(K_{E V A}\right)=\frac{5.5 \%}{1-\tau_{Y}}$ is independent of $r_{D}$ while $F^{\prime}\left(K_{R O E}\right)=\frac{1-\pi}{1-\tau_{Y}} r_{D}$ increases with $r_{D}$. This proves the first claim. The second claim, which does not rely on $\pi=0.25$,

\footnotetext{
${ }^{27}$ Here we can ignore the adjustment of R\&D expenses and nonrecurring incomes in Eq. (1) for a cleaner analysis as they can be viewed as some constant adjustment in the objective.
} 
follows from the fact that

$$
F^{\prime}\left(K_{E V A}\right)-F^{\prime}\left(K_{R O E}\right)=\frac{5.5 \%-0.75 r_{D}}{1-\tau_{Y}}=\frac{7.3 \%-r_{D}}{\frac{4}{3}\left(1-\tau_{Y}\right)}
$$

so that $K_{E V A}$ coincides with $K_{R O E}$ when $r_{D}=7.3 \%$.

Our first result, which concerns how the EVA policy changes the SOE's investment, is immediate given the concavity of $F$. More specifically, the lower the borrowing cost $r_{D}$ (which might be caused by a greater subsidy), the lower the change of investment following the EVA adoption. Our second result implies that from the perspective of shareholders, the EVA policy is value-destroying because the manager no longer maximizes shareholder values. ${ }^{28}$ (We return to the EVA's welfare implication in Section 5). Essentially, the EVA policy leads firms with interest rates higher than $7.3 \%$ to overinvest - relative to $K_{R O E}$, which optimizes $R O E$ - and firms with interest rates lower than $7.3 \%$ to underinvest, and has no impact on firms with $r_{D}=7.3 \%$.

\section{Empirical Results}

We first describe our data in this section and then present our main empirical results, both the raw data pattern and regression analysis. The raw data patttern provides a test for the parallel trends assumption. We report the result on dynamic treatment effect regression in Section 4.4, which also provides a test for the parallel trends assumption.

\subsection{Data}

The SASACs evaluate their SOEs at the "group company" level. Most of these group companies are unlisted. Nevertheless, we collect the data of a sample of them from several sources. For a small number of listed groups, we collect their data from the China Stock Market \& Accounting Research (CSMAR) Database. CSMAR covers all firms listed on China's two stock exchanges. Some other group companies that issued corporate bonds need to disclose their financial statements from the past three years, and we collect their accounting information from the RESSET Database.

\footnotetext{
${ }^{28}$ In our framework, maximizing ROE maximizes the shareholder value. Our empirical analysis, which is a difference-in-differences, does not rely on this assumption. Our analysis goes through as long as implementing EVA hurts shareholder value (relative to without EVA).
} 
This paper focuses on studying the listed SOEs because we have better information about them. Most of these listed SOEs are subsidiaries of group companies. Theoretically, maximizing EVA at the group company-level is always equivalent to maximizing EVA for every subsidiary. Further, if debt is the only financing margin, which is our running assumption, then maximizing ROE at the group company-level is also equivalent to maximizing ROE for every subsidiary (to see this point, see Eq. (6)). For these listed firms, accounting data and stock price data are from CSMAR.

The sample period is from 2004 to 2015 . We start the sample from 2004 because the central and also most provincial SASACs started to evaluate SOEs in 2004. We end the sample in 2015 because the EVA policy for the centrally controlled SOEs was revised then, but the details were not disclosed. ${ }^{29}$

We begin with 11,236 firm-year observations (1,196 unique firms) of nonfinancial SOEs. ${ }^{30}$ We classify a firm as an SOE if its ultimate controlling party is the state. We manually collected the identity of firms' controlling shareholders. ${ }^{31}$ We exclude SOEs controlled by the Tibet SASAC (24 observations), SOEs controlled by government agencies other than SASACs, and SOEs controlled by lower-than-province level SASACs (4,860 observations). We exclude them because we cannot find information as to whether they adopted the EVA policy or not. ${ }^{32}$ As explained in detail toward the end of Section 2.3, we exclude 1) SOEs controlled by the SASACs of Hebei, Gansu, Anhui, and Shaanxi (426 observations) as they do not set the cost of capital at 5.5\% in their EVA policy; and 2) firms that are too levered (393 observations), as the EVA policy mandates them to have a stipulated cost of capital of $6 \% .{ }^{33}$ Including them does not have any material impact on our

\footnotetext{
${ }^{29}$ An alternative data source is the Chinese Annual Survey of Industrial Firms, which is collected by the National Bureau of Statistics in China. This dataset includes all SOEs. Unfortunately, it is widely accepted that the data in the post-2008 period have serious quality issues (e.g., Brandt, Van Biesebroeck, and Zhang, 2014), and we hence conduct our study based on listed firm sample.

${ }^{30}$ The firms listed on ChiNext, a NASDAQ-style subsidiary of the Shenzhen Stock Exchange, are not included, as the first batch of firms started trading on ChiNext on October 30, 2009, which was right before the first wave of EVA adoption.

${ }^{31}$ Chinese listed firms are required by law to disclose their ultimate controlling parties in their annual financial reports. The state is the ultimate controlling party of a firm if (i) the state controls directly or indirectly over $50 \%$ of total shares outstanding. (ii) the state controls directly or indirectly over $30 \%$ of total voting rights, (iii) the voting rights of the state allow it to elect over $50 \%$ of board directors, or (iv) the state has a significant influence on decisions made in shareholder meetings. Many existing studies have used the same definition (Allen, Qian, and Qian, 2005; Fan, Wong, and Zhang, 2007).

${ }^{32}$ The CSMAR dataset classifies whether a listed firm is under the control of the central SASAC or a local SASAC. Unfortunately, we find this field has many errors. We manually double-checked this data field by using information from a firm's or their group's reports and websites, then we corrected the mistakes.

${ }^{33}$ These four SASACs account for about $9 \%$ of our final sample, and firms that are too levered (industrial firms with debt/asset ratios above $75 \%$ or non-industrial firms with debt/asset ratios above $80 \%$ ) account for about $8 \%$. The high-leverage filter is based on the leverage of the group companies. For listed firms for which we do not have
} 
results. We also exclude 817 observations with missing capital expenditure, lagged interest rates, or lagged Tobin's $Q$. Our final sample contains 4,716 observations and 638 unique firms. ${ }^{34}$

We define InterestRate as interest expenses divided by the average of a firm's interest-bearing debts at the beginning of the year and the end of each of four quarters. We use quarterly data to better calculate the average amount of debt used over a year period. Total interest-bearing debts include short-term loans, long-term liabilities due within one year, long-term loans, bonds payable, and long-term payables. This method has been widely used in the accounting and finance literature to calculate interest rates using the U.S. listed firm sample (e.g., Francis, LaFond, Olsson, and Schipper, 2005; Frank and Shen, 2016). ${ }^{35}$

Table 2 reports the summary statistics. Panel A reports the mean, median, standard deviation, and the 25th and 75th percentiles of the variables used in our analysis. Panel B reports the correlation matrix. Here, Capex is capital expenditure divided by lagged total assets; Tobin's $Q$ is defined as the sum of the market value of equity and book value of the liabilities, divided by the book value of total assets; CashFlow is cash flow from operating activities, scaled by lagged total assets; $\log ($ Assets $)$ is the natural logarithm of total assets; Leverage is defined as total liabilities divided by total assets; CEOOwnership is the average fraction of shares held by a firm's general manager and board chair, multiplied by 100. We consider both the general manager (often with the title of $\mathrm{CEO}$ ) and the board chair as the company executives. In China, many board chairs are the ultimate decision makers who are performing the real duty as CEOs in the western economy

data on their group company, the high leverage filter is based on the listed firm's leverage. Our results are very similar if we keep these firms.

${ }^{34}$ A firm's controlling shareholder can change in various ways: between two governments (which could involve different levels of governments and/or the same level) or between the state (various levels of governments) and a nonstate shareholder. Hsieh and Song (2015), Huang, Li, Ma, and Xu (2017), and Gan, Guo, and Xu (2018) study some aspects of these ownership changes. Our data selection is at the firm-year level. In other words, a firm-year is included in our sample if the firm satisfies our data requirement in that year. This firm may not satisfy our data requirement in other years, and those firm-years will be excluded.

${ }^{35}$ We make three points regarding the measurement of interest rate. First, in our theoretical framework, $r_{D}$ should be the expected interest rate, not the promised interest rate (e.g., loan rate); they could differ if there are renegotiations or defaults, and therefore our measurement is closer to our theory than quoted loan rates. (During our sample period, defaults were extremely rare but renegotiations occurred often). Second, the denominator should have interest-bearing debt only; including other non-interest-bearing debt (e.g., accounts payable) may lead to a severe underestimation. To give a concrete example, the Chinese Annual Survey of Industrial Firms data set has information on total debt but not on interest-bearing debt. Based on that dataset, Bai, Lu, and Tian (2018) measure interest rate as the ratio of interest expenses to total debt, and obtain a mean (median) interest rate as $3 \%$ ( $1-2 \%$ ) that is much lower than ours (in fact, even below the government bond yield). Third, although part of interest expenses can be capitalized, the EVA formula specifically states that the interest expense should exclude capitalized interest expenses. We hence follow this definition and exclude the capitalized interest expenses in our estimation (however, our results are robust to include capitalized interest expenses). 
(Jiang and Kim, 2020). Finally, PoliticalConnection is a dummy variable that equals one if either the general manager or the board chair was previously employed as a bureaucrat by the central government or a local government.

The mean Capex is $7.1 \%$ (median is $4.6 \%$ ) of total assets. The mean InterestRate is $5.8 \%$ (median is $5.4 \%$ ). There are large variations for both variables. The 25 th and the 75 th percentiles of Capex are $1.8 \%$ and $9.4 \%$, respectively, and they are $4.2 \%$ and $6.6 \%$ for InterestRate. Consistent with the U.S. data (e.g., Frank and Shen, 2016), Capex and InterestRate are strongly negatively correlated. Also, larger firms, lower Tobin's $Q$ firms, and firms with higher CEO ownership have lower interest rates. Firms with political connections also have lower interest rates, consistent with the existing literature (Li, Meng, Wang, and Zhou, 2008).

\subsection{Empirical Pattern: Raw Data}

Figure 2 presents the test of the parallel trends assumption. ${ }^{36}$ Panel A reports the results of the treatment SASACs, and Panel B reports the results of the control SASACs. For treated SASACs that adopted the EVA policy in year $t$, we use the SASACs that never adopted the EVA in our sample as controls. ${ }^{37}$ Specifically, we sort firms into high and low InterestRate groups by the sample median in each EVA adoption year based on the interest rate at the last year before the EVA adoption. We report the mean of firm investment (with 95\% confidence intervals) from four years before $(t-4)$ to four years after $(t+3)$ the EVA adoption. Year 0 is the first year that the EVA policy became effective. We do this separately for the treated and the control.

There is an overall trend in decreasing investment across all the SOEs, coinciding with a decreasing GDP growth rate in China during this period. More important is that the investment levels of the two groups of firms are parallel before the policy adoption, for both the treated and the control. Among the treated firms, the investment gap between the high and low interest rate groups shrinks from a pre-EVA-adoption level of 3-5\% to almost zero. Most of the shrinkage occurs in the EVA adoption year (year 0). Among the control firms, the investment gap between the high

\footnotetext{
${ }^{36}$ An SOE's controlling shareholder may change from one SASAC to another. As a result, an SOE subject to the EVA policy this year may switch back in a later year. In our sample, there are 24 such changes. Due to the difficulty of defining the event year, we exclude these 24 firms from this analysis. Our results are almost identical if we use the first time an SOE became subject to the EVA policy and ignore the following controlling shareholder changes.

${ }^{37}$ De Chaisemartin and D'Haultfoeuille (2020) show that the standard difference-in-differences estimate based on staggered events may be biased and propose to use the never-treated sample as the control group. Our analysis in Figure 2 follows their approach.
} 
and low interest rate groups shrinks from a pre-EVA-adoption level of $2 \%$ to $1 \%$. The shrinkage is much smaller, and the shrinkage spreads out over the years, rather than being concentrated in year 0. Overall, these tests provide evidence for the validity of our DDD strategy.

\subsection{Baseline Regressions}

The main empirical prediction (the first prediction of our proposition) is that firms with a higher cost of debt will increase their investment after the EVA policy adoption relative to firms with a lower cost of debt. Specifically, we run the following baseline model for our DDD strategy:

$$
C A P E X_{i, t}^{j}=\beta_{1} \text { InterestRate }_{i, t-1}^{j}+\beta_{2} \text { Post }_{i, t}^{j}+\beta_{3} \text { Post }_{i, t}^{j} \times \text { InterestRate }_{i, t-1}^{j}+\gamma^{\prime} \boldsymbol{X}_{i, t}+\epsilon_{i, t} .
$$

Here, $i$ and $t$ index firms and years, respectively; $C A P E X_{i, t}$ is firm $i$ 's capital expenditure divided by lagged total assets in year $t$; InterestRate ${ }_{i, t}$ is the interest rate on a firm's borrowing; Post ${ }_{i, t}$ is a dummy equal to one if firm $i$ is subject to the EVA policy in year $t$ and zero otherwise; $\boldsymbol{X}_{i, t}$ is a set of control variables, including Tobin's Q, CashFlow, Log(Assets), and Leverage. All the control variables are lagged by one year except CashFlow, which is measured contemporaneously. ${ }^{38}$ Depending on the specification, we include firm fixed effects, year fixed effects, industry $\times$ year fixed effects, and SASAC $\times$ year fixed effects. We classify firms into 19 industries based on the industry classification codes provided by the Guidelines for the Industry Classification of Listed Companies (2001) of the Chinese Securities Regulatory Commission. Specifically, we define industries using two-digit industry codes for nonmanufacturers and three-digit codes for manufacturers. The main prediction is that $\beta_{3}>0$. We double-cluster standard errors by SASAC and year. ${ }^{39}$

Table 3 reports the results of the baseline regressions. Column 1 reports the result without any control variables or fixed effects. The coefficient of the interaction term is $0.256(t=2.71)$, consistent with the first prediction of our proposition. After the EVA adoption, firms with a higher borrowing cost increase their investment relative to firms with a lower borrowing cost. We add more control variables and fixed effects from column 2 to column 6. We add Tobin's $Q$ and Cash Flow

\footnotetext{
${ }^{38}$ Some of these control variables may also be affected by the EVA policy. Our results are similar if we do not include any controls.

${ }^{39}$ Occasionally, the $t$-statistics of the coefficient of Post $\times$ InterestRate are significantly higher than most of the estimates. This is likely due to the small sample property of the double-clustered standard errors (Petersen, 2009). For these cases (columns 4 and 5 of Table 3 ), instead of reporting the double-clustered $t$-statistics, we report the more conservative $t$-statistics clustered by SASAC.
} 
in column 2, $\log ($ Assets $)$ and Leverage in column 3, and firm and year fixed effects in column 4.

In columns 5 and 6 , we further add SASAC $\times$ year and industry $\times$ year fixed effects, respectively. These two interactive fixed effects control for the time-varying SASAC-level and industry-level factors. Note that we eliminate the Post dummy because the SASAC $\times$ year dummies fully absorb the Post dummy. The coefficient of the interaction term is similar across different specifications, and the statistical significance with more stringent controls is even stronger relative to the simplest model in column 1.

The magnitude of the coefficient of the interaction term is large. In column 1 , the coefficient of InterestRate is $-0.368(t=-4.16)$. This suggests that, before the EVA adoption, a $1 \%$ increase in InterestRate is associated with a $0.368 \%$ decrease in Capex. In the post-EVA period, a $1 \%$ increase in InterestRate is associated with a $0.112 \%$ decrease in Capex $(-0.368+0.256)$. The sensitivity decreases by close to $70 \%{ }^{40}$ Overall, these results support the first prediction of our proposition.

One concern of the DDD strategy is that the EVA-adoption timing may coincide with political economy or business cycle factors. Table 1 shows that the timing is not associated with many observables and hence mitigates this concern. However, it is impossible to take all possible factors into account, especially unobservables.

We address this concern by exploiting a unique institutional feature in the context of China's SOE reform. Although most SOEs controlled by one provincial SASAC are located in the same province, a number of them are located elsewhere, and the central SASAC controls SOEs located across the country. For example, Yaxing Coach, a bus manufacturer based in Jiangsu province, is controlled by Shandong SASAC. These firms and the central SASAC firms enable us to add province $\times$ year fixed effects to control for time-varying province-level factors. The last column of Table 3 reports the results of this specification. Our results are robust. The magnitude of the coefficient of Post $\times$ InterestRate is also similar to that from column 6 . These results show that time-varying province-level factors have minimal impact on our finding, mitigating the concern that the EVA adoption timing may be endogenous.

\footnotetext{
${ }^{40}$ In Table A.2, we exclude firms that have done any external equity financing during the seven years around the EVA policy adoption and find similar results.
} 


\subsection{Robustness Tests}

\subsubsection{Dynamic estimations}

Figure 2 presents the parallel trends with the raw data. In Figure 3 , we present the effect of the EVA policy in a dynamic regression framework. Specifically, Figure 3 presents the $\beta_{3 s}$ coefficients from the following regression:

$C A P E X_{i, t}^{j}=\beta_{1} \cdot$ InterestRate $_{i, t}^{j}+\sum_{s \neq-1} \beta_{2 s} \cdot$ Post $_{i, t, s}^{j}+\sum_{s \neq-1} \beta_{3 s} \cdot$ InterestRate $_{i, t}^{j} \times$ Post $_{i, t, s}^{j}+\gamma^{\prime} \boldsymbol{X}_{i, t}+\epsilon_{i, t}$.

Here, $s$ indicates the year relative to the EVA adoption, so for firm $i$ in year $t$, Post $_{i, t, s}^{j}=1$ if firm $i$ 's SASAC $j$ adopted the EVA policy in year $t-s$. We use the year before the EVA adoption $(s=-1)$ as the base year and estimate the coefficients of Post $\times$ InterestRate for each event year relative to the base year. The $t$-statistics are calculated by clustering at both the SASAC level and the year level. Panel A presents the results without including the province $\times$ year fixed effects (corresponding to column 6 in Table 3). Panel B presents the results with the province $\times y e a r$ fixed effects (corresponding to column 7 in Table 3 ). The results show that the $\beta_{3 s}$ coefficients are around zero in the pre-EVA-adoption period and become positive in the post-EVA period, consistent with the findings in Figure 2.

\subsubsection{Empirical results based on group-level data}

Even though maximizing EVA at the group company level is equivalent to maximizing EVA for every subsidiary, one potential concern is that the listed firms may not be representative of all the assets of the group companies. We repeat the same exercise using the group company data. From the RESSET Database, we obtain data for 426 state-owned nonfinancial group companies (3,563 firm-year observations) that are either controlled by the central SASAC or by any provincial SASAC. Similar to the listed firm sample, we remove firms controlled by the SASACs of Hebei, Gansu, Anhui, Shaanxi, or Tibet (46 firm-years), firms with high leverage (163 firm-years), and 877 firm-year observations with missing Capex or InterestRate. Our final sample has 2,477 firm-year observations and 385 unique group companies.

Table 4 reports the baseline regression results for this sample. As most of these group companies 
are not public, we do not include Tobin's $Q$ as a control. The coefficient of the interaction term is statistically significant either at the $1 \%$ level or at the $5 \%$ level. The magnitude is between 0.194 to 0.252 , which is comparable to the estimates from Table 3. We report the dynamic estimation results in Figure A.1 of the Appendix and find that they are similar to the estimation in Figure 3. These results mitigate the concern that the listed firm sample may not be representative.

\subsubsection{A placebo test using non-SOEs}

The EVA policy should have affected SOEs only. We hence use non-SOEs as a placebo sample by examining whether the EVA policy adopted by a provincial SASAC affected the non-SOEs located in the same province. Suppose that the EVA adoption coincided with political economy or business cycle factors that had different impacts on firms with different interest rates. In that case, we should expect that non-SOEs with different interest rates changed their investments accordingly, similar to those SOEs that we have studied.

In Table 5, we estimate the baseline regressions reported in Table 3 but using the non-SOE sample. We report the summary statistics of this sample in Appendix A.4. We also replace the SASAC $\times$ year fixed effects with the Province $\times$ year fixed effects, as non-SOEs are not under the control of any SASAC. Table 5 shows that the coefficient of Post $\times$ InterestRate is negative (contrary to the findings for the SOEs), although never statistically significant after the proper fixed effects are included. These findings provide further evidence that our results are unlikely driven by factors coinciding with the EVA adoption.

\subsubsection{Other robustness tests}

In Table A.4, we conduct two robustness tests. In Panel A, we drop the firms controlled by the central SASAC (about half of the sample). In Panel B, we trim the sample based on InterestRate. Extremely low or high InterestRate values are likely to have measurement errors. Specifically, we drop the extreme values that are either lower than the 5 th percentile $(1.9 \%)$ or higher than the 95 th percentile (10.8\%). The estimations from Panels A are similar to the full sample results. In Panel B,

after we drop the interest rates that are more likely to contain measurement errors, the coefficients become slightly higher. Overall, our results are robust to these alternative specifications. 


\subsection{The Impact on ROE}

In Table 6, we test the second prediction and examine the impact of the EVA policy on firm performance. The idea is that, from individual firms' perspectives, the EVA policy leads to distortion in their investment decisions. As discussed in Section 3, a firm with a pre-tax cost of borrowing at $7.3 \%$ is unaffected. Firms with interest rates higher than $7.3 \%$ will overinvest, and firms with interest rates lower than $7.3 \%$ will underinvest. In both cases, the firm performance in terms of ROE will deteriorate. We measure ROE as net income divided by lagged total equity.

To quantify the nonmonotonic impact of the EVA policy on firm performance, we group all firms into six groups by their InterestRate. Specifically, we classify firms with InterestRate below $2.5 \%$, between $2.5 \%$ and $4.5 \%$, between $4.5 \%$ and $6.5 \%$, between $6.5 \%$ and $8.5 \%$, between $8.5 \%$ and 10.5\%, and higher than 10.5\%, as Group 1, Group 2, ..., and Group 6, respectively. The range of InterestRate is wider for Groups 1 and 6 because the density of firms in the tails is lower.

As discussed in Proposition 1 in Section 3, a firm with a pre-tax cost of borrowing at 7.3\% is unaffected and $7.3 \%$ lies about the middle of Group 4. We hence run the regression with the following specification:

$$
R O E_{i t}=\sum_{\text {Group }=1}^{6} \beta_{\text {Group }} \text { Group }_{i, t-1} \times \text { Post }_{i, t}+\alpha_{i}+y_{t}+\gamma^{\prime} \boldsymbol{X}_{i, t}+\epsilon_{i, t}
$$

where $R O E_{i, t}$ is firm $i$ 's ROE in year $t$, and $\alpha_{i}$ and $y_{t}$ are firm fixed effects and year fixed effects, respectively; Group $i, t$ indicates the firms with the InterestRate in any of the six groups as discussed above. The $\beta_{\text {Group }}$ coefficient captures the impact of the EVA policy on ROE of firms in an InterestRate group relative to control firms. We expect that $\beta_{\text {Group }}$ to increase from Group $=1$ to 4 , and then decrease from Group $=4$ to 6 . We also expect $\beta_{\text {Group }=4}$ in Eq. (10) to be close to zero, as their investment decisions were least affected.

The results in Table 6 are consistent with the above predictions. In column $1, \hat{\beta}_{4}=0.020$ with $t=1.90$, which is only marginally significant at the $10 \%$ level. The $\left\{\beta_{\text {Group }}\right\}$ coefficients become more negative for lower InterestRate groups and also for higher InterestRate groups. In other columns, we add different interactive fixed effects, including the SASAC $\times$ year, industry $\times$ year, and province $\times$ year fixed effects. Once the SASAC $\times$ year fixed effects are added, we cannot identify all the $\beta_{\text {Group }}$ coefficients anymore. In these cases, we use $\beta_{\text {Group }=4}$ as the base case and report the 
other coefficients. The $\beta_{\text {Group }}$ coefficients in columns 2-4 can be explained as the difference of the EVA policy impact on firms with different InterestRate. The results show that it is evident that the EVA policy affected firms in Group 4 the least, and other firms were affected more negatively.

Figure 4 displays the relation between InterestRate groups and change in firm performance graphically based on the estimation results of Table 6. The results based on column 3 (Panel A) and column 4 (Panel B) reveal that the EVA policy-induced firm performance reduction is the lowest for the fourth interest rate group, i.e., when InterestRate is between $6.5 \%$ and $8.5 \%$. The EVA policy-induced firm performance reduction increases with the gap between a firm's interest rate and the policy-stipulated one, and in both directions.

The economic magnitudes of these effects are sizable. Based on the estimation in column 4 of Table 6, we find that, relative to the firms with InterestRate between $6.5 \%$ and $8.5 \%$, firms with InterestRate lower than $2.5 \%$ (group 1) had a $4.2 \%$ higher reduction in ROE, and firms with InterestRate higher than $10.5 \%$ (group 6) had a $6.1 \%$ higher reduction in ROE. Overall, these results support result 2 in Proposition 1.

\subsection{Potential Economic Mechanisms and Supporting Evidence}

We present further evidence to show that the effect of EVA reform on firm behaviors is via the channel of the managerial incentives.

\subsubsection{Executive turnover versus executive compensation}

This subsection studies two standard mechanisms through which managerial incentives work: executive turnover and executive compensation. Through the lens of the EVA reform, our results shed light on how managerial incentives work in Chinese SOEs.

We first examine the relationship between firm performance and CEO turnover with demotion. We expect that after the adoption of the EVA policy, an SOE's EVA performance should become a stronger negative predictor for executive turnovers with demotion, while its ROE performance should become a weaker predictor. In our empirical analysis, like when we define CEO ownership and other variables, for each listed company, we consider both the general manager and the board chair as company executives. We define turnovers with demotion to be turnovers excluding promotions where the executive under consideration becomes a government official or moves to the group 
company with a chief position.

Panel A of Table 7 reports the regression results on the relationship between executive turnover and lagged performance measures. The dependent variable equals one if either the general manager or the board chair experiences a turnover with demotion and zero otherwise. We calculate $E V A$ following the EVA rule as in Eq. (2). To make the EVA measure comparable across firms, we scale the dollar EVA by average firm assets. Post is a dummy equal to one if a firm is subject to the EVA policy in a year and zero otherwise. $R O E$ is net income divided by the lagged total equity. All the independent variables are lagged by one year. ${ }^{41}$

The results show that the coefficient of Post $\times E V A$ is significantly negative, consistent with the hypothesis that after the EVA adoption, firms' EVA becomes more important in affecting executive turnover. The coefficient of $R O E$ is negative and significant (-0.366, column 4$)$, suggesting that before the EVA, firms with higher ROE are less likely to have a departing executive. This negative effect is completely eliminated after EVA: the coefficient of Post $\times R O E$ is positive with a point estimate of 0.663 (column 4), suggesting that the effect of $R O E$ on affecting executive turnover becomes weaker after the EVA adoption.

We also conduct the analysis for executive compensation. The regression is the same as in Panel A except for two differences. First, we replace the dependent variable with the natural logarithm of one plus the average compensation of the general manager and the board chair. If one's compensation information is missing, we only use the other executive's compensation. Second, Post, EVA, and ROE are measured in the same year as the compensation. As shown in columns 58, the coefficient of Post $\times E V A$ is positive, and the coefficient of Post $\times R O E$ is negative, suggesting that, after the adoption of the EVA policy, $E V A$ becomes more important in determining executive compensation, and $R O E$ becomes less important. However, the coefficient of Post $\times R O E$ is never statistically significant, and the coefficient of Post $\times E V A$ is only marginally significant in column 8 . The weaker results on executive compensation are consistent with the unique feature of managerial incentives in Chinese SOEs where SOE managers are more like government officials who potentially care more about their political career as opposed to salary remuneration.

\footnotetext{
${ }^{41}$ For a firm-year to enter our sample, we require both the general manager and the chair to have started their current position at least a year prior. We also exclude the observations where their departure is driven by retirement, personal health, or involvement in legal cases. Our results are qualitatively similar if we require either the general manager or the chair to have started their current position at least a year prior or include the above-discussed departures.
} 


\subsubsection{Heterogeneity tests}

In Table 8, we test firm heterogeneity. We hypothesize that the effect should be stronger if the manager was a former government official or if manager ownership is lower.

First, former government officials are less likely to be hired as professional managers and are more likely to be incentivized by promotion within the government system. Former government officials, therefore, are more likely to adhere to the SASAC rules and less likely to take the nonstate shareholders' interests into account. We, therefore, construct PoliticalConnection, which is a dummy variable that equals one if either the general manager or the board chair was previously a government official and zero otherwise. In our sample, the average value of PoliticalConnection is $33.5 \%$.

Second, the EVA policy represented the government's will, i.e., the controlling shareholder, but not necessarily that of the small shareholders who would be simply equity-value maximizers. Managers with higher equity ownership should be more aligned with small shareholders and, therefore, less likely to comply with the EVA rules. We calculate CEOOwnership as the average fraction of shares held by a firm's general manager and board chair. In $25.1 \%$ of our sample firms, CEOs have positive equity ownership. Conditional on positive CEO ownership, the average CEOOwnership is $0.3 \%$, with a market value of RMB 24.57 million, which is about 44 times the average annual compensation.

We test these two predictions by adding two triple interaction terms - Post $\times$ InterestRate $\times$ PoliticalConnection or Post $\times$ InterestRate $\times$ CEOOwnership -into our baseline specification (9). We expect the coefficient of Post $\times$ InterestRate $\times$ PoliticalConnection to be positive, while that of Post $\times$ InterestRate $\times$ CEOOwner ship to be negative. The first four columns of Table 8 report the results on political connection, and the next four columns report the results on CEO ownership. The results in Table 8 confirm these two predictions.

\subsubsection{Other firm behaviors}

We provide two additional pieces of further empirical evidence in this section, one on the implication of debt financing as the investment margin and the other on $R \& D$ investment, which is another component of EVA policy. 
External financing As discussed in Section 3, our model rests on the assumption that firms adjust their investment by issuing or retiring debt. In fact, our results are robust to the sample excluding firms that conducted external equity financing around the EVA policy adoption (see Table A.2 in the Appendix).

We can further test this assumption in Table 9. Specifically, we examine how the EVA policy affects firms' debt financing and equity financing, and for debt financing, we consider both shortterm debt and long-term debt. Long-term debt financing is the change in long-term debt (including long-term loans, bonds payable, long-term payables, and long-term liabilities due within one year) from year $t-1$ to $t$, scaled by lagged total assets. Short-term debt financing is the change in shortterm debt (i.e., short-term loans) from year $t-1$ to $t$, scaled by lagged total assets. External equity financing is the sum of rights issues and seasoned equity offerings (both public equity issuance and private equity placements), scaled by lagged total assets.

The results in Table 9 show that the EVA policy has a different impact on firms' debt financing depending on their cost of debt, but not on their equity financing. Specifically, after the EVA policy adoption, firms with a higher cost of borrowing increase their debt borrowing and mainly long-term debt. The coefficient of Post $\times$ InterestRate is close to zero for external equity financing regressions and short-term debt financing regressions and is significantly positive in the regressions of long-term debt financing. These results are consistent with the fact that external equity financing is strictly regulated, and firms rely on debt to fund their investment, providing support to the assumption discussed in Section 3.2.

R\&D Investment Besides the change in the cost of capital stipulation, the EVA policy adds back R\&D expenses and half of the nonrecurring income. Although these two adjustments are unrelated to a firm's interest rate, these adjustments may have changed firms' policies. For example, they may have increased firms' incentive to invest in $R \& D$. In fact, encouraging SOEs to invest in $R \& D$ activities was one of the SASAC'smotivations. We investigate the impact of the EVA policy on firms' R\&D expenses. In the regression, we include firm fixed effects that absorb the SASAC fixed effects. Because the impact on R\&D does not depend on the firm's interest rate, we focus on the coefficient of Post as opposed to that of Post $\times$ InterestRate. Note, Post is a SASAC-year level variable so we also exclude the SASAC $\times$ year fixed effect in the regression. 
Table 10 reports the regression results with the dependent variable as R\&D scaled by sales. The coefficient of Post varies from 0.003 to 0.015, suggesting that in the post-EVA period, firms increased their $\mathrm{R} \& \mathrm{D} /$ sales ratio by 0.003 to 0.015 . The average $\mathrm{R} \& \mathrm{D} /$ Sales ratio is 0.009 , suggesting that the EVA policy had a significant impact on firms' R\&D expenses. These results confirm that the EVA policy did increase firms' R\&D expenses and also provide additional evidence that the SASAC policies had significant impact on SOEs' behaviors. ${ }^{42}$

\section{Does the EVA Policy Improve Capital Allocation?}

We have presented a collection of strong evidence that Chinese SOEs have reacted to the stipulated cost of capital since the EVA reform was implemented. Taking this point one step further, in this section, we make the first attempt to evaluate the welfare consequence of the EVA policy, under the premise that the EVA policy is implemented at its full scale.

The primary motivation for SASAC to conduct the EVA reform was to urge SOEs to manage capital more efficiently (Adfaith, 2005). From the perspective of allocative efficiency, there are potentially two layers to achieve this policy goal: the first concerns the allocative efficiency among SOEs, and the second concerns the allocative efficiency between SOEs and non-SOEs. But before delving into these two parts, we first provide a conceptual framework that lays out the key elements of the discussion.

\subsection{EVA and Capital Allocative Efficiency: Theory and Discussion}

Following Hsieh and Klenow (2009), we study the welfare implications of EVA policy reform through the lens of comparing Eq. (7) and Eq. (8). Bring back the firm index $i$, and define firm $i$ 's marginal revenue product of capital ( $M R P K$, normalizing the product price to 1) to be $M R P K_{i} \equiv F^{\prime}\left(K_{i}\right)$. Under the ROE policy, using $r_{D i}=\left(1+\tau_{K i}\right) r_{i}$ in Eq. (4) we can rewrite Eq. (7) to be $F^{\prime}\left(K_{i}\right)=$ $\frac{1+\tau_{K i}}{1-\tau_{Y i}}(1-\pi) r_{i}$, which implies that

$$
M R P K_{i}^{R O E}=\frac{1+\tau_{K i}}{1-\tau_{Y i}}(1-\pi) r_{i}
$$

\footnotetext{
${ }^{42}$ Firms can relabel expenses as R\&D. Chen, Liu, Serrato, and Xu (2021) estimate that relabeling accounts for about a quarter of the reported R\&D in China. Firms have stronger incentives to relabel under the ROE rule than the EVA rule. Hence, our estimation should be considered to be a lower bound.
} 
In contrast, under the EVA policy, Eq. (8) implies that

$$
M R P K_{i}^{E V A}=\frac{(0.25-\pi)\left(1+\tau_{K i}\right) r_{i}+5.5 \%}{1-\tau_{Y i}}
$$

To facilitate discussion, we further assume $1-\tau_{Y i}=1-\pi=0.75 .{ }^{43}$ Then we have

$$
M R P K_{i}^{R O E}=\left(1+\tau_{K i}\right) r_{i} \text { and } M R P K_{i}^{E V A}=\frac{5.5 \%}{0.75}=7.33 \%
$$

As hinted in the last point from Section 3.2, the impact of the EVA adoption on allocative efficiency crucially depends on whether the true cost of capital $r_{i}$, which reflects the fair marketbased compensation of the risk of the project, is equal across firms. This answer is a solid "no" from the classic perspective in the finance literature dating back to the capital asset pricing model (CAPM, Sharpe, 1964, Lintner, 1965): the required rate of return, or the cost of capital, should include both the risk-free rate and the compensation for risk-more precisely, the aggregate risk that requires a risk premium. More specifically, the CAPM model, which is widely used in the field of corporate finance (e.g., Berk and DeMarzo (2017)), says

$$
\text { Cost of Capital }=\text { Risk-free Rate }+\beta_{A} \times \text { Market Risk Premium, }
$$

where $\beta_{A}$ stands for $\beta$ of "Asset" which captures the quantity of aggregate risk of this asset's cash flows (for instance, the entire market portfolio has $\beta=1$ ).

Our efficiency discussion will take heterogeneous costs of capital across firms, which are driven by different risk profiles, as given. One could easily introduce cash-flow risk in our setting outlined in Section 3.1; we choose not to model risk explicitly-but discuss the potentially heterogeneous cost of capital - for the ease of exposition.

\subsubsection{Within-group allocative efficiency with equal cost of capital}

We start our discussion by considering firms within a group with the same true cost of capital; they could share a similar risk profile $\beta_{A}$ and hence require the same risk premium. In our empirical analysis later, we take these groups to be industries.

\footnotetext{
${ }^{43}$ For most of our sample firms, we have the corporate tax rate to be $\pi=0.25$.
} 
Comparing (11) and (12), we observe that the EVA policy effectively eliminates the dispersion of actual costs of capital faced by firms, implying a welfare gain (Hsieh and Klenow, 2009). This point is most evident when the firms' true cost of capital is just equal to the EVA stipulated cost of capital, i.e., $r_{i}=r=7.33 \%$; in this case, Eq. (13) implies that $M R P K_{i}^{E V A}=r$ under the EVA reform, reaching the highest allocative efficiency.

Intuitively, in the absence of any policy subsidy, all the SOEs' (before-tax) cost of capital would have been $7.33 \%$, but various policy distortions/subsidies drive the observed heterogeneity in interest rates (i.e., wedge $\tau_{K i}$ ). The EVA policy then would have increased capital allocative efficiency by incentivizing firms not to make capital budgeting decisions based on their distorted "actual" costs of capital. In other words, the one-size-fits-all EVA policy corrects various policy distortions and would kill the "bad" dispersion of $M R P K$ (or the actual cost of capital).

\subsubsection{Across-group allocative efficiency with different costs of capital}

For firms with heterogeneous costs of capital, the simple one-size-fits-all EVA policy typically leads to welfare loss. To illustrate this point, we take a polar assumption that $\tau_{K i}=0$ but $r_{i}$ differs; in words, firms are free from any policy distortion but face heterogeneous costs of capital due to different risk profiles of their business operations. Eq. (13) then becomes

$$
M R P K_{i}^{R O E}=r_{i} \text { and } M R P K_{i}^{E V A}=7.33 \%
$$

As is evident from Eq. (15), the one-size-fits-all EVA policy - which potentially fixes the "bad" dispersion caused by $1+\tau_{K i}$ as highlighted in Section 5.1.1-also necessarily kills the "good" dispersion reflected in the true costs of capital $r_{i}$.

\subsubsection{The level of the EVA cost of capital: Allocative efficiency between SOEs and non-SOEs}

Finally, the stipulated cost of capital by the EVA policy has natural implications on allocative efficiency between SOEs and non-SOEs. If the average true cost of capital of the SOE sector is greater (less) than $7.33 \%$, then a successful implementation of the EVA policy will cause overinvestment (underinvestment) in the SOE sector. Indeed, because SOEs enjoy cheaper access to bank loans 
thanks to the implicit government guarantee, it has been widely documented that the misallocation between SOEs and non-SOEs is responsible for low aggregate productivity in China (Dollar and Wei 2007; Hsieh and Klenow 2009; Song, Storesletten, and Zilibotti 2011; Brandt, Tombe, and Zhu 2013). The EVA policy, via stipulating the hurdle rate for the entire SOE sector, can affect the allocative efficiency in aggregate. We will empirically test this hypothesis in Section 5.2.3.

\subsection{Empirical Analysis on Allocative Efficiency}

The theoretical discussion in Section 5.1 provides a conceptual framework to empirically investigate the overall welfare impact of the EVA reform. The empirical exercises conducted in this section, due to data limitations, are noisy and only suggestive; this is an important research topic for future explorations.

We follow the standard corporate finance textbook (e.g., Berk and DeMarzo (2017)) to empirically measure the true cost of capital:

$$
\text { Cost of Equity } \times(1-\text { Leverage Ratio })+\text { Cost of Debt } \times \text { Leverage Ratio, }
$$

where the cost of equity is estimated as

$$
\text { Cost of Equity }=\text { Risk-free Rate }+\beta_{\text {equity }} \times \text { Market Risk Premium, }
$$

with $\beta_{\text {equity }}$ is defined as the covariance between the firm's equity return and market return, divided by the variance of the market return, and the leverage ratio is defined as the book value of debt divided by the sum of the market value of equity and the book value of debt.

In the empirical analysis, we calculate $\beta_{\text {equity }}$ based on the firm's stock returns from the past 48 months. Since $\beta_{\text {equity }}$ is constructed from the second moment of equity prices, it is unlikely to be affected by policy subsidies. We set the risk-free rate to be the one-year rate of China Development Bank (CDB) bonds. ${ }^{44}$ We will discuss the choice of other parameters (which play relatively minor

\footnotetext{
${ }^{44}$ We use the rate of CDB bonds instead of the Chinese Treasury bonds because CDB bonds have better liquidity, receive zero risk-weight for commercial banks, have the same tax treatment as other non-Treasury bonds, and are widely accepted as the risk-free benchmark in practice (Amstad and He, 2019). During our sample period, the correlation between the one-year CBD bond rate and the one-year Treasury rate is 0.96. Interest income from Treasuries is exempt from tax, but interest income from the CDB bonds is not. If we adjust the Treasury rate by tax (i.e., multiplying it by 1.25), the average tax-adjusted Treasury rate is $3.24 \%$, which is very similar to the average
} 
roles in our exercise) shortly.

Importantly, throughout this subsection, we assume that firms in the same industry share the same cost of capital. Put it differently, we deem that firms in the same industry have the same asset beta, i.e., $\beta_{A}$ in Eq. (14), and therefore industries serve as the equal-cost-of-capial groups in Section 5.1.1. This is a satisfactory assumption for at least two reasons in our context. First, such a treatment has been widely used in the finance literature (e.g., Krüger, Landier, and Thesmar (2015)); in fact, it is a common practice to use the industry asset beta when practitioners estimate a project's cost of capital (Section 12.5, Berk and DeMarzo (2017)), with the underlying assumption that firms in the same industry share a similar line of business. ${ }^{45}$ Second, this assumption echoes Hsieh and Klenow (2009) who have focused on the within-industry $M R P K$ dispersion as a measure of misallocation. In Hsieh and Klenow (2009), there is no aggregate risk in the production function. But once we introduce aggregate risk to that framework, for within-industry $M R P K$ dispersion to measure capital misallocation (within the same industry), researchers need to implicitly assume that firms in the same industry have the same cost of capital.

The capital allocative literature advocates for using finely classified industries. Hence, in this analysis, we classify firms into 60 industries based on three-digit industry classification codes provided by the Guidelines for the Industry Classification of Listed Companies (2012) of the Chinese Securities Regulatory Commission. We provide the list of industries (their codes and short description), and the number of observations of each industry in Appendix A.5.

\subsubsection{The impact of EVA: SOE investment across industries}

Section 5.1 points out that the one-size-fits-all policy ignores the heterogeneity in the true costs of capital and hence could have negative welfare implications. It is difficult to measure the true costs of capital precisely. Given our stand that various industries should have different true costs of capital, we first check whether SOE investment across industries exhibits a similar pattern as in Figure 2 after the EVA reform. That is, do industries with a lower true cost of capital cut their investment relatively more than their higher-cost-of-capital peers?

CDB rate of $3.18 \%$. Not surprisingly, we get very similar results if we use the tax-adjusted Treasury rate as the risk-free rate.

${ }^{45}$ Based on data for U.S. department stores in mid-2009, Example 12.7 in Berk and DeMarzo (2017) shows that while there exist significant differences in the firms' $\beta_{\text {equity }}$ (due to differences in leverage), the firms' $\beta_{A}$ are similar, suggesting that the underlying businesses in this industry have similar market risk. 
We calculate the firm-level cost of capital based on Eq. (16) and Eq. (17). The industry average cost of debt may have a subsidy component. Hence, we use the risk-free rate instead of the actual interest rate. What is more, under the assumption that the same industry shares the same $\beta_{A}$, we follow the common practice and take the industry average cost of capital as a "clean" measure of the firm's true cost of capital; it is clean in the sense that it is not directly affected by subsidies. Figure 5 then sorts firms into high and low cost of capital industry groups and tracks their average investment (similar to Panel A of Figure 2). This method is particularly attractive because the ranking of industry average cost of capital - upon which Figure 5 is based - does not depend on the choices of macroeconomic parameters (i.e., risk-free rate and market risk premium). ${ }^{46}$

Figure 5 shows that, in response to the EVA policy, industries with a relatively lower cost of capital reduced their investment more than industries with a relatively higher cost of capital. In fact, industries with a lower cost of capital invested more in the pre-EVA period, but in the post-EVA period, their investment became similar to industries with a higher cost of capital. Such convergence in investment reduces welfare, suggesting that EVA policy, which kills the "good" dispersion in the true cost of capital, should have unclear overall welfare implications.

\subsubsection{The impact of EVA: A variance decomposition exercise in the SOE sector}

Denote the actual cost of capital for firm $i$ in industry $j$, before EVA, by $\hat{r}_{i j}$; it is the cost of capital faced by the firm subject to the contamination of subsidies before the EVA period. After the EVA policy, firms use $7.33 \%$ as the hurdle rate for their capital budgeting. Under the assumption that firms in any industry share the same true cost of capital, what is the aggregate welfare effect of this one-size-fits-all policy?

A complete answer to this question requires a structural general equilibrium model and hence is beyond the scope of this paper. Here, we perform a nonstructural variance decomposition exercise, whose result offers a preliminary quantitative gauge to this million-dollar question. The following

\footnotetext{
${ }^{46}$ This irrelevance result always holds when we set the cost of debt (of all firms) to be the risk-free rate, which is what we do in this exercise. This is a reasonable assumption because, during our sample period, the default probability of SOE firms is negligible across different industries. Nevertheless, the irrelevance of ranking regarding the macroeconomic parameters also holds in the parameter range that is empirically reasonable.
} 
total variance decomposition is straightforward:

$$
\underbrace{\mathbb{E}\left[\left(\hat{r}_{i j}-7.33 \%\right)^{2}\right]}_{\text {Total Effect }}=\underbrace{\mathbb{E}\left[\left(\hat{r}_{i j}-\mathbb{E}_{j}\left(\hat{r}_{i j}\right)\right)^{2}\right]}_{\text {Within-industry Disperson }}+\underbrace{\mathbb{E}\left[\left(\mathbb{E}_{j}\left(\hat{r}_{i j}\right)-\mathbb{E}\left(\hat{r}_{i j}\right)\right)^{2}\right]}_{\text {Across-industry Disperson }}+\underbrace{\left(\mathbb{E}\left(\hat{r}_{i j}\right)-7.33 \%\right)^{2}}_{\text {Wedge b/w EVA policy rate \& } \mathbb{E}\left(\hat{r}_{i j}\right)},
$$

where $\mathbb{E}_{j}$ is the average operator within the industry $j$ and $\mathbb{E}$ is the average operator across the entire sample.

We consider two alternative measures for the actual cost of capital $\hat{r}_{i j}$ before the EVA policy. The first one is the firm's interest rate that we used in previous sections, as explained in 4.1. The second is based on Eq. (16) which, in addition to the interest rates observed in the data, uses the cost of equity given by (17). The second proxy requires an input of market risk premium; we entertain five values ranging from $5 \%$ to $8 \%$ as an accurate estimate of market risk premium does not exist. ${ }^{47}$ Because our main focus is on cross-sectional dispersion, we perform the decomposition year by year and then average across years. Our decomposition is based on the pre-EVA firm-year observations only; this exercise loses its meaning for the post-EVA period (as firms were no longer using the actual cost of capital for their capital budgeting).

Table 11 reports the total variance decomposition results; Table A.7 in the Appendix shows the decomposition for each year for both proxies of the actual cost of capital (for the second proxy, we set market risk premium to be $6.5 \%$ ). Among the three variance components (within-industry variation, cross-industry variation, and wedge between the average actual cost of capital and the stipulated one), the within-industry variation accounts for $51.7 \%$ of the total variance based on interest rate (Panel A) and about $31.5-49.9 \%$ of the total variance if further taking into account the equity cost of capital (Panel B). Because the within-industry variations represent distortive subsidies under our assumption of equal cost of capital within any industry, there seems to be considerable scope for the EVA policy to kill the "bad" dispersion.

\footnotetext{
${ }^{47} \mathrm{Liu}$, Stambaugh, and Yuan (2019) report an average monthly market return in excess of the one-year benchmark deposit rate of $0.66 \%$, implying an annualized rate of $7.9 \%$. In our sample period, the one-year benchmark deposit rate is about $0.6 \%$ lower than the one-year CDB bond rate. If calculated relative to the CBD bond rate, the market risk premium is about $7.3 \%$. The estimates of the market risk premium in the US have a big range, from about $7 \%$ based on the realized equity returns over the past several decades to 3-4\% implied from fundamentals (Claus and Thomas, 2001; Fama and French, 2002). The survey conducted by Welch (2000) and the follow-up update shows that the average expected market risk premium by finance and economics professors varies over time from about $3 \%$ to $7 \%$. We choose a slightly higher range because the Chinese equity market may be riskier than the United States.
} 
For the remaining two components, cross-industry variations explain about $16.6-26.3 \%$ of the total variance, while the wedge between the average actual cost of capital and $7.33 \%$ explains 23.84-52.9\%. We acknowledge that it is challenging to give a clear "good" or "bad" tag for these two variations. Although the cross-industry variation likely represents a "good" dispersion under our assumption that firms in the same industry have the same $\beta_{A}$, the empirically measured crossindustry dispersion might be contaminated by China's heavy industrial policies and hence could be labeled as "bad." For the third component, it is even more challenging to gauge whether $7.33 \%$ is above or below the average true cost of capital for the whole country. Overall, our result warns that the EVA policy may kill a significant portion of "good" dispersion as well.

A final point is noteworthy: although we can use a similar technique as Hsieh and Klenow (2009) to translate the within-industry dispersion in the cost of capital to aggregate productivity by assuming that firms operate at their first-order condition (when the marginal cost of capital equals the marginal revenue of product of capital), to provide an overall welfare evaluation of the EVA policy requires a full-blown equilibrium framework to integrate this "bad" dispersion with other two dispersions. We await future research for this challenging question.

\subsubsection{The impact of EVA: SOE and Non-SOE}

As hinted by the third part in Eq. (18), if the stipulated cost of capital is higher (lower) than the actual cost of capital of SOEs, then SOEs as a whole should cut (raise) investment in response to the EVA policy, potentially favoring (hurting) non-SOE investment in general equilibrium. In this way, the EVA policy could improve allocative efficiency by relocating capital from SOEs to non-SOEs.

Our sample of publicly listed SOEs has an average before-tax interest rate of $5.8 \%$, which is below $7.33 \%$ but not by a significant margin. It thus remains an empirical question whether this wedge is sufficient to push SOEs to cut back investment relative to their non-SOE peers. In Table 12, we run a difference-in-differences test that includes non-SOEs, with the main variable of interest being Post $\times$ SOE . Our regression allows for province-year fixed effects, and the coefficient of Post $\times$ SOE picks up the additional investment changes of SOEs compared to those of non-SOEs, around the EVA policy for a given (provincial) SASAC in a given year. We exclude the central SASAC from this analysis due to the difficulty in defining its non-SOE peer group. 
We also introduce an additional dummy variable High that indicates firms with a high interest rate (above sample median). In column 5 of Table 12, the coefficient of Post $\times S O E$ captures the change of investment in SOEs with a low interest rate following the EVA adoption, relative to that in the corresponding non-SOE sample; and the coefficient of Post $\times S O E \times H i g h$ captures the additional investment of SOEs with a high interest rate relative to SOEs with a low interest rate. The estimation result in column 5 confirms that that there is a significant difference between high and low interest rate groups, consistent with our findings in Section 4.3; and the EVA policy leads SOEs with a low interest rate to cut investment $(-0.1 \%)$ while those with high interest rate to increase investment $(1.7 \%=-0.001+0.018)$. In other words, our key empirical results are robust to use non-SOEs in the same province-year as the control group.

However, in all columns in Table 12, we find that the estimated coefficient of Post $\times S O E$ is statistically insignificant. Though only suggestive, this result indicates that the $7.33 \%$ EVAstipulated (before) cost of capital - which is not far from the average before-tax interest rate of $5.8 \%$ for our sample of SOEs - is not high enough to persuade the entire SOE sector to downsize.

\subsection{Measurement of $M R P K$ and the Impact of the EVA Policy}

Our paper shares a similar framework with that in Hsieh and Klenow (2009), though we do not measure the firms' $M R P K$ because we can directly measure the actual interest rate faced by firms; in contrast, Hsieh and Klenow (2009) and other more macroeconomic-oriented studies (e.g., Chen and Song (2013)) need to invoke the standard Cobb-Douglas production function and measure $M R P K$ from the production side.

For completeness, this section repeats the same exercise following the methodology in Hsieh and Klenow (2009) and Chen and Song (2013). Given our data limitations, we adopt the MRPK measure used by Chen and Song (2013), which is calculated as the natural logarithm of the ratio between operating profit and lagged fixed assets. ${ }^{48}$ We always adjust $M R P K$ by industry means and also report the results by restricting to manufacturing firms (for better comparison to the literature).

\footnotetext{
${ }^{48}$ Operating profit (before tax) is sales minus costs of goods sold and selling, general and administrative expenses, plus depreciation. The literature provides various approaches to measure capital productivity (Hsieh and Klenow, 2009; Bai, Lu, and Tian, 2018); most measures, however, require data on firm-level industrial value-added, which our sample firms (publicly listed SOEs) do not report.
} 
We are interested in whether the EVA reform leads to a reduction of industry-adjusted $M R P K$ dispersion. Our dependent variable is $M R P K$ dispersion at the SASAC-year level, which is calculated as the standard deviation of the industry-adjusted $M R P K$ across firms controlled by that SASAC in that year. We require at least five firms within each unit of observation at the SASACyear level. In Table 13, column 1 reports the results for manufacturing firms, and column 3 for all firms; columns 2 and 4 include average firm size and average leverage as control, respectively. In all specifications, the coefficients of the dummy Post, which captures the EVA's impact on the treated SASAC's MRPK dispersion, are indistinguishable from zero, suggesting no improvement in allocative efficiency within the SOE sector.

This negative result in Table 13 seems to contradict our main findings in Section 4, where we show that SOEs with a high interest rate cut their investment relative to their low-interest rate peers in response to EVA policies. Measurement error of $M R P K$ is perhaps the leading candidate for the discrepancy between these two findings. ${ }^{49}$ First, as explained above, the method in Chen and Song (2013), which measures $M R P K$ simply by the logarithm of the ratio between operating profit and lagged fixed assets, is quite crude. We have only standard financial statement data for listed companies, as opposed to plant-level data; this prevents us from using a more fine-tuned methodology. What is more, it is challenging to back out the true output $F\left(K_{i}\right)$ of any firm $i$; to estimate $F\left(K_{i}\right)$, we simply take $\left(1-\tau_{Y i}\right) F\left(K_{i}\right)$ observed in the data and adjust taxes and subsidies recorded in financial statements. This may introduce serious measurement errors in our $M R P K$ calculation if other subsidies enter firms' operating profits directly.

\section{Conclusion}

The Chinese SOEs' EVA reform provides us a laboratory to study the real consequences of managerial incentives. The reform stipulated a fixed cost of capital to virtually all SOEs and was adopted in a staggered way across different regulators. We find that, under the EVA rule, SOEs deviated

\footnotetext{
${ }^{49}$ Conceptually, the interest rate, which is the marginal cost of investment, should equal $M R P K$, which, theoretically, gives the marginal benefit of investment. But this does not hold in our data: in our sample of SOEs, interest rates and our measured $M R P K$ 's were largely uncorrelated. Their correlation coefficients are 0.027 and 0.025 among the manufacturing firms and for all firms, respectively. Neither is statistically distinguishable from zero. We also directly test whether the EVA policy increased the investment of firms with a higher measured $M R P K$ more than firms with a lower measured $M R P K$. We conduct the test using a model similar to Eq. (9). Specifically, we replace the independent variable InterestRate with industry-adjusted $M R P K$. Table A.6 in Appendix reports the results. The coefficient of $M R P K \times$ Post is insignificant in all the specifications except in column 6 .
} 
from using their actual cost of borrowing to the stipulated one as the hurdle rates used for their investment decisions. SOEs' actual cost of capital may be distorted by policy subsidies. Thus, the EVA policy may have mitigated some of the negative effects of policy subsidies. However, the EVA policy ignored the legitimate heterogeneity in the costs of capital due to risks, and such imperfection is welfare reducing. Relatedly, we do not find that capital moved from the SOE sector to the non-SOE sector in response to the EVA reform. Perhaps aware of the potential weakness of the fixed stipulation in the cost of capital, the Chinese central SASAC changed to use the firm-specific cost of capital in their EVA evaluation in 2016. Unfortunately, how the cost of capital is calculated now has not been disclosed to the public.

In many countries around the world, governments provide subsidies to various institutions, leading to a lower capital allocative efficiency. Although we do not advocate a simple EVA policy for all these institutions, such an approach may help them recognize any cost of government subsidies in their decision making, especially when removing such subsidies is politically difficult or infeasible. If the hurdle rates were stipulated properly (ideally with firm-specific information to take risk into account), such a policy could play a positive role, and we await future research along this direction.

\section{References}

Adfaith, 2005, A simulated EVA evaluation of central SOEs, CEIBS Business Review 24, 3-12.

Allen, Franklin, Jun Qian, and Meijun Qian, 2005, Law, finance, and economic growth in China, Journal of Financial Economics 77, 57-116.

Amstad, Marlene, and Zhiguo He, 2019, Chinese bond market and interbank market, Discussion paper National Bureau of Economic Research.

Bai, Chong-En, Chang-Tai Hsieh, and Michael Zheng Song, 2016, The long shadow of a fiscal expansion, Brookings Papers on Economic Activity 47, 129-181.

Bai, Yan, Dan Lu, and Xu Tian, 2018, Do financial frictions explain Chinese firms' saving and misallocation?, working paper.

Berk, Jonathan, and Peter DeMarzo, 2017, Corporate Finance: Global Edition (Pearson).

Brandt, Loren, and Hongbin Li, 2003, Bank discrimination in transition economies: ideology, information, or incentives?, Journal of Comparative Economics 31, 387-413.

Brandt, Loren, Trevor Tombe, and Xiaodong Zhu, 2013, Factor market distortions across time, space and sectors in China, Review of Economic Dynamics 16, 39-58. 
Brandt, Loren, Johannes Van Biesebroeck, and Yifan Zhang, 2014, Challenges of working with the Chinese NBS firm-level data, China Economic Review 30, 339-352.

Brandt, Loren, and Xiaodong Zhu, 2000, Redistribution in a decentralized economy: Growth and inflation in China under reform, Journal of Political Economy 108, 422-439.

Chen, Hui, Zhuo Chen, Zhiguo He, Jinyu Liu, and Rengming Xie, 2020, Pledgeability and asset prices: Evidence from the Chinese corporate bond markets, working paper.

Chen, Kaiji, and Zheng Song, 2013, Financial frictions on capital allocation: A transmission mechanism of TFP fluctuations, Journal of Monetary Economics 60, 683-703.

Chen, Zhuo, Zhiguo He, and Chun Liu, 2020, The financing of local government in China: Stimulus loan wanes and shadow banking waxes, Journal of Financial Economics 137, 42-71.

Chen, Zhao, Zhikuo Liu, Juan Carlos Suárez Serrato, and Daniel Yi Xu, 2021, Notching R\&D investment with corporate income tax cuts in China, The American Economic Review forthcoming.

Claus, James, and Jacob Thomas, 2001, Equity premia as low as three percent? evidence from analysts' earnings forecasts for domestic and international stock markets, The Journal of Finance 56, 1629-1666.

Cong, Lin William, Haoyu Gao, Jacopo Ponticelli, and Xiaoguang Yang, 2019, Credit allocation under economic stimulus: Evidence from China, The Review of Financial Studies 32, 3412-3460.

De Chaisemartin, Clément, and Xavier D'Haultfoeuille, 2020, Two-way fixed effects estimators with heterogeneous treatment effects, American Economic Review 110, 2964-96.

Deng, Yongheng, Randall Morck, Jing Wu, and Bernard Yeung, 2015, China's pseudo-monetary policy, Review of Finance 19, 55-93.

Ding, Yi, Wei Xiong, and Jinfan Zhang, 2020, Overpricing in China's corporate bond market, working paper.

Dollar, David, and Shang-Jin Wei, 2007, Das (wasted) kapital: firm ownership and investment efficiency in China, working paper.

Du, Fei, David H Erkens, S Mark Young, and Guliang Tang, 2018, How adopting new performance measures affects subjective performance evaluations: Evidence from EVA adoption by Chinese state-owned enterprises, The Accounting Review 93, 161-185.

Edmans, Alex, Vivian W Fang, and Katharina A Lewellen, 2017, Equity vesting and investment, The Review of Financial Studies 30, 2229-2271.

Edmans, Alex, Xavier Gabaix, and Dirk Jenter, 2017, Executive compensation: A survey of theory and evidence, in The Handbook of the Economics of Corporate Governance, vol. 1 . pp. 383-539 (Elsevier).

Fama, Eugene F, and Kenneth R French, 2002, The equity premium, The Journal of Finance 57, 637-659.

Fan, Gang, Xiaolu Wang, and Hengpeng Zhu, 2010, NERI index of Marketization of China's Provinces 2009 Report (Economic Science Press). 
Fan, Joseph PH, Tak Jun Wong, and Tianyu Zhang, 2007, Politically connected CEOs, corporate governance, and post-IPO performance of China's newly partially privatized firms, Journal of Financial Economics 84, 330-357.

Flammer, Caroline, and Pratima Bansal, 2017, Does a long-term orientation create value? Evidence from a regression discontinuity, Strategic Management Journal 38, 1827-1847.

Francis, Jennifer, Ryan LaFond, Per Olsson, and Katherine Schipper, 2005, The market pricing of accruals quality, Journal of Accounting and Economics 39, 295-327.

Frank, Murray Z, and Tao Shen, 2016, Investment and the weighted average cost of capital, Journal of Financial Economics 119, 300-315.

Freixas, Xavier, Roger Guesnerie, and Jean Tirole, 1985, Planning under incomplete information and the ratchet effect, The Review of Economic Studies 52, 173-191.

Frydman, Carola, and Dirk Jenter, 2010, CEO compensation, Annual Review of Financial Economics 2, 75-102.

Gan, Jie, Yan Guo, and Chenggang Xu, 2018, Decentralized privatization and change of control rights in China, The Review of Financial Studies 31, 3854-3894.

Geng, Zhe, and Jun Pan, 2021, The SOE premium and government support in China's credit market, working paper.

Groves, Theodore, Yongmiao Hong, John McMillan, and Barry Naughton, 1994, Autonomy and incentives in Chinese state enterprises, The Quarterly Journal of Economics 109, 183-209.

Hayek, F. A., 1945, The use of knowledge in society, The American Economic Review 35, 519-530.

Hennessy, Christopher A, and Ilya A Strebulaev, 2020, Beyond random assignment: credible inference and extrapolation in dynamic economies, The Journal of Finance 75, 825-866.

Hsieh, Chang-Tai, and Peter J Klenow, 2009, Misallocation and manufacturing TFP in China and India, The Quarterly Journal of Economics 124, 1403-1448.

Hsieh, Chang-Tai, and Zheng Michael Song, 2015, Grasp the large, let go of the small: the transformation of the state sector in China, Brookings Papers on Economic Activity pp. 295-346.

Huang, Zhangkai, Lixing Li, Guangrong Ma, and Lixin Colin Xu, 2017, Hayek, local information, and commanding heights: Decentralizing state-owned enterprises in China, American Economic Review 107, 2455-78.

Jiang, Fuxiu, and Kenneth A Kim, 2020, Corporate Governance in China: A Survey, Review of Finance 24, 733-772.

Kerr, Steven, 1975, On the folly of rewarding A, while hoping for B, Academy of Management Journal 18, 769-783.

Krüger, Philipp, Augustin Landier, and David Thesmar, 2015, The wacc fallacy: The real effects of using a unique discount rate, The Journal of Finance 70, 1253-1285.

Li, Bo, Zhengwei Wang, and Hao Zhou, 2021, China's anti-corruption campaign and credit reallocation from SOEs to non-SOEs, PBCSF-NIFR Research Paper. 
Li, Hongbin, Lingsheng Meng, Qian Wang, and Li-An Zhou, 2008, Political connections, financing and firm performance: Evidence from Chinese private firms, Journal of Development Economics $87,283-299$.

Li, Shengyu, and Hongsong Zhang, 2021, Does external monitoring improve the performance of state-owned enterprises?, Economic Journal forthcoming.

Li, Xi, Xuewen Liu, and Yong Wang, 2015, A model of China's state capitalism, working paper.

Lintner, John, 1965, The valuation of risk assets and the selection of risky investments in stock portfolios and capital budgets, The Review of Economics and Statistics 47, 13-37.

Liu, Jianan, Robert F Stambaugh, and Yu Yuan, 2019, Size and value in china, Journal of Financial Economics 134, 48-69.

Lucas, Deborah, 2014, Evaluating the cost of government credit support: the OECD context, Economic Policy 29, 553-597.

Mengistae, Taye, and Lixin Colin Xu, 2004, Agency theory and executive compensation: The case of Chinese state-owned enterprises, Journal of Labor Economics 22, 615-637.

Midrigan, Virgiliu, and Daniel Yi Xu, 2014, Finance and misallocation: Evidence from plant-level data, American Economic Review 104, 422-58.

Modigliani, Franco, and Merton H Miller, 1958, The cost of capital, corporation finance and the theory of investment, The American Economic Review 48, 261-297.

Murphy, Kevin J, 1999, Executive Compensation, Handbook of Labor Economics 3, 2485-2563.

, 2013, Executive compensation: Where we are, and how we got there, in Handbook of the Economics of Finance, vol. 2 . pp. 211-356 (Elsevier).

Naughton, Barry, 2008, SASAC and rising corporate power in China, China Leadership Monitor $24,1-9$.

, 2015, The transformation of the state sector: SASAC, the market economy, and the new national champions, State Capitalism, Institutional Adaptation, and the Chinese Miracle pp. 4671.

Petersen, Mitchell A., 2009, Estimating standard errors in finance panel data sets: Comparing approaches, The Review of Financial Studies 22, 435-480.

Restuccia, Diego, and Richard Rogerson, 2008, Policy distortions and aggregate productivity with heterogeneous establishments, Review of Economic Dynamics 11, 707-720.

— 2013, Misallocation and productivity, .

— 2017, The causes and costs of misallocation, Journal of Economic Perspectives 31, 151-74.

Rogerson, William P, 1997, Intertemporal cost allocation and managerial investment incentives: A theory explaining the use of economic value added as a performance measure, Journal of Political Economy 105, 770-795.

Sharpe, William F, 1964, Capital asset prices: A theory of market equilibrium under conditions of risk, The Journal of Finance 19, 425-442. 
Shue, Kelly, and Richard R Townsend, 2017, How do quasi-random option grants affect CEO risktaking?, The Journal of Finance 72, 2551-2588.

Song, Zheng, Kjetil Storesletten, and Fabrizio Zilibotti, 2011, Growing like China, American Economic Review 101, 196-233.

Stern, Erik, 2011, China adopts EVA: An essential step in the Great Leap Forward, Journal of Applied Corporate Finance 23, 57-62.

Syverson, Chad, 2011, What determines productivity?, Journal of Economic literature 49, 326-65.

Wang, Xiaolu, Gang Fan, and Lipeng Hu, 2019, Marketization Index of China's Provinces: NERI Report 2018 (Social Sciences Academic Press).

Weitzman, Martin L, 1980, The "ratchet principle" and performance incentives, The Bell Journal of Economics pp. 302-308.

Welch, Ivo, 2000, Views of financial economists on the equity premium and on professional controversies, The Journal of Business 73, 501-537. 
Table 1: Determinants of the EVA policy adoption

This table presents the regression results on how province characteristics affect the timing of the EVA policy adoption. The unit of analysis is province-year. The dependent variable is one if a province adopts the EVA policy in that year, and zero otherwise. Province-years after the EVA adoption are excluded from the analysis. Age $\geq 65$ is a dummy variable equal to one if the age of the secretary of the provincial Communist Party committee is equal to or greater than 65 years, and zero otherwise. Tenure is the natural log of one plus the number of years that the party secretary has been in office. \% of SOE Assets is the proportion of SOE assets among all the industrial enterprises of the province. SOE Investment Growth is the average growth rate of capital expenditure of all SOEs controlled by a provincial SASAC, calculated over the past three years. Marketization is the Marketization index from Fan, Wang, and Zhu (2010) and Wang, Fan, and $\mathrm{Hu}$ (2019), measuring the importance of the market in resource allocation. The sample period is 2004-2015. All the independent variables are lagged by one year. T-statistics computed with standard errors clustered at the province and year levels are reported in the parentheses. ${ }^{* * *},{ }^{* *}$, and ${ }^{*}$ indicate significance at the $1 \%, 5 \%$, and $10 \%$ levels, respectively.

\begin{tabular}{|c|c|c|c|c|c|c|c|c|}
\hline & (1) & (2) & (3) & (4) & (5) & (6) & (7) & (8) \\
\hline GDP Growth & $\begin{array}{l}1.116^{*} \\
(1.71)\end{array}$ & & & & & & & $\begin{array}{c}1.138 \\
(1.45)\end{array}$ \\
\hline GDP per capita & & $\begin{array}{l}-0.001 \\
(-0.06)\end{array}$ & & & & & & $\begin{array}{l}0.028 \\
(0.58)\end{array}$ \\
\hline Age $\geq 65$ & & & $\begin{array}{l}0.043 \\
(0.57)\end{array}$ & & & & & $\begin{array}{l}0.060 \\
(0.71)\end{array}$ \\
\hline Temure & & & & $\begin{array}{l}-0.018 \\
(-1.32)\end{array}$ & & & & $\begin{array}{l}-0.028 \\
(-1.54)\end{array}$ \\
\hline$\%$ of SOE Assets & & & & & $\begin{array}{c}0.116^{* * *} \\
(2.24)\end{array}$ & & & $\begin{array}{l}0.121 \\
(0.93)\end{array}$ \\
\hline SOE Investment Growth & & & & & & $\begin{array}{l}0.010 \\
(0.82)\end{array}$ & & $\begin{array}{l}0.009 \\
(0.65)\end{array}$ \\
\hline Marketization & & & & & & & $\begin{array}{l}-0.007 \\
(-1.13)\end{array}$ & $\begin{array}{l}-0.006 \\
(-0.31)\end{array}$ \\
\hline Observations & 272 & 272 & 272 & 272 & 272 & 267 & 272 & 267 \\
\hline R-squared & 0.087 & 0.078 & 0.079 & 0.081 & 0.087 & 0.081 & 0.081 & 0.109 \\
\hline Year FE & Yes & Yes & Yes & Yes & Yes & Yes & Yes & Yes \\
\hline
\end{tabular}


Table 2: Summary Statistics

This table reports the summary statistics: Panel A for mean, median, standard deviation, and percentiles and Panel B for correlations. Capex is capital expenditure scaled by the lagged total assets. InterestRate is a firm's interest expenses divided by the average of its interest-bearing debts at the beginning of the year and the end of each of the four quarters. The interest-bearing debts include short-term loans, long-term liabilities due within one year, long-term loans, bonds payable, and long-term payables. Tobin's $Q$ is measured as the sum of the market value of equity and book value of total liabilities, divided by the book value of total assets. CashFlow is cash flow from operating activities, scaled by the lagged total assets. Log(Assets) is the natural logarithm of total assets. Leverage is total liabilities divided by total assets. CEOOwnership is the average fraction of shares held by a firm's general manager and board chair, multiplied by 100. PoliticalConnection is a dummy variable that equals one if either the general manager or the board chair was previously employed as a bureaucrat by the central government or a local government. ${ }^{* * *}, * *$, and $*$ indicate significance at the $1 \%, 5 \%$, and $10 \%$ levels, respectively.

Panel A: Mean, median, standard deviation, and percentiles

\begin{tabular}{lcccccc}
\hline & $\mathrm{N}$ & Mean & Median & Std. Dev. & P25 & P75 \\
\hline Capex & 4716 & 0.071 & 0.046 & 0.080 & 0.018 & 0.094 \\
InterestRate & 4716 & 0.058 & 0.054 & 0.033 & 0.042 & 0.066 \\
Tobin's $Q$ & 4716 & 1.976 & 1.597 & 1.239 & 1.206 & 2.268 \\
CashFlow & 4716 & 0.056 & 0.051 & 0.097 & 0.006 & 0.102 \\
Log(Assets) & 4716 & 22.256 & 22.030 & 1.416 & 21.222 & 23.099 \\
Leverage & 4716 & 0.530 & 0.533 & 0.192 & 0.390 & 0.662 \\
CEOOwnership (\%) & 4698 & 0.046 & 0 & 0.527 & 0 & 0.001 \\
PoliticalConnection & 4716 & 0.335 & 0 & 0.472 & 0 & 1 \\
\hline
\end{tabular}

Panel B: Correlations

\begin{tabular}{|c|c|c|c|c|c|c|c|c|}
\hline & Capex & InterestRate & Tobin's $Q$ & CashFlow & $\log ($ Assets $)$ & Leverage & CEOOwnership (\%) & PoliticalConnection \\
\hline Capex & 1 & & & & & & & \\
\hline InterestRate & $-0.110 * * *$ & 1 & & & & & & \\
\hline Tobin's $Q$ & $0.056^{* * *}$ & $0.125 * * *$ & 1 & & & & & \\
\hline CashFlow & $0.295 * * *$ & -0.023 & $0.083^{* * *}$ & 1 & & & & \\
\hline $\log ($ Assets $)$ & $0.056 * * *$ & $-0.173 * * *$ & $-0.329 * * *$ & $0.047 * * *$ & 1 & & & \\
\hline Leverage & $-0.126 * * *$ & 0.032 & $-0.186^{* * *}$ & $-0.154 * * *$ & $0.221 * * *$ & 1 & & \\
\hline CEOOwnership (\%) & $0.065 * * *$ & -0.020 & $0.029 * *$ & -0.028 & -0.023 & 0.000 & 1 & \\
\hline PoliticalConnection & $0.075 * * *$ & $-0.054 * * *$ & $-0.046^{* * *}$ & $0.076^{* * *}$ & $0.115 * * *$ & $0.026 *$ & $-0.047 * * *$ & 1 \\
\hline
\end{tabular}


Table 3: Baseline regressions

This table reports the results of the baseline regressions. The dependent variable is Capex. Capex is capital expenditure scaled by the lagged total assets. InterestRate is a firm's interest expenses divided by the average of its interest-bearing debts at the beginning of the year and the end of each of the four quarters. The interest-bearing debts include short-term loans, long-term liabilities due within one year, long-term loans, bonds payable, and long-term payables. Post is a dummy equal to one if a firm is subject to the EVA policy in year $t$ and zero otherwise. Tobin's $Q$ is measured as the sum of the market value of equity and book value of total liabilities, divided by the book value of total assets. CashFlow is cash flow from operating activities, scaled by the lagged total assets. Log(Assets) is the natural logarithm of total assets. Leverage is total liabilities divided by total assets. All the control variables are lagged by one year except CashFlow. SASAC*Year, Industry*Year, and Province*Year are three interactive fixed effects. In all columns except columns (4) and (5), $t$-statistics are calculated by clustering at the SASAC and year levels. In columns (4) and (5), $t$-statistics are calculated by clustering at the SASAC level. ${ }^{* * *}, * *$, and $*$ indicate significance at the $1 \%, 5 \%$, and $10 \%$ levels, respectively.

\begin{tabular}{|c|c|c|c|c|c|c|c|}
\hline & $(1)$ & (2) & (3) & (4) & (5) & $(6)$ & (7) \\
\hline Post $\times$ InterestRate & $\begin{array}{c}0.256^{* * *} \\
(2.71)\end{array}$ & $\begin{array}{c}0.233 * * * \\
(2.68)\end{array}$ & $\begin{array}{c}0.240^{* * *} \\
(2.62)\end{array}$ & $\begin{array}{c}0.186 * * * \\
(4.13)\end{array}$ & $\begin{array}{c}0.175^{* * *} \\
(4.31)\end{array}$ & $\begin{array}{c}0.179 * * * \\
(3.37)\end{array}$ & $\begin{array}{c}0.190 * * * \\
(3.17)\end{array}$ \\
\hline Post & $\begin{array}{c}-0.032 * * * \\
(-3.13)\end{array}$ & $\begin{array}{c}-0.026 * * * \\
(-2.76)\end{array}$ & $\begin{array}{c}-0.030 * * \\
(-2.54)\end{array}$ & $\begin{array}{l}-0.005 \\
(-0.99)\end{array}$ & & & \\
\hline InterestRate & $\begin{array}{c}-0.368 * * * \\
(-4.16)\end{array}$ & $\begin{array}{c}-0.357 * * * \\
(-4.20)\end{array}$ & $\begin{array}{c}-0.321 * * * \\
(-4.60)\end{array}$ & $\begin{array}{c}-0.196 * * * \\
(-4.46)\end{array}$ & $\begin{array}{c}-0.156 * * * \\
(-2.92)\end{array}$ & $\begin{array}{c}-0.183 * * \\
(-2.90)\end{array}$ & $\begin{array}{c}-0.170 * * \\
(-2.88)\end{array}$ \\
\hline Tobin's $Q$ & & $\begin{array}{c}0.003 * * * \\
(3.22)\end{array}$ & $\begin{array}{c}0.004^{* * *} \\
(4.27)\end{array}$ & $\begin{array}{c}0.007 * * * \\
(4.21)\end{array}$ & $\begin{array}{c}0.006 * * * \\
(3.77)\end{array}$ & $\begin{array}{c}0.005^{* *} \\
(2.93)\end{array}$ & $\begin{array}{c}0.004^{* *} \\
(2.24)\end{array}$ \\
\hline CashFlow & & $\begin{array}{c}0.232 * * * \\
(10.26)\end{array}$ & $\begin{array}{c}0.215^{* * *} \\
(7.63)\end{array}$ & $\begin{array}{c}0.106^{* * *} * \\
(5.57)\end{array}$ & $\begin{array}{c}0.101 * * * \\
(5.32)\end{array}$ & $\begin{array}{c}0.087 * * * \\
(7.29)\end{array}$ & $\begin{array}{c}0.078 * * * \\
(6.77)\end{array}$ \\
\hline $\log ($ Assets $)$ & & & $\begin{array}{l}0.005^{*} \\
(1.84)\end{array}$ & $\begin{array}{c}-0.016 * * * \\
(-2.82)\end{array}$ & $\begin{array}{c}-0.017 * * \\
(-2.76)\end{array}$ & $\begin{array}{c}-0.021 * \\
(-2.02)\end{array}$ & $\begin{array}{c}-0.027 * * \\
(-2.83)\end{array}$ \\
\hline Leverage & & & $\begin{array}{c}-0.036^{* *} \\
(-2.46)\end{array}$ & $\begin{array}{c}-0.058^{* * *} \\
(-3.13)\end{array}$ & $\begin{array}{c}-0.048^{* *} \\
(-2.53)\end{array}$ & $\begin{array}{c}-0.039 * \\
(-2.14)\end{array}$ & $\begin{array}{l}-0.028 \\
(-1.73)\end{array}$ \\
\hline Observations & 4,716 & 4,716 & 4,716 & 4,682 & 4,648 & 4,628 & 4,616 \\
\hline R-squared & 0.025 & 0.107 & 0.118 & 0.471 & 0.514 & 0.549 & 0.591 \\
\hline Firm FE & NO & NO & NO & YES & YES & YES & YES \\
\hline Year FE & NO & NO & NO & YES & NO & NO & NO \\
\hline SASAC*Year FE & NO & NO & NO & NO & YES & YES & YES \\
\hline Industry*Year FE & NO & NO & NO & NO & NO & YES & YES \\
\hline Province*Year FE & NO & NO & NO & NO & NO & NO & YES \\
\hline
\end{tabular}


Table 4: Results using the group company sample

This table reports the results of the baseline regressions using the group company sample. The dependent variable is Capex. Capex is capital expenditure scaled by the lagged total assets. InterestRate is a firm's interest expenses divided by the average of its interest-bearing debts at the beginning of the year and the end of the year. The interest-bearing debts include short-term loans, long-term liabilities due within one year, long-term loans, bonds payable, and long-term payables. Post is a dummy equal to one if a firm is subject to the EVA policy in year $t$ and zero otherwise. CashFlow is cash flow from operating activities, scaled by the lagged total assets. $\log ($ Assets $)$ is the natural logarithm of total assets. Leverage is total liabilities divided by total assets. All the control variables are lagged by one year except CashFlow. Province $\times$ Year and Industry $\times$ Year are two interactive fixed effects; we do not include SASAC $\times$ year because for non-SOE sample this dummy coincides with Province $\times$ Year exactly). T-statistics computed with standard errors clustered at the SASAC and year levels are reported in the parentheses. ${ }^{* *},{ }^{* *}$, and ${ }^{*}$ indicate significance at the $1 \%, 5 \%$, and $10 \%$ levels, respectively.

\begin{tabular}{lcccc}
\hline & $(1)$ & $(2)$ & $(3)$ & $(4)$ \\
\hline Post $\times$ InterestRate & $0.252^{* *}$ & $0.221^{* * *}$ & $0.194^{* *}$ & $0.200^{* *}$ \\
Post & $(3.23)$ & $(2.75)$ & $(2.17)$ & $(2.24)$ \\
& -0.014 & & & \\
InterestRate & $(-1.64)$ & & & \\
& -0.032 & -0.015 & 0.003 & 0.018 \\
CashFlow & $(-0.60)$ & $(-0.25)$ & $(0.05)$ & $(0.26)$ \\
& $0.069^{* *}$ & $0.078^{* *}$ & $0.070^{* *}$ & $0.062^{* *}$ \\
Log(Assets) & $(2.78)$ & $(3.04)$ & $(3.16)$ & $(2.91)$ \\
& -0.017 & $-0.021^{*}$ & $-0.028^{* *}$ & $-0.027^{*}$ \\
Leverage & $(-1.77)$ & $(-1.96)$ & $(-2.34)$ & $(-2.21)$ \\
& $-0.103^{* *}$ & $-0.104^{* *}$ & $-0.090^{*}$ & $-0.103^{* *}$ \\
Observations & $(-3.00)$ & $(-2.74)$ & $(-2.10)$ & $(-2.49)$ \\
R-squared & 2,459 & 2,438 & 2,417 & 2,404 \\
Firm FE & 0.637 & 0.692 & 0.723 & 0.734 \\
Year FE & YES & YES & YES & YES \\
SASAC*Year FE & YES & NO & NO & NO \\
Industry*Year FE & NO & YES & YES & YES \\
Province*Year FE & NO & NO & YES & YES \\
& NO & NO & NO & YES \\
\hline
\end{tabular}


Table 5: Non-state owned enterprises as a placebo group

This table reports the results of the baseline regressions on non-SOEs. The dependent variable is Capex. Capex is capital expenditure scaled by the lagged total assets. InterestRate is a firm's interest expenses divided by the average of its interest-bearing debts at the beginning of the year and the end of each of the four quarters. The interest-bearing debts include short-term loans, long-term liabilities due within one year, long-term loans, bonds payable, and long-term payables. Post is a dummy equal to one if a firm is subject to the EVA policy in year $t$ and zero otherwise. Tobin's $Q$ is measured as the sum of the market value of equity and book value of total liabilities, divided by the book value of total assets. CashFlow is cash flow from operating activities, scaled by the lagged total assets. Log(Assets) is the natural logarithm of total assets. Leverage is total liabilities divided by total assets. All the control variables are lagged by one year except CashFlow. Province $\times$ Year and Industry $\times$ Year are two interactive fixed effects; we do not include SASAC $\times$ year because for non-SOE sample this dummy coincides with Province $\times$ Year exactly). T-statistics computed with standard errors clustered at the province and year levels are reported in the parentheses. ***, ${ }^{* *}$, and ${ }^{*}$ indicate significance at the $1 \%, 5 \%$, and $10 \%$ levels, respectively.

\begin{tabular}{lcccccc}
\hline & $(1)$ & $(2)$ & $(3)$ & $(4)$ & $(5)$ & $(6)$ \\
\hline Post $\times$ InterestRate & -0.086 & $-0.095^{*}$ & $-0.112^{* *}$ & -0.049 & -0.029 & -0.040 \\
& $(-1.57)$ & $(-1.78)$ & $(-2.01)$ & $(-1.12)$ & $(-0.75)$ & $(-0.96)$ \\
Post & 0.005 & 0.007 & 0.006 & 0.001 & & \\
& $(0.61)$ & $(0.94)$ & $(0.82)$ & $(0.11)$ & & \\
InterestRate & -0.057 & -0.069 & -0.064 & -0.008 & -0.012 & -0.014 \\
& $(-1.19)$ & $(-1.57)$ & $(-1.57)$ & $(-0.23)$ & $(-0.38)$ & $(-0.52)$ \\
Tobin's $Q$ & & $0.002^{* *}$ & $0.005^{* * *}$ & $0.005^{* *}$ & $0.005^{* *}$ & $0.005^{* *}$ \\
& & $(2.20)$ & $(4.29)$ & $(2.76)$ & $(2.75)$ & $(2.70)$ \\
CashFlow & & $0.148^{* * *}$ & $0.136^{* * *}$ & $0.059^{* *}$ & $0.061^{* *}$ & $0.057^{* *}$ \\
& & $(9.75)$ & $(9.98)$ & $(2.95)$ & $(2.96)$ & $(2.88)$ \\
Log(Assets) & & & 0.001 & $-0.017 * * *$ & $-0.018^{* * *}$ & $-0.021^{* * *}$ \\
& & & $(0.22)$ & $(-4.01)$ & $(-3.95)$ & $(-5.01)$ \\
Leverage & & & $-0.030^{* * *}$ & $-0.024 * *$ & $-0.024^{* *}$ & $-0.022^{* *}$ \\
& & $(-4.34)$ & $(-2.84)$ & $(-2.84)$ & $(-2.89)$ \\
Observations & 6,459 & 6,459 & 6,459 & 6,343 & 6,334 & 6,326 \\
R-squared & 0.003 & 0.044 & 0.073 & 0.486 & 0.533 & 0.566 \\
Firm FE & NO & NO & NO & YES & YES & YES \\
Year FE & NO & NO & NO & YES & NO & NO \\
Province*Year FE & NO & NO & NO & NO & YES & YES \\
Industry*Year FE & NO & NO & NO & NO & NO & YES \\
\hline
\end{tabular}


Table 6: Firm performance

This table reports the results on how the EVA policy affected firm performance as measured with ROE. $R O E$ is net income divided by lagged equity. Firms are sorted into six groups by lagged interest rates. We classify firms with InterestRate below $2.5 \%$, between $2.5 \%$ and $4.5 \%$, between $4.5 \%$ and $6.5 \%$, between $6.5 \%$ and $8.5 \%$, between $8.5 \%$ and $10.5 \%$, and higher than $10.5 \%$, as group 1 , group $2, \ldots$, and group 6 , respectively. Post is a dummy equal to one if a firm is subject to the EVA policy in year $t$ and zero otherwise. Log(Assets) is the natural logarithm of total assets. Leverage is total liabilities divided by total assets. All the variables are lagged by one year. SASAC $\times$ Year, Industry $\times$ Year, and Province $\times$ Year are three interactive fixed effects. T-statistics computed with standard errors clustered at the SASAC and year levels are reported in parentheses. $* * *, * *$, and ${ }^{*}$ indicate statistical significance at the $1 \%, 5 \%$, and $10 \%$ levels, respectively.

\begin{tabular}{lcccc}
\hline & $(1)$ & $(2)$ & $(3)$ & $(4)$ \\
\hline Post $\times$ Group1 & -0.012 & $-0.035^{* *}$ & $-0.048^{* * *}$ & $-0.042^{* * *}$ \\
Post $\times$ Group2 & $(-0.53)$ & $(-2.72)$ & $(-4.85)$ & $(-3.56)$ \\
& -0.030 & $-0.046^{* *}$ & $-0.047^{* * *}$ & $-0.049^{* *}$ \\
Post $\times$ Group3 & $(-1.57)$ & $(-2.40)$ & $(-3.16)$ & $(-2.77)$ \\
& 0.019 & -0.003 & -0.009 & -0.005 \\
Post $\times$ Group4 & $(1.50)$ & $(-0.33)$ & $(-1.22)$ & $(-0.44)$ \\
& $0.020^{*}$ & & & \\
Post $\times$ Group5 & $(1.90)$ & & & \\
& -0.012 & -0.040 & $-0.045^{*}$ & -0.025 \\
Post $\times$ Group6 & $(-0.43)$ & $(-1.52)$ & $(-2.14)$ & $(-1.20)$ \\
& -0.036 & -0.053 & -0.079 & $-0.061^{* *}$ \\
Log $($ Assets $)$ & $(-0.98)$ & $(-1.31)$ & $(-1.72)$ & $(-2.28)$ \\
& $-0.053^{* *}$ & $-0.053 * *$ & $-0.056^{* *}$ & $-0.065^{* *}$ \\
Leverage & $(-2.70)$ & $(-2.62)$ & $(-2.90)$ & $(-3.05)$ \\
& 0.089 & 0.116 & 0.133 & $0.152^{*}$ \\
Observations & $(1.04)$ & $(1.43)$ & $(1.71)$ & $(1.93)$ \\
R-squared & 4,624 & 4,586 & 4,567 & 4,554 \\
Firm FE & 0.375 & 0.439 & 0.486 & 0.565 \\
Year FE & YES & YES & YES & YES \\
SASAC*Year FE & YES & NO & NO & NO \\
Industry*Year FE & NO & YES & YES & YES \\
Province*Year FE & NO & NO & YES & YES \\
\hline & NO & NO & NO & YES \\
\hline
\end{tabular}


Table 7: EVA, executive turnover, and compensation

This table reports the OLS regression results on the relationship between EVA and executive turnover (Panel A) and the relationship between EVA and executive compensation (Panel B). In Panel A, the dependent variable equals one if either the general manager or the board chair departs and zero otherwise. In Panel $\mathrm{B}$, the dependent variable is the $\log (1+$ the average compensation of the general manager and the board chair). EVA is calculated following the SASAC report as in Eq. (2). To make the EVA measure comparable across firms, we scale the dollar EVA by average firm assets. Post is a dummy equal to one if a firm is subject to the EVA policy in year $t$ and zero otherwise. ROE is net income divided by the lagged equity. Tobin's $Q$ is measured as the sum of the market value of equity and book value of total liabilities, divided by the book value of total assets. Log(Assets) is the natural logarithm of total assets. Leverage is total liabilities divided by total assets. We also control for the age and tenure of the general manager and the board chair. In Panel $\mathrm{A}$, all the variables are lagged by one year. In Panel $\mathrm{B}$, Post, $E V A$, and $R O E$ are contemporaneous with compensation and all other variables are lagged by one year. SASAC $\times$ Year, Industry $\times$ Year, and Province $\times$ Year are three interactive fixed effects. T-statistics computed with standard errors clustered at the SASAC and year levels are reported in parentheses. ${ }^{* * *},{ }^{* *}$, and ${ }^{*}$ indicate statistical significance at the $1 \%, 5 \%$, and $10 \%$ levels, respectively.

\begin{tabular}{|c|c|c|c|c|c|c|c|c|}
\hline & \multicolumn{4}{|c|}{ Panel A. Turnover } & \multicolumn{4}{|c|}{ Panel B. Compensation } \\
\hline & (1) & (2) & (3) & (4) & $(5)$ & (6) & (7) & (8) \\
\hline \multirow[t]{2}{*}{ Post $\times E V A$} & $-0.999^{*}$ & $-1.272^{2 *} k_{k}$ & $-0.919^{*}$ & $-1.469{ }^{*} * k_{k}$ & -0.092 & 0.176 & 1.244 & $4.455^{*}$ \\
\hline & $(-1.83)$ & $(-2.39)$ & $(-2.03)$ & $(-2.67)$ & $(-0.03)$ & $(0.05)$ & $(0.39)$ & $(1.79)$ \\
\hline \multirow[t]{2}{*}{ Post } & -0.043 & & & & -0.391 & & & \\
\hline & $(-1.28)$ & & & & $(-1.14)$ & & & \\
\hline \multirow[t]{2}{*}{$E V A$} & -0.029 & 0.264 & 0.138 & 0.408 & 0.604 & 0.647 & -0.450 & -1.514 \\
\hline & $(-0.08)$ & $(0.55)$ & $(0.27)$ & $(0.86)$ & $(0.18)$ & $(0.18)$ & $(-0.17)$ & $(-0.58)$ \\
\hline \multirow[t]{2}{*}{ Post $\times R O E$} & $0.478^{2 *} k^{k}$ & $0.568^{*}$ 水水 & $0.530^{2}$ 水水 & $0.663^{2} k^{2} k_{k}$ & 0.026 & 0.215 & -0.094 & -1.686 \\
\hline & $(2.99)$ & $(5.19)$ & $(5.27)$ & $(3.28)$ & $(0.02)$ & $(0.13)$ & $(-0.06)$ & $(-1.46)$ \\
\hline \multirow[t]{2}{*}{$R O E$} & $-0.270^{*} *$ & $-0.368^{*} *$ & $-0.323^{*} k^{*}$ & $-0.366^{k} k^{k}$ & -0.012 & -0.149 & 0.040 & 1.025 \\
\hline & $(-2.28)$ & $(-2.74)$ & $(-2.30)$ & $(-2.26)$ & $(-0.01)$ & $(-0.10)$ & $(0.04)$ & (1.05) \\
\hline \multirow[t]{2}{*}{ Tobin's $Q$} & -0.005 & -0.006 & -0.009 & -0.018 & -0.103 & -0.100 & $-0.125^{*}$ & $-0.177^{*}$ \\
\hline & $(-0.30)$ & $(-0.28)$ & $(-0.41)$ & $(-0.86)$ & $(-1.18)$ & $(-1.36)$ & $(-1.92)$ & $(-1.81)$ \\
\hline \multirow[t]{2}{*}{$\log ($ Assets $)$} & $-0.074^{*} *$ & $-0.072^{* k} k_{k} k^{2}$ & $-0.082^{*}$ 水水 & $-0.109 * k \cdots$ & 0.278 & 0.287 & 0.187 & 0.228 \\
\hline & $(-2.75)$ & $(-3.80)$ & $(-3.61)$ & $(-4.13)$ & $(1.36)$ & (1.16) & $(0.86)$ & $(0.83)$ \\
\hline \multirow[t]{2}{*}{ Leverage } & $0.255^{2}$ 水水 & $0.320^{2}$ 水水 & $0.305^{*}$ 水水 & 0.259 * $k^{2}$ & -0.726 & -0.162 & -0.166 & -0.590 \\
\hline & (3.24) & $(3.83)$ & $(3.12)$ & $(2.53)$ & $(-0.62)$ & $(-0.14)$ & $(-0.15)$ & $(-0.56)$ \\
\hline \multirow{2}{*}{$\begin{array}{l}\text { Log (Age of } \\
\quad \text { general manager) }\end{array}$} & $0.319^{2}$ 水水 & $0.378^{*} k^{*} k^{2} k$ & $0.352^{2}$ 水水 & $0.327^{*}$ 水 & $-1.946^{*} k^{*}$ & $-1.645^{*} k^{*}$ & $-1.793^{*} v^{*}$ & $-1.851^{k}$ \\
\hline & $(4.00)$ & $(5.28)$ & (3.37) & $(2.30)$ & $(-3.08)$ & $(-2.60)$ & $(-2.31)$ & $(-2.06)$ \\
\hline \multirow{2}{*}{$\begin{array}{l}\log (1+\text { tenure of } \\
\text { general manager })\end{array}$} & $0.136^{*}$ 水水 & 0.139 水水 & $0.137^{2}$ 水水 & $0.128^{*} k^{*} k^{2}$ & $3.066^{k} k^{2} k_{k}$ & $3.175^{\text {水水 }}$ & 3.179 水水 & 3.166 水水 \\
\hline & (6.44) & $(8.18)$ & $(12.74)$ & $(11.07)$ & $(11.52)$ & $(12.85)$ & $(14.24)$ & $(15.05)$ \\
\hline \multirow{2}{*}{$\begin{array}{r}\log (\text { Age of } \\
\text { chair })\end{array}$} & 0.049 & 0.041 & 0.055 & 0.106 & $2.208^{*}$ & 1.900 & $1.981^{*}$ & $2.267^{*}$ \\
\hline & $(0.52)$ & $(0.47)$ & $(0.55)$ & (1.04) & $(2.19)$ & $(1.71)$ & $(2.06)$ & $(2.20)$ \\
\hline \multirow{2}{*}{$\begin{array}{c}\log (1+\text { temure of } \\
\text { chair })\end{array}$} & $0.136^{*} k^{*} k^{2}$ & $0.143^{2} k^{*} k_{k}$ & $0.145^{*} k^{*} k^{2}$ & $0.146^{*} * k_{k}$ & $-0.837^{2}$ 水水 & $-0.824^{2}$ 水水 & $-0.855^{\text {水水水 }}$ & $-0.861^{*} k_{k} k^{2}$ \\
\hline & (6.09) & (6.56) & $(8.77)$ & $(6.71)$ & $(-8.03)$ & $(-8.29)$ & $(-9.27)$ & $(-7.41)$ \\
\hline Observations & 3,637 & 3,594 & 3,561 & 3,537 & 3,675 & 3,630 & 3,602 & 3,577 \\
\hline R-squared & 0.248 & 0.311 & 0.348 & 0.426 & 0.594 & 0.625 & 0.646 & 0.682 \\
\hline Firm FE & YES & YES & YES & YES & YES & YES & YES & YES \\
\hline Year FE & NO & NO & NO & NO & YES & NO & NO & NO \\
\hline SASAC * Year FE & YES & YES & YES & YES & NO & YES & YES & YES \\
\hline Industry ${ }^{*}$ Year FE & NO & NO & YES & YES & NO & NO & YES & YES \\
\hline Province * Year FE & NO & $\mathrm{NO}$ & $\mathrm{NO}$ & YES & NO & $\mathrm{NO}$ & NO & YES \\
\hline
\end{tabular}


Table 8: Firm heterogeneity

This table reports results on firm heterogeneity: Panel A on political connection and Panel B on CEO ownership. PoliticalConnection is a dummy variable that equals one if either the general manager or the board chair was previously employed as a bureaucrat by the central government or a local government. CEOOwnership is the average fraction of shares held by a firm's general manager and board chair, multiplied by 100 . The dependent variable is Capex. Capex is capital expenditure scaled by lagged total assets. InterestRate is a firm's interest expenses divided by the average of its interest-bearing debts at the beginning of the year and the end of each of the four quarters. The interest-bearing debts include short-term loans, long-term liabilities due within one year, long-term loans, bonds payable, and long-term payables. Post is a dummy equal to one if a firm is subject to the EVA policy in year $t$ and zero otherwise. Tobin's $Q$ is measured as the sum of the market value of equity and book value of total liabilities, divided by the book value of total assets. CashFlow is cash flow from operating activities, scaled by the lagged total assets. Log(Assets) is the natural logarithm of total assets. Leverage is total liabilities divided by total assets. All the control variables are lagged by one year except CashFlow. SASAC*Year, Industry*Year, and Province*Year are three interactive fixed effects. T-statistics computed with standard errors clustered at the SASAC and year levels are reported in the parentheses. ***, **, and * indicate significance at the $1 \%, 5 \%$, and $10 \%$ levels, respectively.

\begin{tabular}{|c|c|c|c|c|c|c|c|c|}
\hline & \multicolumn{4}{|c|}{ Panel A: Political connection } & \multicolumn{4}{|c|}{ Panel B. CEO ownership } \\
\hline & (1) & (2) & (3) & (4) & (5) & (6) & (7) & (8) \\
\hline Post $\times$ InterestRate & $\begin{array}{l}0.075 \\
(1.28)\end{array}$ & $\begin{array}{l}0.065 \\
(1.20)\end{array}$ & $\begin{array}{l}0.093 \\
(1.28)\end{array}$ & $\begin{array}{l}0.122 \\
(1.42)\end{array}$ & 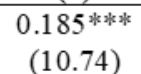 & $\begin{array}{c}0.175^{2} \text { 水水 } \\
(6.24)\end{array}$ & 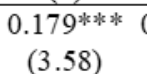 & $\begin{array}{c}0.195^{\text {* }} \text { 水水 } \\
(3.25)\end{array}$ \\
\hline Post $\times$ Interest Rate $\times$ Political Connection & $\begin{array}{c}0.327^{* * *} \\
(2.84)\end{array}$ & $\begin{array}{c}0.330^{* * *} \\
(2.76)\end{array}$ & $\begin{array}{c}0.249^{* * *} \\
(2.30)\end{array}$ & $\begin{array}{l}0.197^{*} \\
(1.68)\end{array}$ & & & & \\
\hline Post $\times$ PoliticalConnection & $\begin{array}{c}-0.026^{*} * k^{2} \\
(-2.38)\end{array}$ & $\begin{array}{c}-0.025^{*} * k \\
(-2.38)\end{array}$ & $\begin{array}{c}-0.020^{*} \\
(-2.06)\end{array}$ & $\begin{array}{l}-0.017 \\
(-1.56)\end{array}$ & & & & \\
\hline InterestRate $\times$ PoliticalConnection & $\begin{array}{c}-0.192^{*} \\
(-2.19)\end{array}$ & $\begin{array}{c}-0.170^{*} \\
(-1.85)\end{array}$ & $\begin{array}{l}-0.134 \\
(-1.41)\end{array}$ & $\begin{array}{l}-0.103 \\
(-0.88)\end{array}$ & & & & \\
\hline Post $\times$ InterestRate $\times$ CEOOwnership & & & & & $\begin{array}{l}-0.242 \\
(-1.38)\end{array}$ & $\begin{array}{c}-0.242^{* * *} \\
(-2.35)\end{array}$ & $\begin{array}{c}-0.383^{* *} * \\
(-2.59)\end{array}$ & 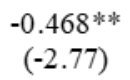 \\
\hline Post $\times$ CEOOwnership & & & & & $\begin{array}{l}0.001 \\
(0.07)\end{array}$ & $\begin{array}{l}0.000 \\
(0.00)\end{array}$ & $\begin{array}{l}0.001 \\
(0.19)\end{array}$ & $\begin{array}{l}0.003 \\
(0.39)\end{array}$ \\
\hline Interest Rate $\times$ CEOOwnership & & & & & $\begin{array}{l}-0.050 \\
(-0.36)\end{array}$ & $\begin{array}{l}-0.075 \\
(-0.60)\end{array}$ & $\begin{array}{l}-0.098 \\
(-1.01)\end{array}$ & $\begin{array}{l}-0.087 \\
(-0.92)\end{array}$ \\
\hline Post & $\begin{array}{l}0.003 \\
(0.51)\end{array}$ & & & & $\begin{array}{l}-0.005 \\
(-0.98)\end{array}$ & & & \\
\hline InterestRate & $\begin{array}{l}-0.124^{*} \\
(-2.09)\end{array}$ & $\begin{array}{l}-0.090 \\
(-1.24)\end{array}$ & $\begin{array}{l}-0.129 \\
(-1.55)\end{array}$ & $\begin{array}{l}-0.127 \\
(-1.51)\end{array}$ & $\begin{array}{c}-0.191 \text { * } \text { * }^{*} \text { 水 } \\
(-5.42)\end{array}$ & $\begin{array}{c}-0.150^{*} * * * \\
(-3.75)\end{array}$ & $\begin{array}{c}-0.175^{\text {** }} \text { 水 } \\
(-2.98)\end{array}$ & $\begin{array}{c}-0.165^{* * *} \\
(-2.89)\end{array}$ \\
\hline PoliticalConnection & $\begin{array}{c}0.023^{*}{ }^{*} k^{2} \\
(3.05)\end{array}$ & $\begin{array}{c}0.021^{\text {* }} \text { * } \\
(2.67)\end{array}$ & $\begin{array}{c}0.020^{*} \text { * } \\
(2.83)\end{array}$ & $\begin{array}{c}0.017^{*}{ }^{*} k^{2} \\
(2.31)\end{array}$ & & & & \\
\hline CEOOwnership & & & & & $\begin{array}{l}0.019 \\
(1.57)\end{array}$ & $\begin{array}{l}0.021^{*} \\
(2.02)\end{array}$ & $\begin{array}{c}0.023 * * \\
(2.52)\end{array}$ & $\begin{array}{c}0.022^{*} * \\
(2.45)\end{array}$ \\
\hline Tobin's $Q$ & $\begin{array}{c}0.007^{*} \text { 水 } \\
(2.84)\end{array}$ & $\begin{array}{c}0.006^{\text {** }} \\
(2.83)\end{array}$ & $\begin{array}{c}0.005^{\text {* } k^{2}} \\
(2.40)\end{array}$ & $\begin{array}{l}0.004^{*} \\
(1.81)\end{array}$ & $\begin{array}{l}0.007^{*} \\
(2.13)\end{array}$ & $\begin{array}{l}0.006^{*} \\
(1.95)\end{array}$ & $\begin{array}{l}0.005^{*} \\
(2.06)\end{array}$ & $\begin{array}{l}0.004 \\
(1.64)\end{array}$ \\
\hline Cash Flow & $\begin{array}{c}0.105^{\text {*k } * * *} \\
(6.56)\end{array}$ & 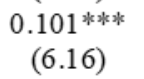 & $\begin{array}{c}0.087^{* * * *} * \\
(6.31)\end{array}$ & $\begin{array}{c}0.078^{*} \text { 水水 } \\
(6.27)\end{array}$ & $\begin{array}{c}0.105^{*} k^{*} * k \\
(6.66)\end{array}$ & 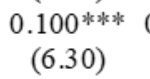 & $\begin{array}{c}0.087^{*} k_{k} * \\
(7.43)\end{array}$ & $\begin{array}{c}0.078^{* * * *} * \\
(6.85)\end{array}$ \\
\hline $\log ($ Assets $)$ & $\begin{array}{c}-0.016^{*} \\
(-1.98)\end{array}$ & $\begin{array}{c}-0.017^{*} \\
(-1.80)\end{array}$ & $\begin{array}{c}-0.021 * \\
(-2.05)\end{array}$ & $\begin{array}{c}-0.027^{\text {*3 }} \text { 水 } \\
(-2.81)\end{array}$ & $\begin{array}{l}-0.015 \\
(-1.51)\end{array}$ & $\begin{array}{l}-0.017 \\
(-1.48)\end{array}$ & $\begin{array}{c}-0.020^{*} \\
(-1.81)\end{array}$ & $\begin{array}{c}-0.026^{* *} \cdot k \\
(-2.42)\end{array}$ \\
\hline Leverage & $\begin{array}{c}-0.058^{*} \text { * } \\
(-2.86)\end{array}$ & $\begin{array}{c}-0.048^{* *} \cdot k \\
(-2.35)\end{array}$ & $\begin{array}{c}-0.039^{*} \\
(-1.91)\end{array}$ & $\begin{array}{l}-0.028 \\
(-1.53)\end{array}$ & $\begin{array}{c}-0.056^{*} \cdot k \\
(-2.79)\end{array}$ & $\begin{array}{c}-0.046^{*} \\
(-1.88)\end{array}$ & $\begin{array}{l}-0.038 \\
(-1.79)\end{array}$ & $\begin{array}{l}-0.027 \\
(-1.48)\end{array}$ \\
\hline Observations & 4,682 & 4,648 & 4,628 & 4,616 & 4,665 & 4,630 & 4,610 & 4,598 \\
\hline R-squared & 0.473 & 0.516 & 0.551 & 0.592 & 0.472 & 0.515 & 0.550 & 0.591 \\
\hline Firm FE & YES & YES & YES & YES & YES & YES & YES & YES \\
\hline Year FE & YES & NO & NO & NO & YES & NO & NO & NO \\
\hline SASAC ${ }^{*}$ Year FE & NO & YES & YES & YES & NO & YES & YES & YES \\
\hline Industry* Year FE & NO & NO & YES & YES & NO & NO & YES & YES \\
\hline Province*Year FE & NO & $\mathrm{NO}$ & NO & YES & NO & $\mathrm{NO}$ & NO & YES \\
\hline
\end{tabular}




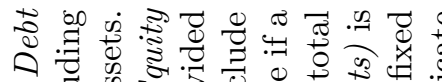

ह

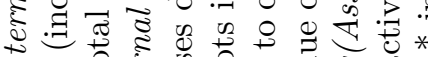

今े

के व

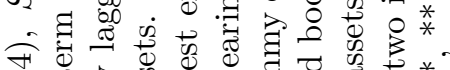

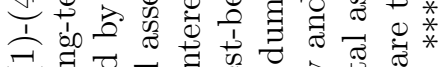

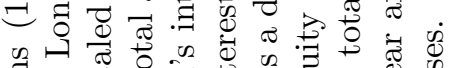

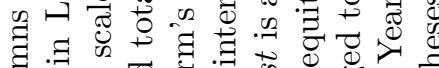

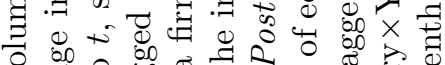

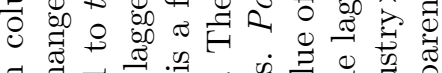

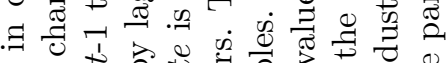

के

胥

క.

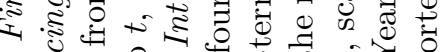

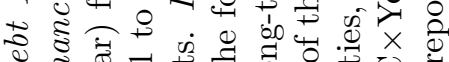

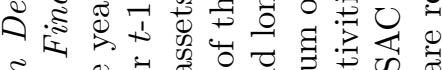

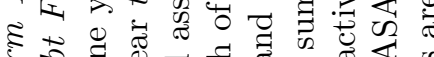

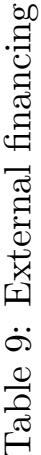

sँ 0 \%

के

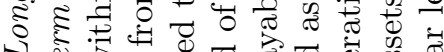

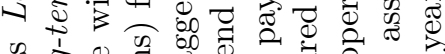

.

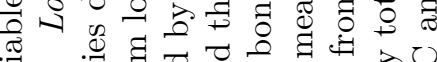

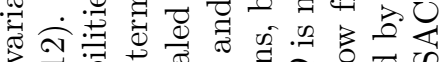

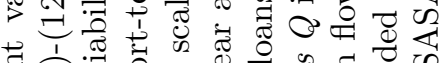

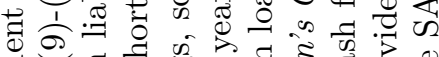

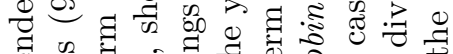

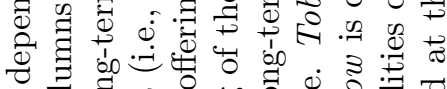

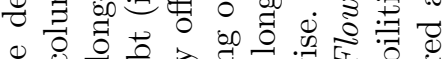

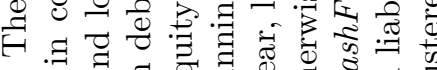

.

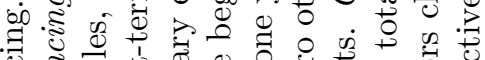

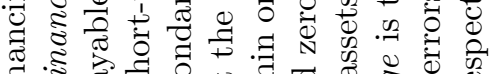

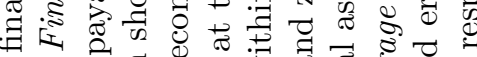

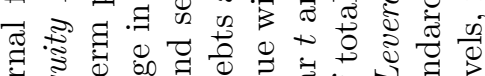

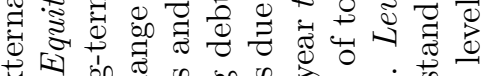

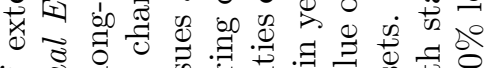
눙 온 0 .

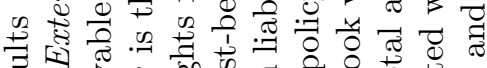
क

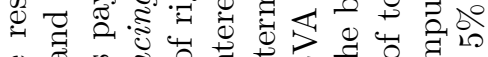

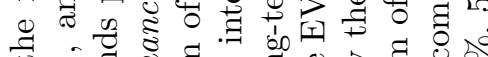
† के

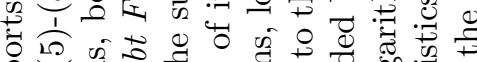

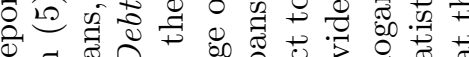
四 의 है के

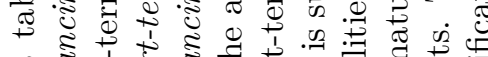

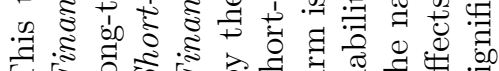

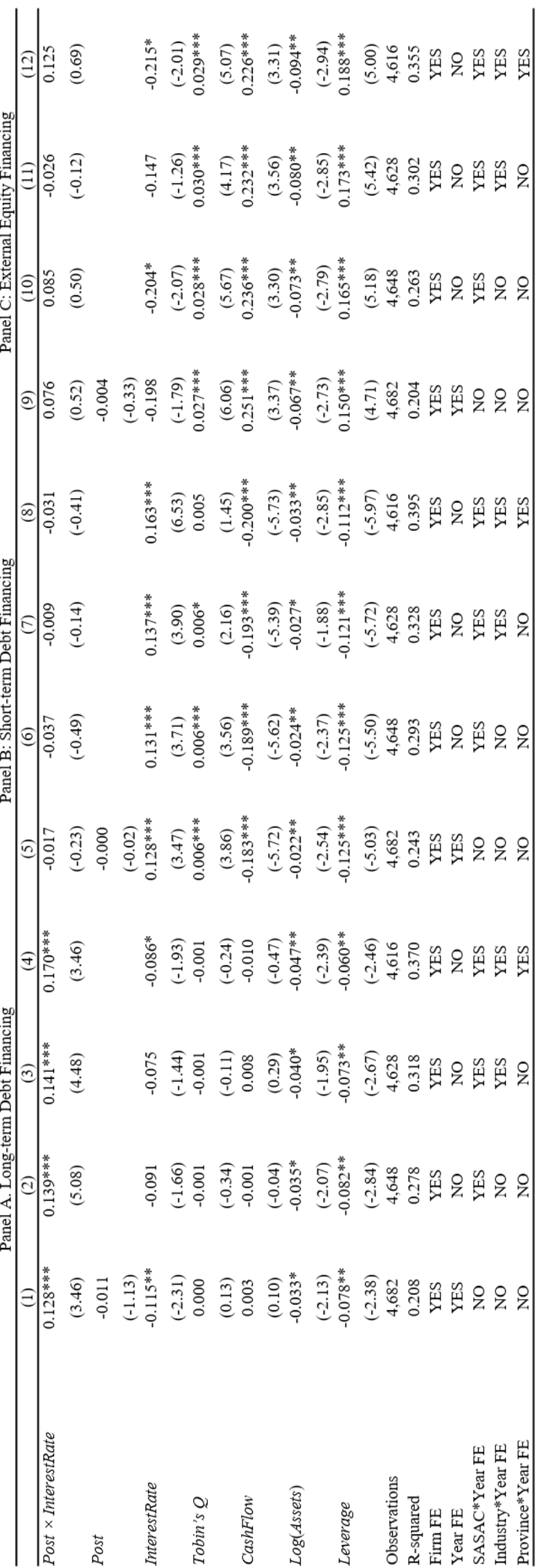


Table 10: R\&D expenses

This table reports the difference-in-differences tests on how the EVA policy affected firms' R\&D expenses. The dependent variable is $R \mathscr{E} D$. $R \mathscr{E} D$ is $\mathrm{R} \& \mathrm{D}$ expenses scaled by sales. Missing $\mathrm{R} \& \mathrm{D}$ values are treated as zero. Post is a dummy equal to one if a firm is subject to the EVA policy in year $t$ and zero otherwise. InterestRate is a firm's interest expenses divided by the average of its total debts at the beginning of the year and the end of each quarter. The total debts include short-term loans, long-term liabilities due within one year, long-term loans, bonds payable, and long-term payables. Tobin's $Q$ is measured as the sum of the market value of equity and book value of total liabilities, divided by the book value of total assets. CashFlow is cash flow from operating activities, scaled by the lagged total assets. Log(Assets) is the natural logarithm of total assets. Leverage is total liabilities divided by total assets. Industrym $\times$ Year are interactive fixed effects. Data of R\&D expenses are hand collected for 2004-2006 and are from CSMAR for 2007 onward. T-statistics computed with standard errors clustered at the SASAC and year levels are reported in the parentheses. ${ }^{* * *},{ }^{* *}$, and $*^{*}$ indicate significance at the $1 \%, 5 \%$, and $10 \%$ levels, respectively.

\begin{tabular}{lcccccc}
\hline & $(1)$ & $(2)$ & $(3)$ & $(4)$ & $(5)$ & $(6)$ \\
\hline Post & $0.015^{* * *}$ & $0.015^{* * *}$ & $0.015^{* * *}$ & $0.005^{* *}$ & $0.007^{* *}$ & $0.003^{* *}$ \\
& $(6.03)$ & $(6.19)$ & $(5.60)$ & $(2.69)$ & $(2.60)$ & $(2.47)$ \\
InterestRate & & 0.017 & 0.017 & $-0.030^{* * *}$ & -0.015 & -0.007 \\
& & $(1.22)$ & $(1.61)$ & $(-3.85)$ & $(-1.45)$ & $(-1.22)$ \\
Tobin's $Q$ & & $0.001^{*}$ & 0.001 & $0.001^{* *}$ & 0.000 & -0.000 \\
& & $(1.82)$ & $(1.38)$ & $(2.48)$ & $(0.43)$ & $(-0.40)$ \\
CashFlow & & $-0.008^{* *}$ & $-0.010^{* *}$ & -0.001 & -0.001 & $-0.003^{* *}$ \\
& & $(-1.98)$ & $(-2.03)$ & $(-0.68)$ & $(-0.36)$ & $(-2.30)$ \\
Log(Assets) & & & -0.001 & $-0.001 * * *$ & $-0.002 *$ & -0.001 \\
& & & $(-1.01)$ & $(-7.77)$ & $(-2.10)$ & $(-1.78)$ \\
Leverage & & & $-0.011^{* * *}$ & $-0.007 * * *$ & -0.004 & $-0.004^{* *}$ \\
& & & $(-3.61)$ & $(-3.50)$ & $(-1.25)$ & $(-2.36)$ \\
Observations & 4,714 & 4,714 & 4,714 & 4,714 & 4,679 & 4,659 \\
R-squared & 0.135 & 0.144 & 0.158 & 0.386 & 0.599 & 0.698 \\
Industry FE & NO & NO & NO & YES & NO & NO \\
Firm FE & NO & NO & NO & NO & YES & YES \\
Year FE & NO & NO & NO & YES & YES & NO \\
Industry*Year FE & NO & NO & NO & NO & NO & YES \\
\hline
\end{tabular}


Table 11: Cost of capital decomposition

In this table, we decompose the firm-level cost of capital into three components: within-in-industry dispersion, across-industry dispersion, and wedge between the EVA policy rate and the sample average. Panel A analyzes interest rate, and Panel B considers the cost of capital by accounting both the cost of debt and the cost of equity. We do the decomposition year by year. The reported fractions are the fractions of variations explained by each component, averaged across the sample years. In Panel B, each row represents the analysis of one choice of the market risk premium, from $5 \%$ to $8 \%$. We only include the pre-EVA firm-year observations.

\begin{tabular}{cccc}
\hline Market risk premium & Within-industry & Across-industry & Wedge b/w EVA rate and sample mean \\
\hline Panel A. Interest rate & \multicolumn{3}{c}{} \\
\hline N/A & 0.517 & 0.224 & 0.259 \\
\hline Panel B. Considering the cost of equity & & & \\
\hline $5 \%$ & 0.499 & 0.263 & 0.238 \\
$6 \%$ & 0.474 & 0.248 & 0.279 \\
$6.5 \%$ & 0.435 & 0.228 & 0.336 \\
$7 \%$ & 0.389 & 0.206 & 0.405 \\
$8 \%$ & 0.305 & 0.166 & 0.529 \\
\hline
\end{tabular}


Table 12: Capital reallocation between SOEs and non-SOEs

In this table, we examine how the EVA policy affected capital reallocation between SOEs and non-SOEs. The sample contains all SOEs from the SASACs that adopted the EVA (except the central SASAC) and non-SOEs from these provinces. The dependent variable is Capex. Capex is capital expenditure scaled by lagged total assets. Post is a dummy equal to one if a firm is subject to the EVA policy in year $t$ and zero otherwise. $S O E$ equals one for SOEs and zero for non-SOEs. Tobin's $Q$ is measured as the sum of the market value of equity and book value of total liabilities, divided by the book value of total assets. CashFlow is cash flow from operating activities, scaled by the lagged total assets. Log(Assets) is the natural logarithm of total assets. Leverage is total liabilities divided by total assets. High equals one for SOEs with an interest rate higher than the median of SOEs and zero otherwise. We do not include the SOEdummy in the model because it is absorbed by firm fixed effects. In column 5, High, SOE*High, and Post High are included but unreported. All the control variables are lagged by one year except CashFlow. T-statistics computed with standard errors clustered at the SASAC and year levels are reported in the parentheses. ***, **, and * indicate significance at the $1 \%, 5 \%$, and $10 \%$ levels, respectively.

\begin{tabular}{|c|c|c|c|c|c|}
\hline & (1) & (2) & (3) & (4) & (5) \\
\hline Post $\times S O E$ & $\begin{array}{l}-0.004 \\
(-0.49)\end{array}$ & $\begin{array}{l}0.004 \\
(0.32)\end{array}$ & $\begin{array}{l}0.009 \\
(1.01)\end{array}$ & $\begin{array}{l}0.009 \\
(0.98)\end{array}$ & $\begin{array}{l}-0.001 \\
(-0.07)\end{array}$ \\
\hline Post & $\begin{array}{l}0.004 \\
(0.76)\end{array}$ & & & & \\
\hline Post $\times$ SOE $\times$ High & & & & & $\begin{array}{c}0.018 * * * \\
(5.42)\end{array}$ \\
\hline Tobin's $Q$ & $\begin{array}{c}0.008 * * * \\
(5.47)\end{array}$ & $\begin{array}{c}0.008 * * * \\
(5.04)\end{array}$ & $\begin{array}{c}0.008 * * * \\
(5.56)\end{array}$ & $\begin{array}{c}0.008 * * * \\
(5.33)\end{array}$ & $\begin{array}{c}0.008 * * * \\
(5.21)\end{array}$ \\
\hline CashFlow & $\begin{array}{c}0.060 * * * \\
(3.30)\end{array}$ & $\begin{array}{c}0.055^{* * * *} \\
(3.21)\end{array}$ & $\begin{array}{c}0.048 * * \\
(2.89)\end{array}$ & $\begin{array}{c}0.048^{* *} \\
(2.81)\end{array}$ & $\begin{array}{c}0.048 * * \\
(2.64)\end{array}$ \\
\hline $\log$ (Assets) & $\begin{array}{c}-0.015^{*} \\
(-2.20)\end{array}$ & $\begin{array}{c}-0.018 * * \\
(-2.36)\end{array}$ & $\begin{array}{c}-0.020 * * \\
(-2.75)\end{array}$ & $\begin{array}{c}-0.019^{* *} \\
(-2.60)\end{array}$ & $\begin{array}{c}-0.019 * * \\
(-2.59)\end{array}$ \\
\hline Leverage & $\begin{array}{l}-0.012 \\
(-1.44)\end{array}$ & $\begin{array}{l}-0.015 \\
(-1.62)\end{array}$ & $\begin{array}{l}-0.013 \\
(-1.52)\end{array}$ & $\begin{array}{l}-0.014 \\
(-1.64)\end{array}$ & $\begin{array}{l}-0.013 \\
(-1.57)\end{array}$ \\
\hline Observations & 3,198 & 3,198 & 3,166 & 3,141 & 3,141 \\
\hline R-squared & 0.517 & 0.556 & 0.603 & 0.608 & 0.609 \\
\hline Firm FE & YES & YES & YES & YES & YES \\
\hline Year FE & YES & NO & NO & NO & NO \\
\hline SASAC*Year FE & NO & YES & YES & YES & YES \\
\hline Industry*Year FE & NO & NO & YES & YES & YES \\
\hline Province*Year FE & NO & NO & NO & YES & YES \\
\hline
\end{tabular}


Table 13: Aggregate capital productivity: Evidence based on $M R P K$ dispersion

This table reports the results on aggregate capital productivity. In columns (1) and (2), we only keep manufacturing firms in the analysis. In columns (3) and (4), we keep all the firms. We measure aggregate capital productivity using the dispersion of marginal revenue product of capital (MRPK) and examine how the EVA policy affects the dispersion. The unit of analysis is SASAC-year. The dependent variable is the dispersion of industry-adjusted $M R P K$ across all the SOEs under the control of a SASAC. MRPK is the natural logarithm of the ratio between operating profit and lagged fixed assets. Operating profit is sales minus costs of goods sold and selling, general and administrative expenses, plus depreciation. Post is a dummy equal to one if a firm is subject to the EVA policy in year $t$ and zero otherwise. Average Log(Assets) is the mean of lagged log total assets among firms controlled by a SASAC. Average Leverage is the mean of lagged leverage among firms controlled by a SASAC. T-statistics computed with standard errors clustered at the SASAC and year levels are reported in the parentheses. ${ }^{* * *},{ }^{* *}$, and ${ }^{*}$ indicate significance at the $1 \%, 5 \%$, and $10 \%$ levels, respectively.

\begin{tabular}{lcccc}
\hline & \multicolumn{2}{c}{ Manufacturing Firms } & \multicolumn{2}{c}{ All Firms } \\
\hline & $(1)$ & $(2)$ & $(3)$ & $(4)$ \\
\hline Post & 0.009 & -0.079 & -0.027 & -0.024 \\
& $(0.10)$ & $(-0.56)$ & $(-0.28)$ & $(-0.24)$ \\
Average Log(Assets) & & $-0.246^{* *}$ & & -0.141 \\
& $(-2.85)$ & & $(-1.24)$ \\
Average Leverage & & $1.360^{*}$ & & -0.270 \\
& & $(2.11)$ & 198 & $(-0.40)$ \\
Observations & 120 & 0.305 & 198 \\
R-squared & 120 & 0.452 & YES & 0.316 \\
SASAC FE & 0.397 & YES & YES & YES \\
Year FE & YES & YES & & YES \\
\hline
\end{tabular}


Figure 1: Year of EVA policy adoptiont

This figure reports the year of the EVA policy adoption. "Year of adoption" is the first year when the policy was effective. Hebei and Gansu consider the actual cost of capital in their EVA policies. Anhui sets the cost of capital at $4.5 \%$ instead of $5.5 \%$. Shaanxi sets a firm's cost of capital as the average return-on-assets of its industry peers. They are included in the figure but are excluded from our analysis. Tibet is excluded because its information is missing. Hong Kong, Macao, and Taiwan are also excluded as they do not have SASACs. "No EVA Adoption" indicates that the EVA has not been adopted by 2015.

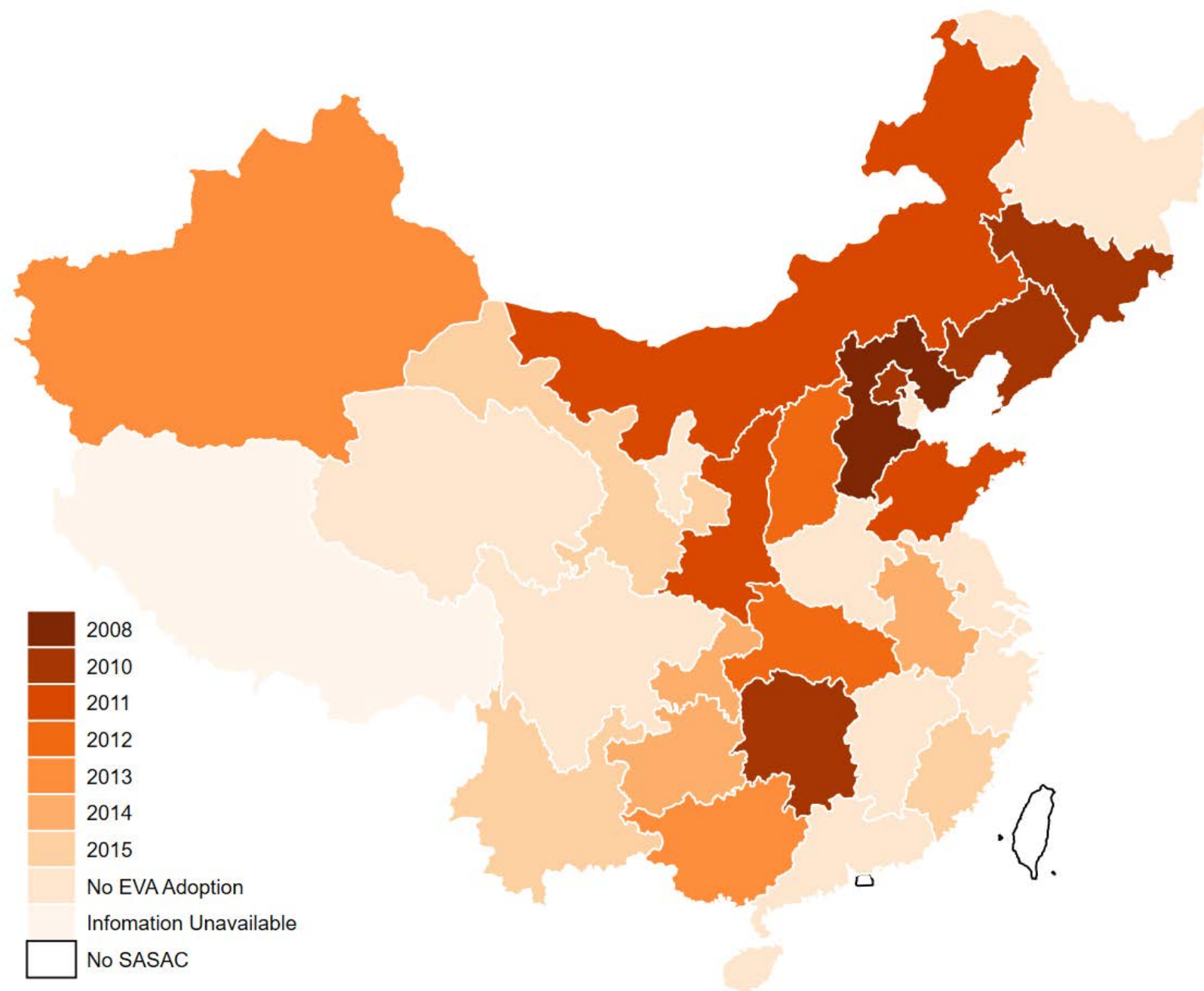


Figure 2: Parallel trends assumption

This figure presents the average Capex (the y-axis) for firms with high and low InterestRate by event year (the x-axis) from four years before to three years after the EVA adoption. Panel A reports the results of the treated SASACs, and Panel B reports the results of the control SASACs. We sort firms into High and Low InterestRate groups by the sample median based on the interest rate at the last year before EVA adoption. The solid red line represents the Low group, and the blue dashed line represents the High group. The dotted lines are the $95 \%$ confidence intervals. The dashed vertical line indicates the first year that the EVA policy was adopted.

Panel A: The treated SASACs

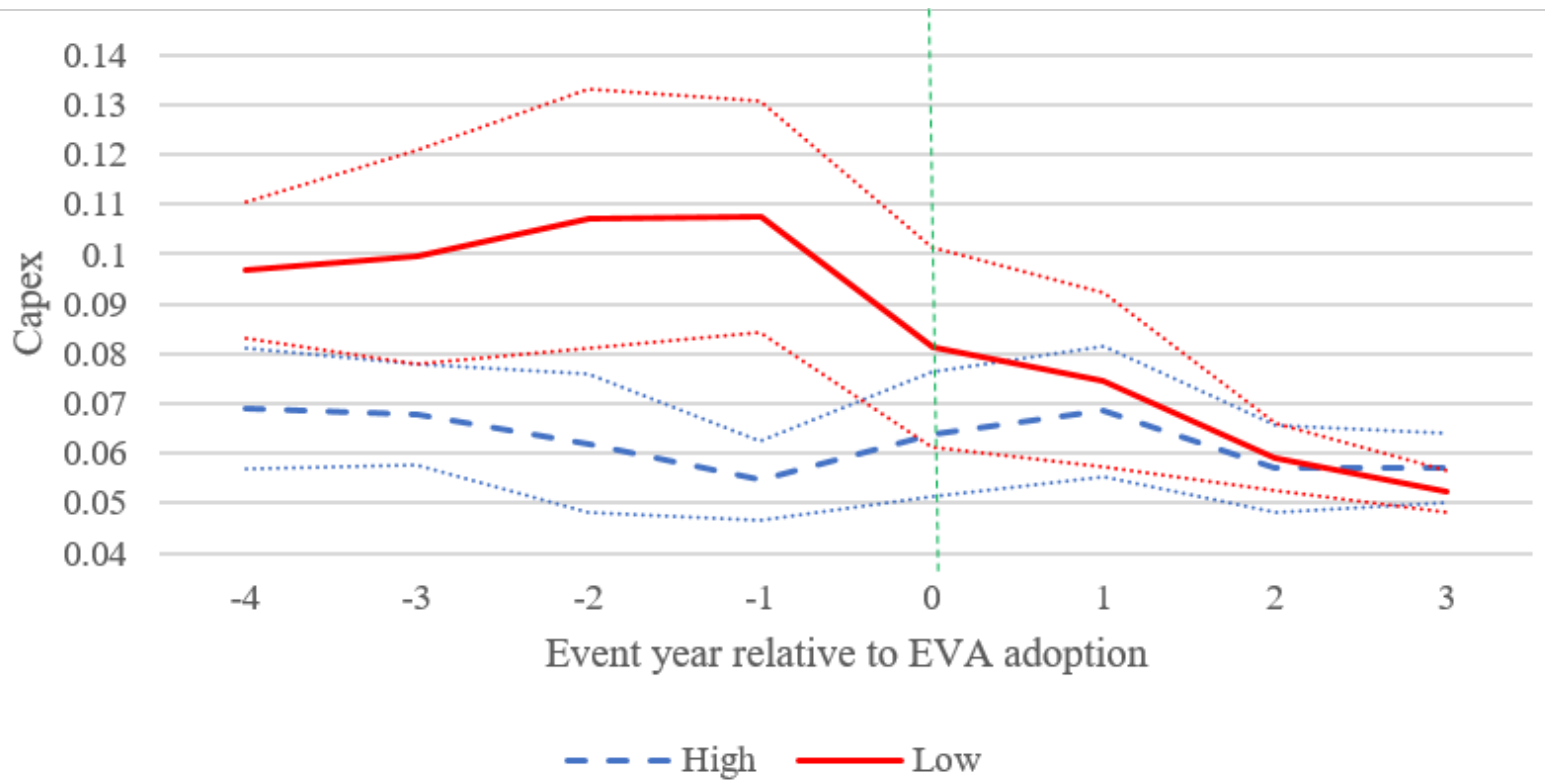

Panel B: The control SASACs

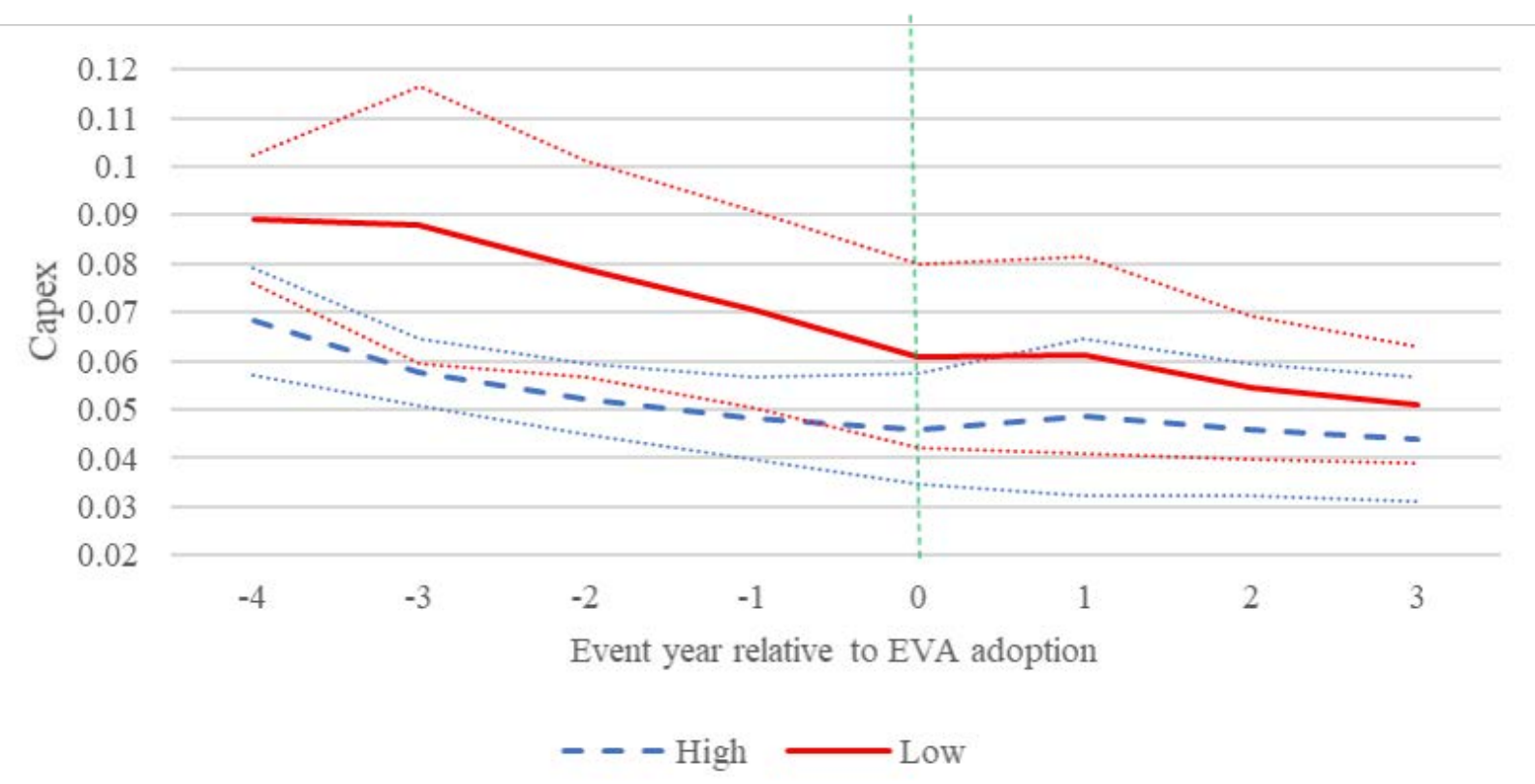


Figure 3: Dynamic regression coefficients

This figure reports the $\beta_{2, s}$ coefficients from the following regressions. In Panel $\mathrm{A}$, we include firm fixed effects, SASAC $\times$ year fixed effects, and the industry $\times$ year fixed effects. In Panel B, we further add the provincexyear fixed effects. The t-statistics are calculated by clustering at both the SASAC level and the year level.

$C A P E X_{i, t}^{j}=\beta_{1}$ InterestRate $_{i, t}^{j}+\sum_{s \neq-1} \beta_{2, s}$ Post $_{i, t, s}^{j}+\sum_{s \neq-1} \beta_{3, s}$ InterestRate $_{i, t}^{j} \times$ Post $_{i, t, s}^{j}+\gamma^{\prime} X_{i, t}+\epsilon_{i, t}$

Panel A: Without the province $\times$ year fixed effects

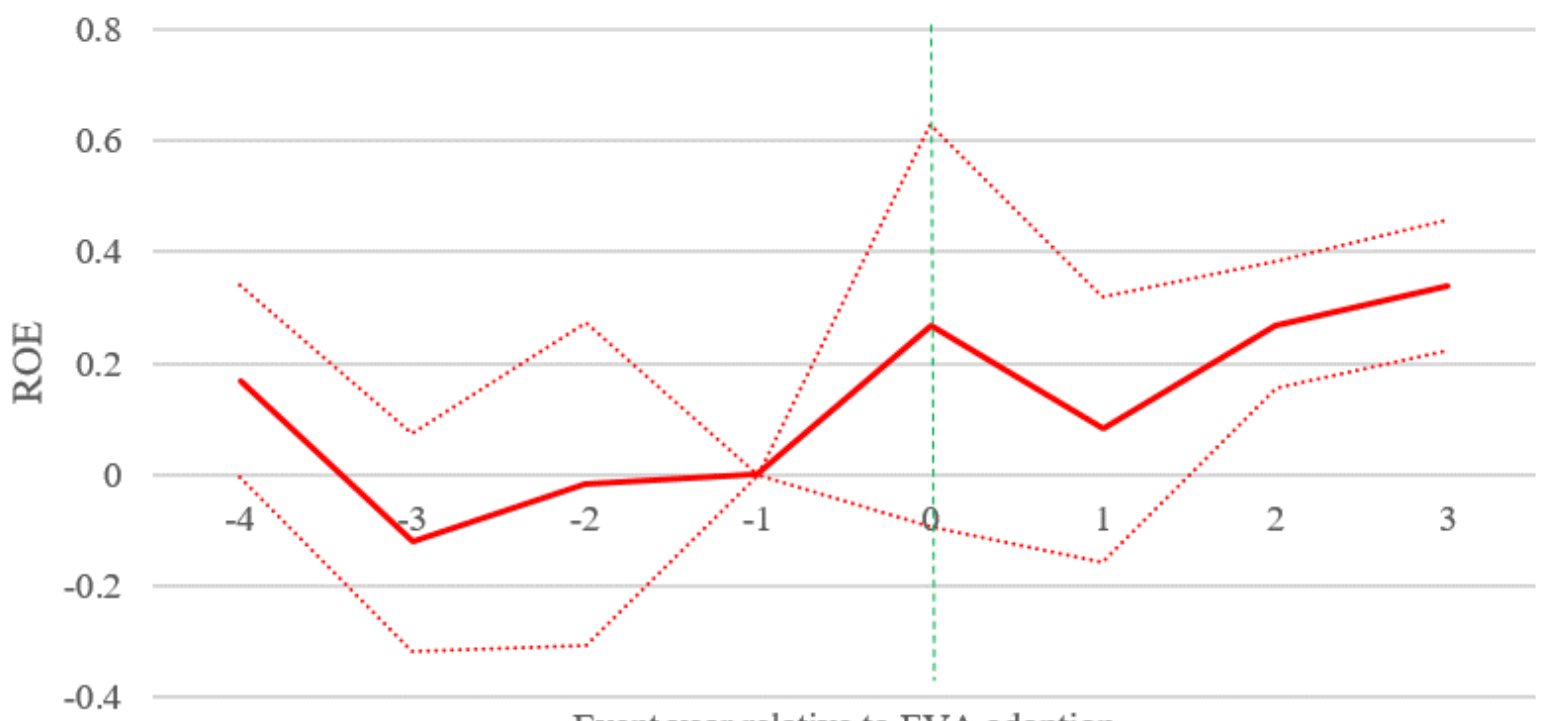

Event year relative to EVA adoption

Panel B: With the province* year fixed effects

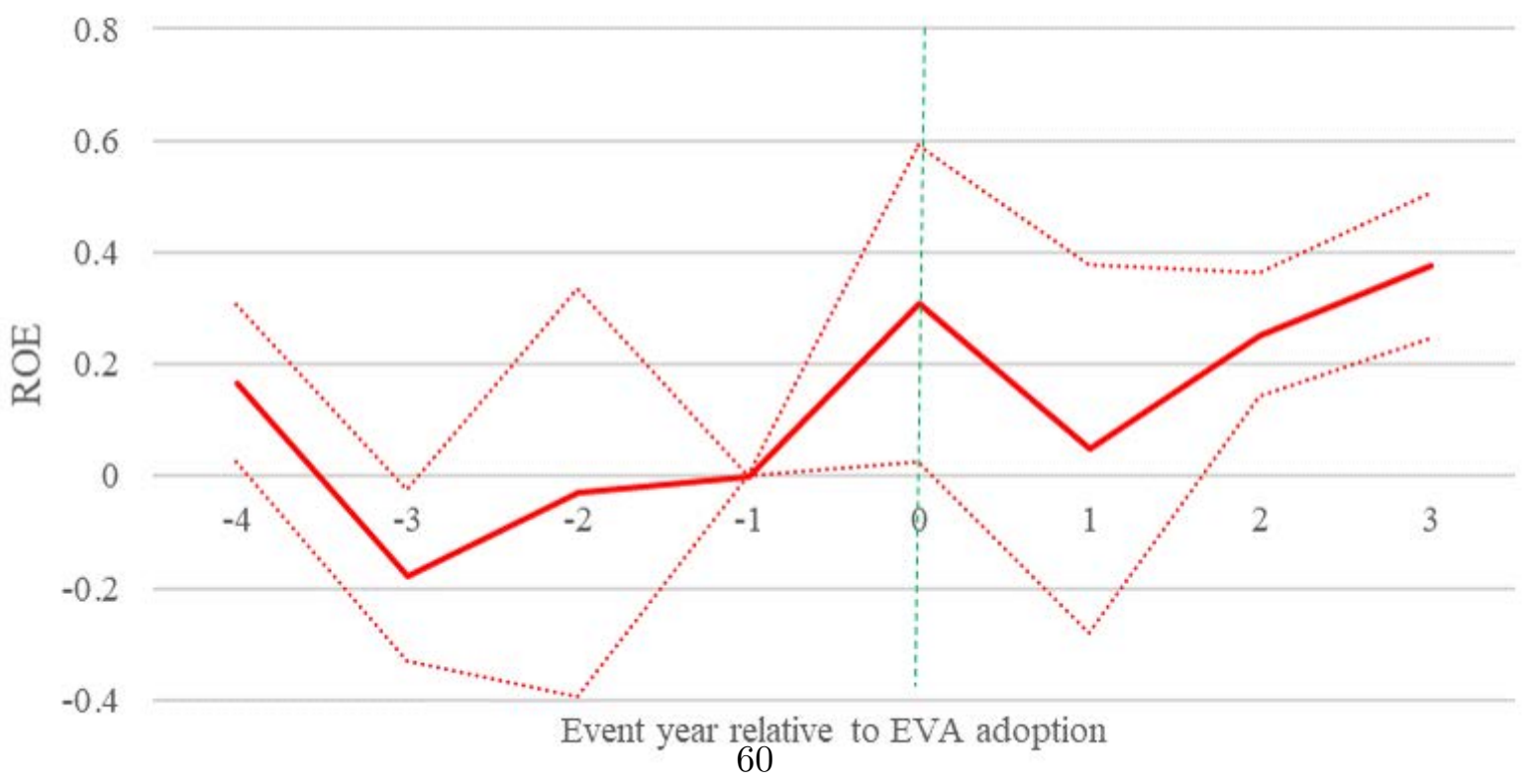


Figure 4: EVA and firm performance

This figure displays the change in firm performance (measured with ROE) by the level of interest rates. Firms are sorted into six groups by lagged interest rates. We classify firms with InterestRate below $2.5 \%$, between $2.5 \%$ and $4.5 \%$, between $4.5 \%$ and $6.5 \%$, between $6.5 \%$ and $8.5 \%$, between $8.5 \%$ and $10.5 \%$, and higher than $10.5 \%$, as group 1, group $2, \ldots$, and group 6 , respectively. Panel A displays the $\beta_{\text {Group }}$ coefficients of column 3 of Table 6 , and Panel B displays the $\beta_{\text {Group }}$ coefficients of column 4 of Table 6.

Panel A: without the province* year fixed effects

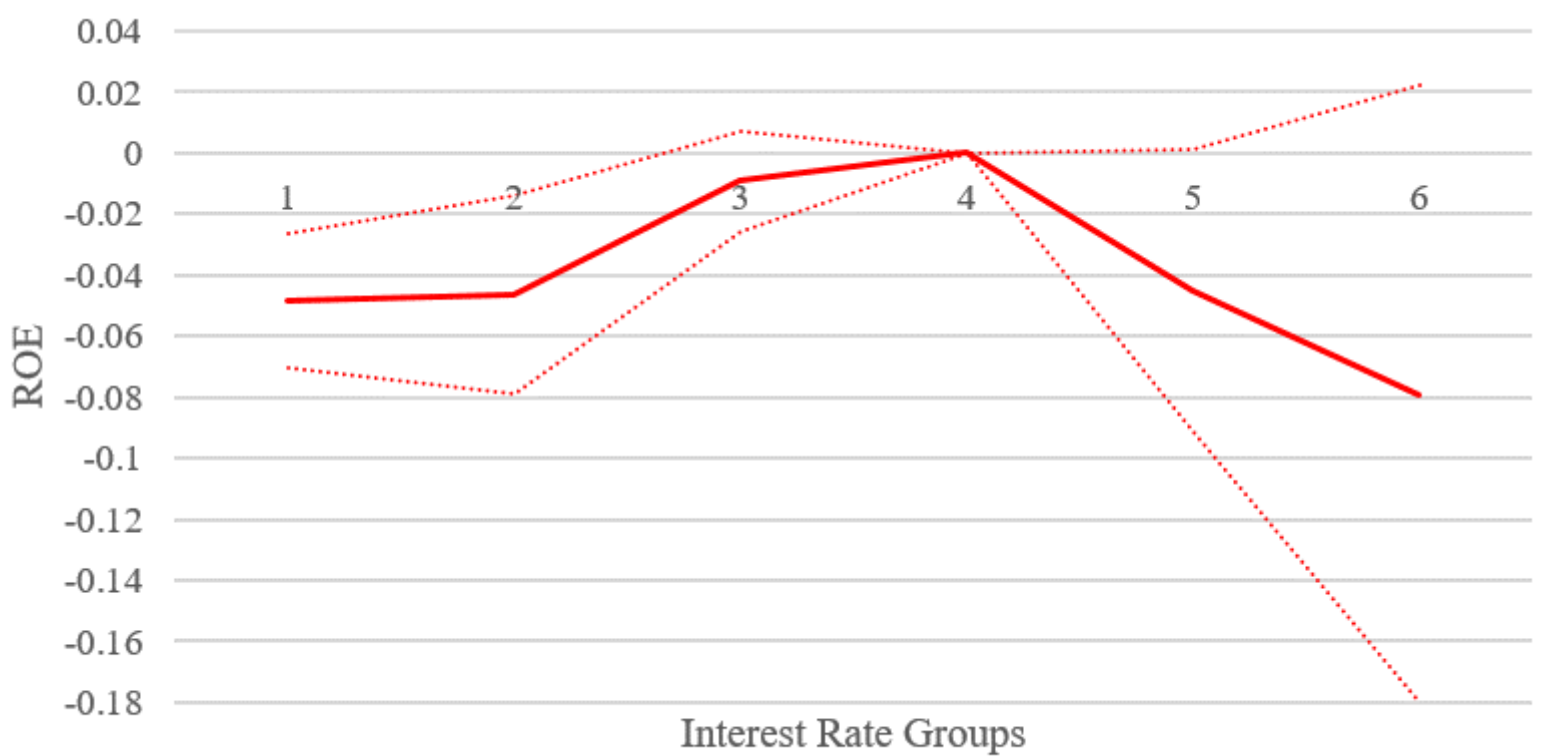

Panel B: with the province* year fixed effects

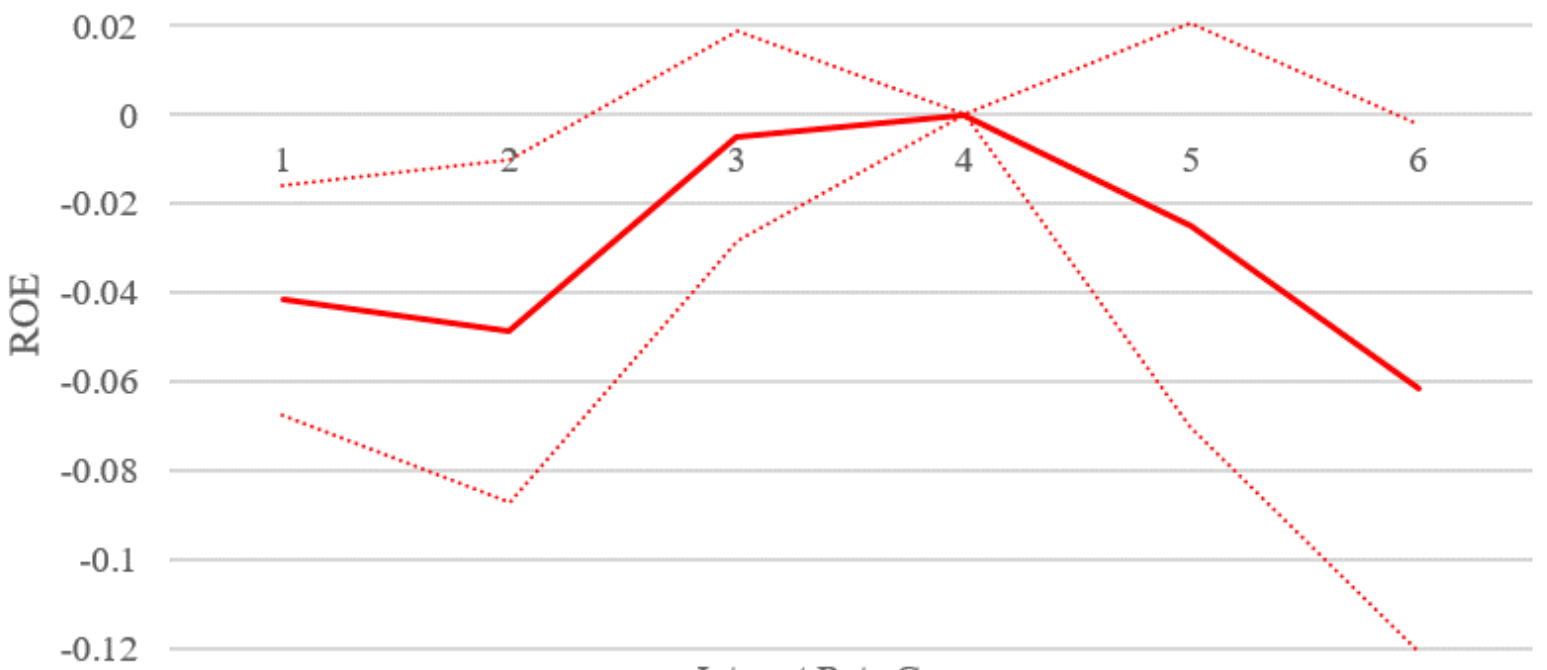

Interest Rate Groups 
Figure 5: EVA and firm investment based on industry average cost of capital

This figure presents the average Capex (the y-axis) for firms with high and low industry average cost of capital by event year (the x-axis) from four years before to three years after the EVA adoption. The sample includes the firms controlled by all the treated SASACs. We sort firms into High and Low cost of capital groups by the sample median based on the industry average cost of capital at the last year before EVA adoption. The solid red line represents the Low group, and the blue dashed line represents the High group. The dotted lines are the $95 \%$ confidence intervals. The dashed vertical line indicates the first year that the EVA policy was adopted.

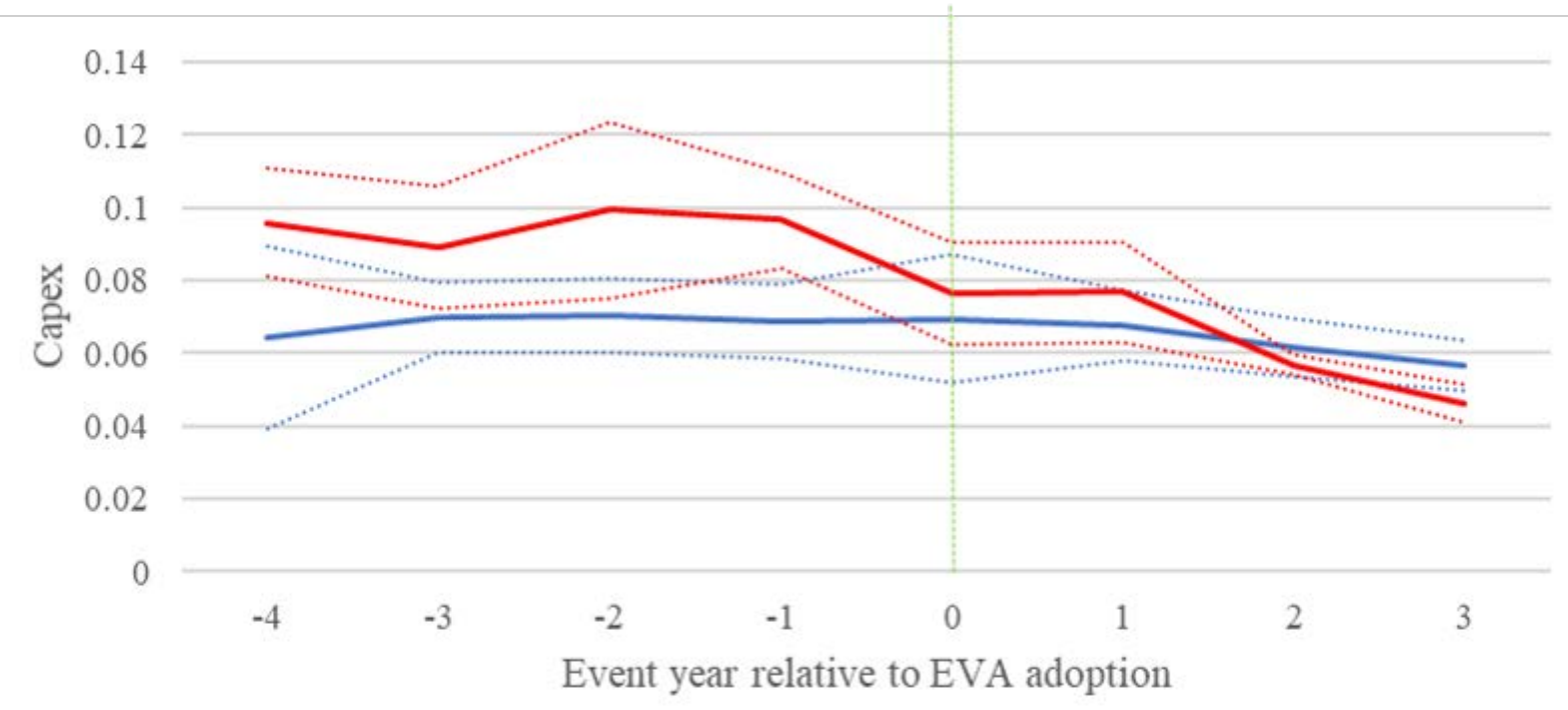

High L Low 


\section{A Appendix}

\section{A.1 An Example of a Project with Aggregate Risk}

Consider a one-period setting where an SOE firm is operating with a production function $F(K)=F(D+E)$, where $F^{\prime}(K)>0$ and $F^{\prime \prime}(K)<0$. Here, $K$ is the capital that the SOE is employing, with the accounting identify $K=D+E$ so that the physical capital asset $(K)$ is financed via either debt $(D)$ or equity $(E)$. Recall $F(K)$ is the firm's earnings before interests and taxes. Throughout our analysis is under the assumption that debt is the only margin to adjust; we, therefore, do not take a stand on the potential benefit of debt or the bankruptcy cost.

As explained in Section 3.1, the risk-neutral analysis we conduct in the main model goes through if the project involves idiosyncratic risk only. Now suppose that with probability $p \in(0,1)$ the

project succeeds and generates a cash flow of $\tilde{Y}=\frac{F(K)}{p}$, while with probability $1-p$ it fails with zero output $\tilde{Y}=0$; this implies the expected output is still $F(K)$. The "failure" state is an aggregate state with a higher risk-adjusted price; say that the Arrow-Debrew price of the "failure" state is $\theta>1$. In this example, for simplicity, we set the output after failure to be zero, which implies that the expected cash flows (under measure $\mathbb{P}$ ) are equal to the market value of the cash flows (under measure $\mathbb{Q}$ ); but our conclusion does not depend on this simplifying assumption. Finally, suppose that the time discount rate for deterministic cash flow streams is $\rho>1$.

We now derive the borrowing cost of the firm. Because the debt holders of this project receive nothing in the failure state, the equilibrium "quoted" interest rate should be

$$
\frac{p\left(1+r_{D}\right)}{\rho}=1 \Rightarrow r_{D}=\frac{\rho}{p}-1
$$

Because the lenders are fairly compensated for the aggregate risk (i.e., they lose the principal and interest in the failure state), $r_{D}$ is the right cost of capital that enters the firm's optimization 
decision. ${ }^{50}$ In fact, we can also solve for the implied risk-free rate in this economy, denoted by $r$, as

$$
\frac{p(1+r)+(1-p) \theta(1+r)}{\rho}=1 \Rightarrow r=\frac{\rho}{p+(1-p) \theta}-1
$$

The credit spread, which is defined as the difference between the quoted interest rate and the risk-free rate, is

$$
r_{D}-r=\frac{\rho}{p}-\frac{\rho}{p+(1-p) \theta}=\frac{(1-p) \rho \theta}{p(p+(1-p) \theta)}>0
$$

This example also offers a theoretical framework where the equilibrium interest rate $r_{D}$ is independent of leverage $D$, which is the running assumption in Eq. (4) as discussed extensively in Section 3.2. We emphasize that here $p$ captures the aggregate risk, and this framework is appealing in the context of Chinese SOEs whose default is extremely rare during our sample period 2009-2015.

\section{A.2 External Equity Financing}

During our sample period, external equity financing activities of Chinese listed firms were strictly regulated; for instance, concerning the poor corporate governance, the China Securities Regulatory Commission (CSRC) required a firm to have positive earnings and at least $20 \%$ dividend payout ratio over the past three years to qualify for public seasoned equity offerings.

In Table A.1, we show that in most of the years during our sample, less than $0.5 \%$ of listed firms conducted public seasoned equity offerings; dividend payments were low and strongly persistent, and repurchases were almost nonexistent. Since 2006, virtually all external equity was issued via private equity placements. Private equity placements required neither positive earnings nor a certain dividend payout, hence they were relatively easier to get approval. However, these private placements could serve a different purpose than financing investment as they typically involve either a change of controlling shareholders or the addition of new large shareholders. Consistent with the view of potential control change, we find that the average private placement's issuance amount is large (conditional on conducting a private placement, the new issuance was $42.6 \%$ of the existing

${ }^{50}$ More specifically, the firm who is taking into account of the aggregate risk is maximizing

$$
p \cdot \underbrace{\left[\frac{F(D+E)}{p}-r_{D} \cdot D\right]}_{\text {success }}+(1-p) \cdot \underbrace{0}_{\text {failure }}=F(D+E)-(1+\rho) D,
$$

and we use Eq. (19) to get the second equation. In fact, $F(D+E)$ is the market value of the cashflows $\tilde{Y}$ (evaluated at time 1) while the market value of investment (via debt) is $(1+\rho) D$. 
equity base), and about $70 \%$ of investors are either enterprises or private equities during our sample period. As a result, we assume that equity adjustment cost is prohibitive and assume that the debt is the margin to adjust for investment financing.

In Table A.2, we report that our results are robust if we exclude firms that conducted external equity financing around the EVA policy adoption.

\section{A.3 Dynamic Estimation for Group Companies}

We report the dynamic estimation results of the group company sample in Figure A.1. Specifically, Figure A.1 presents the $\beta_{3 s}$ coefficients from the following regression:

$C A P E X_{i, t}^{j}=\beta_{1} \cdot$ InterestRate $_{i, t}^{j}+\sum_{s \neq-1} \beta_{2 s} \cdot$ Post $_{i, t, s}^{j}+\sum_{s \neq-1} \beta_{3 s} \cdot$ InterestRate $_{i, t}^{j} \times$ Post $_{i, t, s}^{j}+\gamma^{\prime} \boldsymbol{X}_{i, t}+\epsilon_{i, t}$

Here, $s$ indicates the year relative to the EVA adoption, so for firm $i$ in year $t$, Post $_{i, t, s}^{j}=1$ if firm $i$ 's SASAC $j$ adopted the EVA policy in year $t-s$. We use the year before the EVA adoption $(s=-1)$ as the base year and estimate the coefficients of Post $\times$ InterestRate for each event year relative to the base year. The $t$-statistics are calculated by clustering at both the SASAC level and the year level.

\section{A.4 Summary Statistics of Non-SOEs}

Table A.3 reports the summary statistics of the listed non-SOE sample. Although we focus SOEs in our analysis, we also use the non-SOE sample in some regressions. The results show that the non-SOEs and SOEs have similar Capex - both the level and the distribution. Consistent with the literature on misallocation of resources between SOEs and non-SOEs in China (e.g., Song, Storesletten, and Zilibotti, 2011; Brandt, Tombe, and Zhu, 2013), in our sample of listed firms, non-SOEs are with a higher financing cost: the average InterestRate among non-SOEs is 6.5\%, which is $0.7 \%$ higher than the average InterestRate of SOEs. Based on the issuance yields of corporate bonds by listed firms in Chinese stock markets, Geng and Pan (2021) document a similar difference between SOEs and non-SOEs for their cost of debt. Like the SOE sample, Capex and InterestRate are strongly negatively correlated in the non-SOE sample, although the correlation coefficient is lower. The most distinct difference between SOEs and non-SOEs is perhaps their average size - on average, SOEs are much bigger than non-SOEs. Finally, it is not surprising to 
see that non-SOEs are with higher Tobin's $Q$ in general.

\section{A.5 Other Robustness Tests}

In Table A.4, we conduct two robustness tests. In Panel A, we drop the firms controlled by the central SASAC (about half of the sample). In Panel B, we trim the sample based on InterestRate. Overall, our results are robust to these alternative specifications. 
Table A.1: Summary of external equity financing

This table reports the summary statistics of the external equity financing of our sample firms. External equity financing includes rights issuance, non-rights public equity issuance, and private equity placements. We also consider cash dividend and stock repurchases.

Panel A: Fraction of firms with each type of external financing activity and the amount relative to existing share base

\begin{tabular}{|c|c|c|c|c|c|c|c|c|c|c|c|}
\hline Year & $\begin{array}{l}\text { Fraction of Firms } \\
\text { with External } \\
\text { Equity Financing }\end{array}$ & $\begin{array}{l}\text { Fraction of Firms } \\
\text { with Private } \\
\text { equity placements }\end{array}$ & $\begin{array}{l}\text { Fraction of Firms } \\
\text { with Right } \\
\text { sissuance }\end{array}$ & $\begin{array}{l}\text { Fraction of Firms } \\
\text { with non-rights } \\
\text { public equity } \\
\text { offerings }\end{array}$ & $\begin{array}{l}\text { Fraction of Firms } \\
\text { with public equity } \\
\text { offerings }\end{array}$ & $\begin{array}{l}\text { Private Equity } \\
\text { Placements/ } \\
\text { Existing Share } \\
\text { Base conditional } \\
\text { on being an issuer }\end{array}$ & $\begin{array}{l}\text { Rights Issuance/ } \\
\text { Existing Share } \\
\text { Base conditional } \\
\text { on being an issuer }\end{array}$ & $\begin{array}{l}\text { Non-rights public } \\
\text { equity offerings/ } \\
\text { Existing Share } \\
\text { Base conditional } \\
\text { on being an issuer }\end{array}$ & $\begin{array}{l}\text { Public equity } \\
\text { offerings/ Existing } \\
\text { Share Base } \\
\text { conditional } \\
\text { on being an issuer }\end{array}$ & $\begin{array}{l}\text { g Fraction of Firms } \\
\text { with cash } \\
\text { dividend payment }\end{array}$ & $\begin{array}{l}\text { Fraction of firms } \\
\text { with repurchases }\end{array}$ \\
\hline$\overline{2004}$ & $2.66 \%$ & $0.00 \%$ & $1.60 \%$ & $1.06 \%$ & $2.66 \%$ & $0.00 \%$ & $6.91 \%$ & $13.02 \%$ & $19.93 \%$ & $57.98 \%$ & $0.00 \%$ \\
\hline 2005 & $0.51 \%$ & $0.00 \%$ & $0.00 \%$ & $0.51 \%$ & $0.51 \%$ & $0.00 \%$ & $0.00 \%$ & $40.28 \%$ & $40.28 \%$ & $60.71 \%$ & $0.00 \%$ \\
\hline 2006 & $5.65 \%$ & $4.91 \%$ & $0.00 \%$ & $0.74 \%$ & $0.74 \%$ & $55.38 \%$ & $0.00 \%$ & $3.09 \%$ & $3.09 \%$ & $55.77 \%$ & $2.70 \%$ \\
\hline 2007 & $11.22 \%$ & $9.27 \%$ & $0.73 \%$ & $1.22 \%$ & $1.95 \%$ & $47.40 \%$ & $1.92 \%$ & $1.08 \%$ & $3.00 \%$ & $58.29 \%$ & $0.24 \%$ \\
\hline 2008 & $10.92 \%$ & $7.76 \%$ & $1.15 \%$ & $2.01 \%$ & $3.16 \%$ & $21.51 \%$ & $2.26 \%$ & $3.78 \%$ & $6.04 \%$ & $59.20 \%$ & $0.00 \%$ \\
\hline 2009 & $10.23 \%$ & $8.70 \%$ & $0.77 \%$ & $0.77 \%$ & $1.53 \%$ & $50.48 \%$ & $2.17 \%$ & $1.57 \%$ & $3.74 \%$ & $59.34 \%$ & $0.00 \%$ \\
\hline 2010 & $11.11 \%$ & $10.00 \%$ & $0.74 \%$ & $0.37 \%$ & $1.11 \%$ & $41.83 \%$ & $1.26 \%$ & $0.30 \%$ & $1.57 \%$ & $64.07 \%$ & $0.37 \%$ \\
\hline 2011 & $10.75 \%$ & $9.11 \%$ & $1.17 \%$ & $0.47 \%$ & $1.64 \%$ & $51.87 \%$ & $2.64 \%$ & $0.72 \%$ & $3.36 \%$ & $64.72 \%$ & $0.00 \%$ \\
\hline 2012 & $9.58 \%$ & $8.18 \%$ & $0.93 \%$ & $0.47 \%$ & $1.40 \%$ & $47.15 \%$ & $2.65 \%$ & $1.05 \%$ & $3.70 \%$ & $66.59 \%$ & $0.00 \%$ \\
\hline 2013 & $14.49 \%$ & $12.62 \%$ & $1.40 \%$ & $0.47 \%$ & $1.87 \%$ & $41.06 \%$ & $2.70 \%$ & $0.61 \%$ & $3.31 \%$ & $67.99 \%$ & $1.17 \%$ \\
\hline 2014 & $12.06 \%$ & $11.35 \%$ & $0.71 \%$ & $0.00 \%$ & $0.71 \%$ & $38.54 \%$ & $1.22 \%$ & $0.00 \%$ & $1.22 \%$ & $70.92 \%$ & $1.65 \%$ \\
\hline 2015 & $17.59 \%$ & $17.59 \%$ & $0.00 \%$ & $0.00 \%$ & $0.00 \%$ & $45.41 \%$ & $0.00 \%$ & $0.00 \%$ & $0.00 \%$ & $70.60 \%$ & $1.45 \%$ \\
\hline Mean & $9.80 \%$ & $8.38 \%$ & $0.76 \%$ & $0.66 \%$ & $1.42 \%$ & $42.62 \%$ & $1.79 \%$ & $1.43 \%$ & $3.22 \%$ & $63.17 \%$ & $0.66 \%$ \\
\hline
\end{tabular}

Panel B: Financing activity scaled by lagged assets

\begin{tabular}{|c|c|c|c|c|c|c|c|c|}
\hline Year & $\begin{array}{l}\text { External } \\
\text { Equity Financing / } \\
\text { Lagged Assets }\end{array}$ & $\begin{array}{l}\text { Rights Issues } \\
\text { / Lagged Assets }\end{array}$ & $\begin{array}{l}\text { Private Equity } \\
\text { Placements/Lagged } \\
\text { Assets }\end{array}$ & $\begin{array}{l}\text { Non-rights public } \\
\text { equity offerings / } \\
\text { Lagged Assets }\end{array}$ & $\begin{array}{l}\text { Cash Dividends/ } \\
\text { Lagged Assets }\end{array}$ & $\begin{array}{l}\text { Stock Repurchases/ } \\
\text { Lagged Assets }\end{array}$ & $\begin{array}{l}\text { Change in Debt/ } \\
\text { Lagged Assets }\end{array}$ & $\begin{array}{l}\text { | Change in Debt } \mid \text { / } \\
\text { Lagged Assets }\end{array}$ \\
\hline 2004 & $0.42 \%$ & $0.19 \%$ & $0.00 \%$ & $0.11 \%$ & $1.28 \%$ & $0.00 \%$ & $4.54 \%$ & $8.72 \%$ \\
\hline 2005 & $0.00 \%$ & $0.00 \%$ & $0.00 \%$ & $0.00 \%$ & $1.49 \%$ & $0.00 \%$ & $1.84 \%$ & $6.68 \%$ \\
\hline 2006 & $1.48 \%$ & $0.00 \%$ & $1.40 \%$ & $0.00 \%$ & $1.33 \%$ & $0.27 \%$ & $3.15 \%$ & $10.09 \%$ \\
\hline 2007 & $5.59 \%$ & $0.00 \%$ & $4.93 \%$ & $0.09 \%$ & $1.27 \%$ & $0.00 \%$ & $8.21 \%$ & $12.35 \%$ \\
\hline 2008 & $3.99 \%$ & $0.12 \%$ & $3.46 \%$ & $0.23 \%$ & $1.27 \%$ & $0.00 \%$ & $6.92 \%$ & $11.41 \%$ \\
\hline 2009 & $4.40 \%$ & $0.00 \%$ & $4.06 \%$ & $0.00 \%$ & $0.96 \%$ & $0.00 \%$ & $6.57 \%$ & $10.61 \%$ \\
\hline 2010 & $2.85 \%$ & $0.00 \%$ & $2.63 \%$ & $0.00 \%$ & $0.99 \%$ & $0.00 \%$ & $4.84 \%$ & $8.49 \%$ \\
\hline 2011 & $6.16 \%$ & $0.13 \%$ & $5.93 \%$ & $0.00 \%$ & $0.95 \%$ & $0.00 \%$ & $6.93 \%$ & $9.10 \%$ \\
\hline 2012 & $3.47 \%$ & $0.00 \%$ & $3.22 \%$ & $0.00 \%$ & $0.92 \%$ & $0.00 \%$ & $5.03 \%$ & $8.09 \%$ \\
\hline 2013 & $3.94 \%$ & $0.25 \%$ & $3.54 \%$ & $0.00 \%$ & $0.87 \%$ & $0.00 \%$ & $3.69 \%$ & $7.61 \%$ \\
\hline 2014 & $4.28 \%$ & $0.00 \%$ & $4.16 \%$ & $0.00 \%$ & $0.80 \%$ & $0.00 \%$ & $2.90 \%$ & $7.54 \%$ \\
\hline 2015 & $5.85 \%$ & $0.00 \%$ & $5.85 \%$ & $0.00 \%$ & $0.82 \%$ & $0.00 \%$ & $2.90 \%$ & $7.18 \%$ \\
\hline Mean & $3.60 \%$ & $0.06 \%$ & $3.33 \%$ & $0.03 \%$ & $1.08 \%$ & $0.02 \%$ & $4.77 \%$ & $8.96 \%$ \\
\hline
\end{tabular}


Table A.2: Excluding firms with external equity financing

This table reports the results of how the EVA policy affected firm investment. In this table, we exclude firms with any external equity financing from three years before to three years after the EVA policy adoption. We only include the firm-years from three years before to three years after the EVA policy adoption. The dependent variable is Capex. Capex is capital expenditure scaled by lagged total assets. InterestRate is a firm's interest expenses divided by the average of its interest-bearing debts at the beginning of the year and the end of each of the four quarters. The interest-bearing debts include short-term loans, long-term liabilities due within one year, long-term loans, bonds payable, and long-term payables. Tobin's $Q$ is measured as the sum of the market value of equity and book value of total liabilities, divided by the book value of total assets. CashFlow is cash flow from operating activities, scaled by the lagged total assets. Log(Assets) is the natural logarithm of total assets. Leverage is total liabilities divided by total assets. All the control variables are lagged by one year except CashFlow. SASAC $\times$ Year, Industry $\times$ Year, and Province $\times$ Year are three interactive fixed effects. T-statistics computed with standard errors clustered at the SASAC and year levels are reported in the parentheses. ${ }^{* * *},{ }^{* *}$, and * indicate significance at the $1 \%, 5 \%$, and $10 \%$ levels, respectively.

\begin{tabular}{|c|c|c|c|c|c|c|c|}
\hline & $(1)$ & (2) & (3) & (4) & (5) & (6) & (7) \\
\hline Post $\times$ InterestRate & $\begin{array}{c}0.192 * * * \\
(3.05)\end{array}$ & $\begin{array}{c}0.203^{* * *} \\
(5.14)\end{array}$ & $\begin{array}{c}0.229 * * * \\
(3.97)\end{array}$ & $\begin{array}{c}0.175^{* * *} \\
(4.16)\end{array}$ & $\begin{array}{c}0.136 * * * \\
(3.52)\end{array}$ & $\begin{array}{c}0.106^{* * *} \\
(5.70)\end{array}$ & $\begin{array}{c}0.118 * * \\
(2.67)\end{array}$ \\
\hline Post & $\begin{array}{c}-0.022 * * * \\
(-2.89)\end{array}$ & $\begin{array}{c}-0.020^{* * *} \\
(-3.10)\end{array}$ & $\begin{array}{c}-0.028 * * * \\
(-3.51)\end{array}$ & $\begin{array}{c}-0.013^{*} \\
(-2.00)\end{array}$ & & & \\
\hline InterestRate & $\begin{array}{c}-0.354 * * * \\
(-4.06)\end{array}$ & $\begin{array}{c}-0.330 * * * \\
(-5.73)\end{array}$ & $\begin{array}{c}-0.296 * * * \\
(-5.50)\end{array}$ & $\begin{array}{c}-0.086 * * \\
(-2.66)\end{array}$ & $\begin{array}{c}-0.054^{* *} \\
(-3.15)\end{array}$ & $\begin{array}{c}-0.070^{* *} \\
(-2.42)\end{array}$ & $\begin{array}{l}-0.094 \\
(-1.42)\end{array}$ \\
\hline Tobin's $Q$ & & $\begin{array}{l}0.000 \\
(0.06)\end{array}$ & $\begin{array}{l}0.002 \\
(1.14)\end{array}$ & $\begin{array}{l}0.002 \\
(1.20)\end{array}$ & $\begin{array}{l}0.002 \\
(1.17)\end{array}$ & $\begin{array}{l}-0.000 \\
(-0.08)\end{array}$ & $\begin{array}{l}0.004 \\
(1.29)\end{array}$ \\
\hline CashFlow & & $\begin{array}{c}0.221^{* * *} \\
(8.33)\end{array}$ & $\begin{array}{c}0.163 * * * \\
(7.92)\end{array}$ & $\begin{array}{c}0.071^{* * *} \\
\quad(3.52)\end{array}$ & $\begin{array}{c}0.079 * * * \\
(3.68)\end{array}$ & $\begin{array}{c}0.044^{* * *} \\
\quad(3.90)\end{array}$ & $\begin{array}{c}0.019^{*} \\
(1.86)\end{array}$ \\
\hline $\log$ (Assets) & & & $\begin{array}{c}0.010^{* * *} \\
(5.10)\end{array}$ & $\begin{array}{l}-0.013 \\
(-1.52)\end{array}$ & $\begin{array}{l}-0.012 \\
(-1.59)\end{array}$ & $\begin{array}{c}-0.025^{* *} \\
(-3.23)\end{array}$ & $\begin{array}{c}-0.038 * * * \\
(-3.39)\end{array}$ \\
\hline Leverage & & & $\begin{array}{c}-0.046 * * * \\
(-4.49)\end{array}$ & $\begin{array}{c}-0.067^{*} \\
(-1.88)\end{array}$ & $\begin{array}{l}-0.066 \\
(-1.81)\end{array}$ & $\begin{array}{l}-0.037 \\
(-1.21)\end{array}$ & $\begin{array}{l}0.015 \\
(0.37)\end{array}$ \\
\hline Observations & 993 & 993 & 993 & 950 & 931 & 905 & 863 \\
\hline R-squared & 0.029 & 0.098 & 0.149 & 0.609 & 0.622 & 0.700 & 0.773 \\
\hline Firm FE & NO & NO & NO & YES & YES & YES & YES \\
\hline Year FE & NO & NO & NO & YES & NO & NO & NO \\
\hline SASAC*Year FE & NO & NO & NO & NO & YES & YES & YES \\
\hline Industry*Year FE & NO & NO & NO & NO & NO & YES & YES \\
\hline Province*Year FE & NO & NO & $\mathrm{NO}$ & NO & NO & NO & YES \\
\hline
\end{tabular}


Table A.3: Summary Statistics for Non-SOEs

This table reports the summary statistics for non-SOEs: Panel A for mean, median, standard deviation, and percentiles and Panel B for correlations. Capex is capital expenditure scaled by the lagged total assets. InterestRate is a firm's interest expenses divided by the average of its interest-bearing debts at the beginning of the year and the end of each of the four quarters. The interest-bearing debts include short-term loans, long-term liabilities due within one year, long-term loans, bonds payable, and long-term payables. Tobin's $Q$ is measured as the sum of the market value of equity and book value of total liabilities, divided by the book value of total assets. CashFlow is cash flow from operating activities, scaled by the lagged total assets. $\log ($ Assets) is the natural logarithm of total assets. Leverage is total liabilities divided by total assets. ***, **, and $*$ indicate significance at the $1 \%, 5 \%$, and $10 \%$ levels, respectively.

Panel A: Mean, median, standard deviation, and percentiles

\begin{tabular}{lcccccc}
\hline & $\mathrm{N}$ & Mean & Median & Std. Dev. & P25 & P75 \\
\hline Capex & 6459 & 0.070 & 0.045 & 0.079 & 0.016 & 0.096 \\
InterestRate & 6459 & 0.065 & 0.060 & 0.045 & 0.047 & 0.072 \\
Tobin's $Q$ & 6459 & 2.618 & 1.959 & 3.158 & 1.437 & 2.912 \\
CashFlow & 6459 & 0.043 & 0.042 & 0.099 & -0.005 & 0.095 \\
Log(Assets) & 6459 & 21.375 & 21.319 & 1.071 & 20.663 & 22.05 \\
Leverage & 6459 & 0.517 & 0.466 & 0.569 & 0.309 & 0.620 \\
\hline
\end{tabular}

Panel B: Correlations

\begin{tabular}{lcccccc}
\hline & Capex & InterestRate & Tobin's $Q$ & CashFlow & Log(Assets) & Leverage \\
\hline Capex & 1 & & & & & \\
InterestRate & $-0.046^{* * *}$ & 1 & & & & \\
Tobin's $Q$ & $0.077^{* * *}$ & $0.118^{* * * *}$ & 1 & & & \\
CashFlow & $0.185^{* * *}$ & -0.011 & -0.013 & 1 & & \\
Log(Assets) & $-0.024^{*}$ & $-0.146^{* * *}$ & $-0.372^{* * *}$ & $0.029^{* *}$ & 1 & \\
Leverage & $-0.106^{* * *}$ & $0.066^{* * *}$ & $0.583^{* * *}$ & $-0.076^{* * *}$ & $-0.166^{* * *}$ & 1 \\
\hline
\end{tabular}


Table A.4: Other Robustness Tests

This table reports two robustness tests. In Panel A, we check whether the results are driven by firms controlled by the central SASAC. In Panel B, we drop the observations where InterestRate is extreme. Specifically, we drop the extreme values that are either lower than the 5th percentile (1.9\%) or higher than then 95th percentile (10.8\%). The dependent variable is Capex. Capex is capital expenditure scaled by the lagged total assets. InterestRate is a firm's interest expenses divided by the average of its interest-bearing debts at the beginning of the year and the end of each of the four quarters. The interest-bearing debts include short-term loans, long-term liabilities due within one year, long-term loans, bonds payable, and long-term payables. Post is a dummy equal to one if a firm is subject to the EVA policy in year $t$ and zero otherwise. Tobin's $Q$ is measured as the sum of the market value of equity and book value of total liabilities, divided by the book value of total assets. CashFlow is cash flow from operating activities, scaled by the lagged total assets. $\log ($ Assets $)$ is the natural logarithm of total assets. Leverage is total liabilities divided by total assets. All the control variables are lagged by one year except CashFlow. SASAC $\times$ Year, Industry $\times$ Year, and Province $\times$ Year are three interactive fixed effects. T-statistics computed with standard errors clustered at the SASAC and year levels are reported in the parentheses. ${ }^{* * *},{ }^{* *}$, and ${ }^{*}$ indicate significance at the $1 \%, 5 \%$, and $10 \%$ levels, respectively.

\begin{tabular}{lcccccccc}
\hline & \multicolumn{2}{c}{ Panel A. Dropping central SASAC firms } & \multicolumn{3}{c}{ Panel B: Dropping extreme InterestRate } \\
\hline & $(1)$ & $(2)$ & $(3)$ & $(4)$ & $(5)$ & $(6)$ & $(7)$ & $(8)$ \\
\hline Post $\times$ InterestRate & $0.226^{* *}$ & $0.209^{* * *}$ & $0.184^{*}$ & $0.185^{* *}$ & $0.382^{* * *}$ & $0.270^{* *}$ & $0.235^{* *}$ & $0.225^{* *}$ \\
& $(2.93)$ & $(3.34)$ & $(2.17)$ & $(2.15)$ & $(4.62)$ & $(2.62)$ & $(2.66)$ & $(2.50)$ \\
Post & -0.009 & & & & -0.013 & & & \\
& $(-1.18)$ & & & & $(-1.48)$ & & & \\
InterestRate & $-0.179^{* * *}$ & $-0.109^{* * *}$ & $-0.108^{* *}$ & $-0.110^{* *}$ & $-0.509^{* * *}$ & $-0.349^{* * *}$ & $-0.356^{* * *}$ & $-0.314^{* * *}$ \\
& $(-3.57)$ & $(-3.15)$ & $(-2.53)$ & $(-2.43)$ & $(-27.32)$ & $(-15.05)$ & $(-59.40)$ & $(-10.20)$ \\
Tobin's $Q$ & $0.007 * *$ & 0.006 & 0.004 & 0.005 & $0.007^{* * *}$ & $0.007 * * *$ & 0.005 & 0.005 \\
& $(2.27)$ & $(1.54)$ & $(1.19)$ & $(1.21)$ & $(3.48)$ & $(3.28)$ & $(1.75)$ & $(1.75)$ \\
CashFlow & $0.094^{* *}$ & $0.084^{* *}$ & $0.075^{*}$ & $0.078^{* *}$ & $0.117^{* * *}$ & $0.110^{* * *}$ & $0.098^{* * * *}$ & $0.084^{* * *}$ \\
& $(2.97)$ & $(2.58)$ & $(2.15)$ & $(2.26)$ & $(6.03)$ & $(4.77)$ & $(6.27)$ & $(5.99)$ \\
Log(Assets) & $-0.025^{* *}$ & $-0.028^{* *}$ & $-0.034^{*}$ & $-0.033^{*}$ & $-0.018^{*}$ & -0.019 & $-0.022^{*}$ & $-0.029^{* * *}$ \\
& $(-2.68)$ & $(-2.23)$ & $(-2.06)$ & $(-1.91)$ & $(-1.87)$ & $(-1.42)$ & $(-1.85)$ & $(-3.23)$ \\
Leverage & -0.050 & -0.028 & -0.017 & -0.019 & $-0.056^{* *}$ & $-0.047^{*}$ & -0.042 & -0.030 \\
& $(-1.56)$ & $(-0.88)$ & $(-0.59)$ & $(-0.61)$ & $(-2.86)$ & $(-1.95)$ & $(-1.65)$ & $(-1.48)$ \\
Observations & 2,504 & 2,468 & 2,447 & 2,442 & 4,209 & 4,169 & 4,149 & 4,130 \\
R-squared & 0.479 & 0.550 & 0.594 & 0.602 & 0.478 & 0.527 & 0.563 & 0.609 \\
Firm FE & YES & YES & YES & YES & YES & YES & YES & YES \\
Year FE & YES & NO & NO & NO & YES & NO & NO & NO \\
SASAC*Year FE & NO & YES & YES & YES & NO & YES & YES & YES \\
Industry*Year FE & NO & NO & YES & YES & NO & NO & YES & YES \\
Province*Year FE & NO & NO & NO & YES & NO & NO & NO & YES \\
\hline
\end{tabular}


Table A.5: Industry list

This table reports the list of industries in our sample: industry code, short description, and the number of observations.

\begin{tabular}{|c|c|c|c|}
\hline Number & Industry Code & Industry Name & \# of obs. \\
\hline 1 & $\mathrm{~A} 01$ & Agriculture & 15 \\
\hline 2 & $\mathrm{~A} 02$ & Forestry & 9 \\
\hline 3 & $\mathrm{~A} 03$ & Animal husbandry & 5 \\
\hline 4 & A04 & Fishery & 13 \\
\hline 5 & B06 & Coal mining and dressing industry & 132 \\
\hline 6 & B07 & Oil and natural gas exploitation industry & 29 \\
\hline 7 & B08 & Ferrous metal ore mining and dressing industry & 4 \\
\hline 8 & B09 & Non-ferrous metal ore mining and dressing industry & 63 \\
\hline 9 & B11 & Exploitation auxiliary activities & 25 \\
\hline 10 & $\mathrm{C} 13$ & Agricultural and sideline food processing industry & 29 \\
\hline 11 & $\mathrm{C} 14$ & Food manu facturing & 61 \\
\hline 12 & $\mathrm{C} 15$ & Alcohol, beverage and refined tea manufacturing & 70 \\
\hline 13 & $\mathrm{C} 17$ & Textile industry & 48 \\
\hline 14 & $\mathrm{C} 18$ & Textile garment and apparel industry & 10 \\
\hline 15 & $\mathrm{C} 22$ & Papermaking and paper product industry & 38 \\
\hline 16 & $\mathrm{C} 23$ & Printing and recording media reproduction industry & 11 \\
\hline 17 & $\mathrm{C} 25$ & Industries of petroleum processing, coking, and nuclear fuel processing & 69 \\
\hline 18 & $\mathrm{C} 26$ & Manufacturing of chemical raw materials and chemical products & 296 \\
\hline 19 & $\mathrm{C} 27$ & Pharmaceutical industry & 172 \\
\hline 20 & $\mathrm{C} 28$ & Chemical fiber manufacturing & 16 \\
\hline 21 & $\mathrm{C} 29$ & Industry of rubber and plastic products & 22 \\
\hline 22 & $\mathrm{C} 30$ & Industry of non-metallic mineral products & 109 \\
\hline 23 & $\mathrm{C} 31$ & Industry of ferrous metal smelting and rolling processing & 191 \\
\hline 24 & $\mathrm{C} 32$ & Industry of non-ferrous metal smelting and rolling processing & 176 \\
\hline 25 & $\mathrm{C} 33$ & Metal product industry & 46 \\
\hline 26 & $\mathrm{C} 34$ & General equipment manu facturing & 94 \\
\hline 27 & $\mathrm{C} 35$ & Special-purpose equipment manufacturing & 195 \\
\hline 28 & $\mathrm{C} 36$ & Automobile manufacturing & 240 \\
\hline 29 & $\mathrm{C} 37$ & Manufacturing of railways, ships, aircrafts, spacecrafts and other transportation equipment & 171 \\
\hline 30 & $\mathrm{C} 38$ & Electric machinery and equipment manufacturing & 91 \\
\hline 31 & $\mathrm{C} 39$ & Manufacturing of computers, communications and other electronic equipment & 354 \\
\hline 32 & $\mathrm{C} 40$ & Instrument and meter manufacturing & 10 \\
\hline 33 & $\mathrm{C} 41$ & Other manufacturing industries & 7 \\
\hline 34 & $\mathrm{C} 42$ & Industry of comprehensive utilization of waste resources & 2 \\
\hline 35 & D44 & Industry of electric power and heat production and supply & 276 \\
\hline 36 & D45 & Gas production and supply industry & 4 \\
\hline 37 & D46 & Water production and supply industry & 31 \\
\hline 38 & E48 & Civil engineering construction industry & 159 \\
\hline 39 & E49 & Construction installation industry & 12 \\
\hline 40 & E50 & Architectural decoration and other construction industries & 11 \\
\hline 41 & F51 & Wholesale industry & 258 \\
\hline 42 & F52 & Retail industry & 140 \\
\hline 43 & G54 & Road transport industry & 133 \\
\hline 44 & G55 & Waterway transport industry & 116 \\
\hline 45 & G56 & Air transport industry & 60 \\
\hline 46 & G58 & Industry of loading/unloading & 16 \\
\hline 47 & G59 & Storage industry & 12 \\
\hline 48 & H61 & Accommodation industry & 42 \\
\hline 49 & H62 & Catering industry & 7 \\
\hline 50 & I63 & Telecommunications, radio and television and satellite transmission services & 23 \\
\hline 51 & I64 & Internet and related services & 15 \\
\hline 52 & I65 & Industry of software and information technology services & 129 \\
\hline 53 & K70 & Real estate industry & 333 \\
\hline 54 & L72 & Commercial service industry & 29 \\
\hline 55 & M74 & Professional technical service industry & 18 \\
\hline 56 & N77 & Ecological protection and environmental governance industry & 7 \\
\hline 57 & N78 & Public facility management industry & 15 \\
\hline 58 & Q83 & Health & 14 \\
\hline 59 & R85 & Press and publishing industry & 19 \\
\hline 60 & $\mathrm{~S} 90$ & Diversified industries & 14 \\
\hline
\end{tabular}


Table A.6: Capital reallocation across SOEs

In this table, we examine how the EVA policy affected capital reallocation across SOEs with different MRPK. This table has the same sample as in our baseline analysis with the requirement that we can calculate $M R P K$. Capex is capital expenditure scaled by lagged total assets. MRPK is the natural logarithm of the ratio between operating profit and lagged fixed assets. Operating profit is sales minus costs of goods sold and selling, general and administrative expenses, plus depreciation. $M R P K$ is industry-adjusted. SOE equals one for SOEs and zero for non-SOEs. Tobin's $Q$ is measured as the sum of the market value of equity and book value of total liabilities, divided by the book value of total assets. CashFlow is cash flow from operating activities, scaled by the lagged total assets. Log(Assets) is the natural logarithm of total assets. Leverage is total liabilities divided by total assets. All the control variables are lagged by one year except CashFlow. SASAC $\times$ Year, Industry $\times$ Year, and Province $\times$ Year are three interactive fixed effects. In columns (1) - (4), we only keep manufacturing firms in the analysis. T-statistics computed with standard errors clustered at the SASAC and year levels are reported in the parentheses. ${ }^{* *},{ }^{* *}$, and ${ }^{*}$ indicate significance at the $1 \%$, $5 \%$, and $10 \%$ levels, respectively.

\begin{tabular}{|c|c|c|c|c|c|c|c|c|}
\hline & \multicolumn{4}{|c|}{ Manufacturing Firms } & \multicolumn{4}{|c|}{ All Firms } \\
\hline & (1) & (2) & (3) & (4) & $(5)$ & $(6)$ & $(7)$ & $(8)$ \\
\hline Post $\times M R P K$ & $\begin{array}{l}0.002 \\
(0.54)\end{array}$ & $\begin{array}{l}0.002 \\
(0.39)\end{array}$ & $\begin{array}{l}-0.001 \\
(-0.33)\end{array}$ & $\begin{array}{l}-0.000 \\
(-0.01)\end{array}$ & $\begin{array}{l}0.005 \\
(1.55)\end{array}$ & $\begin{array}{l}0.005^{*} \\
(1.85)\end{array}$ & $\begin{array}{l}0.002 \\
(0.74)\end{array}$ & $\begin{array}{l}0.005 \\
(1.09)\end{array}$ \\
\hline Post & $\begin{array}{l}0.012 \\
(1.64)\end{array}$ & & & & $\begin{array}{l}0.006 \\
(1.12)\end{array}$ & & & \\
\hline$M R P K$ & $\begin{array}{c}0.015^{\text {*k*k }} \text { k } \\
(3.98)\end{array}$ & $\begin{array}{c}0.016^{*} \text { *k } * \\
(4.94)\end{array}$ & $\begin{array}{c}0.017^{*} \text { * } k^{*} \cdot k \\
(5.40)\end{array}$ & 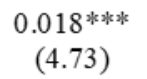 & $\begin{array}{c}0.009 \text { * } k^{*} * k \\
(4.83)\end{array}$ & $\begin{array}{c}0.009 \text { * } * \text { * } k^{*} \\
(5.31)\end{array}$ & $\begin{array}{c}0.009^{*} * * * \\
(5.19)\end{array}$ & $\begin{array}{c}0.007 \text { * } k^{*} * k \\
(4.10)\end{array}$ \\
\hline Tobin's $Q$ & $\begin{array}{l}0.001 \\
(0.25)\end{array}$ & $\begin{array}{l}0.001 \\
(0.28)\end{array}$ & $\begin{array}{l}0.001 \\
(0.29)\end{array}$ & $\begin{array}{l}0.001 \\
(0.24)\end{array}$ & 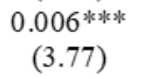 & $\begin{array}{c}0.005^{*} \text { *k } k^{*} \\
(3.87)\end{array}$ & $\begin{array}{c}0.005^{* * *} * k \\
(3.22)\end{array}$ & $\begin{array}{c}0.004^{* *} * \\
(2.63)\end{array}$ \\
\hline CashFlow & $\begin{array}{c}0.092^{\text {*k }} \text { k } \\
(5.35)\end{array}$ & 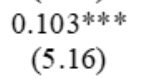 & 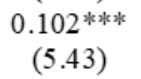 & 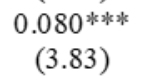 & $\begin{array}{c}0.096^{* * * *} * k \\
(8.23)\end{array}$ & $\begin{array}{c}0.090^{*} \text { * } k^{*} \cdot k \\
(6.75)\end{array}$ & $\begin{array}{c}0.078^{*} k^{*} * \\
(6.55)\end{array}$ & $\begin{array}{c}0.067^{\text {* } k^{*} *} \\
(4.83)\end{array}$ \\
\hline $\log ($ Assets $)$ & $\begin{array}{c}-0.025^{*} k^{2} \\
(-2.82)\end{array}$ & $\begin{array}{c}-0.026^{* k} \cdot k \\
(-2.73)\end{array}$ & $\begin{array}{c}-0.027^{\text {* }} \text { 水 } \\
(-2.84)\end{array}$ & 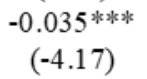 & $\begin{array}{c}-0.022^{*} * \\
(-2.82)\end{array}$ & 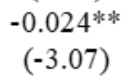 & $\begin{array}{c}-0.025^{\text {* }} \text { * } \\
(-2.91)\end{array}$ & 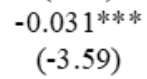 \\
\hline Leverage & $\begin{array}{l}-0.051 \\
(-1.75)\end{array}$ & $\begin{array}{l}-0.039 \\
(-1.31)\end{array}$ & $\begin{array}{l}-0.033 \\
(-1.16)\end{array}$ & $\begin{array}{l}-0.013 \\
(-0.33)\end{array}$ & $\begin{array}{c}-0.049^{*} \\
(-1.94)\end{array}$ & $\begin{array}{l}-0.033 \\
(-1.43)\end{array}$ & $\begin{array}{l}-0.033 \\
(-1.62)\end{array}$ & $\begin{array}{l}-0.029 \\
(-1.27)\end{array}$ \\
\hline Observations & 1,929 & 1,873 & 1,863 & 1,834 & 4,028 & 3,987 & 3,963 & 3,946 \\
\hline R-squared & 0.473 & 0.556 & 0.580 & 0.649 & 0.489 & 0.537 & 0.569 & 0.615 \\
\hline Firm FE & YES & YES & YES & YES & YES & YES & YES & YES \\
\hline Year FE & YES & NO & NO & NO & YES & NO & NO & NO \\
\hline SASAC*Year FE & NO & YES & YES & YES & NO & YES & YES & YES \\
\hline Industry*Year FE & NO & NO & YES & YES & NO & NO & YES & YES \\
\hline Province*Year FE & NO & NO & $\mathrm{NO}$ & YES & NO & $\mathrm{NO}$ & $\mathrm{NO}$ & YES \\
\hline
\end{tabular}


Table A.7: Cost of capital decomposition by year

In this table, we decompose the firm-level cost of capital into three components: within-in-industry dispersion, across-industry dispersion, and wedge between the EVA policy rate and the sample average. Panel A analyzes interest rate, and Panel B considers the cost of capital by accounting both the cost of debt and the cost of equity. We do the decomposition year by year. The reported fractions are the fractions of variations explained by each component, averaged across the sample years. In Panel B, we report the analysis of one choice of the market risk premium, $6.5 \%$. We only include the pre-EVA firm-year observations.

\begin{tabular}{|c|c|c|c|c|}
\hline Market risk premium & Year & Within-industry & Across-industry & Wedge b/w EVA rate and sample mean \\
\hline \multicolumn{5}{|l|}{ Panel A. Interest rate } \\
\hline $\mathrm{N} / \mathrm{A}$ & 2004 & 0.473 & 0.092 & 0.435 \\
\hline $\mathrm{N} / \mathrm{A}$ & 2005 & 0.535 & 0.169 & 0.296 \\
\hline N/A & 2006 & 0.652 & 0.144 & 0.204 \\
\hline N/A & 2007 & 0.633 & 0.236 & 0.131 \\
\hline $\mathrm{N} / \mathrm{A}$ & 2008 & 0.716 & 0.247 & 0.037 \\
\hline $\mathrm{N} / \mathrm{A}$ & 2009 & 0.324 & 0.128 & 0.548 \\
\hline $\mathrm{N} / \mathrm{A}$ & 2010 & 0.317 & 0.255 & 0.427 \\
\hline N/A & 2011 & 0.549 & 0.369 & 0.082 \\
\hline $\mathrm{N} / \mathrm{A}$ & 2012 & 0.516 & 0.451 & 0.033 \\
\hline $\mathrm{N} / \mathrm{A}$ & 2013 & 0.541 & 0.188 & 0.270 \\
\hline $\mathrm{N} / \mathrm{A}$ & 2014 & 0.654 & 0.242 & 0.104 \\
\hline $\mathrm{N} / \mathrm{A}$ & 2015 & 0.293 & 0.167 & 0.540 \\
\hline \multicolumn{5}{|c|}{ Panel B. Considering the cost of equity } \\
\hline $6.5 \%$ & 2004 & 0.426 & 0.150 & 0.424 \\
\hline $6.5 \%$ & 2005 & 0.725 & 0.274 & 0.001 \\
\hline $6.5 \%$ & 2006 & 0.536 & 0.263 & 0.201 \\
\hline $6.5 \%$ & 2007 & 0.197 & 0.106 & 0.697 \\
\hline $6.5 \%$ & 2008 & 0.716 & 0.284 & 0.000 \\
\hline $6.5 \%$ & 2009 & 0.587 & 0.252 & 0.161 \\
\hline $6.5 \%$ & 2010 & 0.225 & 0.198 & 0.577 \\
\hline $6.5 \%$ & 2011 & 0.316 & 0.263 & 0.421 \\
\hline $6.5 \%$ & 2012 & 0.338 & 0.273 & 0.389 \\
\hline $6.5 \%$ & 2013 & 0.254 & 0.121 & 0.625 \\
\hline $6.5 \%$ & 2014 & 0.301 & 0.173 & 0.527 \\
\hline $6.5 \%$ & 2015 & 0.603 & 0.384 & 0.013 \\
\hline
\end{tabular}


Figure A.1: Dynamic regression coefficients of group companies

This figure reports the $\beta_{2, s}$ coefficients from the following regressions based on the group company sample. In Panel A, we include firm fixed effects, SASAC $\times$ year fixed effects, and the industry $\times$ year fixed effects. In Panel B, we further add the provincexyear fixed effects. The t-statistics are calculated by clustering at both the SASAC level and the year level.

$C A P E X_{i, t}^{j}=\beta_{1}$ InterestRate $_{i, t}^{j}+\sum_{s \neq-1} \beta_{2, s}$ Post $_{i, t, s}^{j}+\sum_{s \neq-1} \beta_{3, s}$ InterestRate $_{i, t}^{j} \times$ Post $_{i, t, s}^{j}+\gamma^{\prime} X_{i, t}+\epsilon_{i, t}$

Panel A: Without the province $\times$ year fixed effects

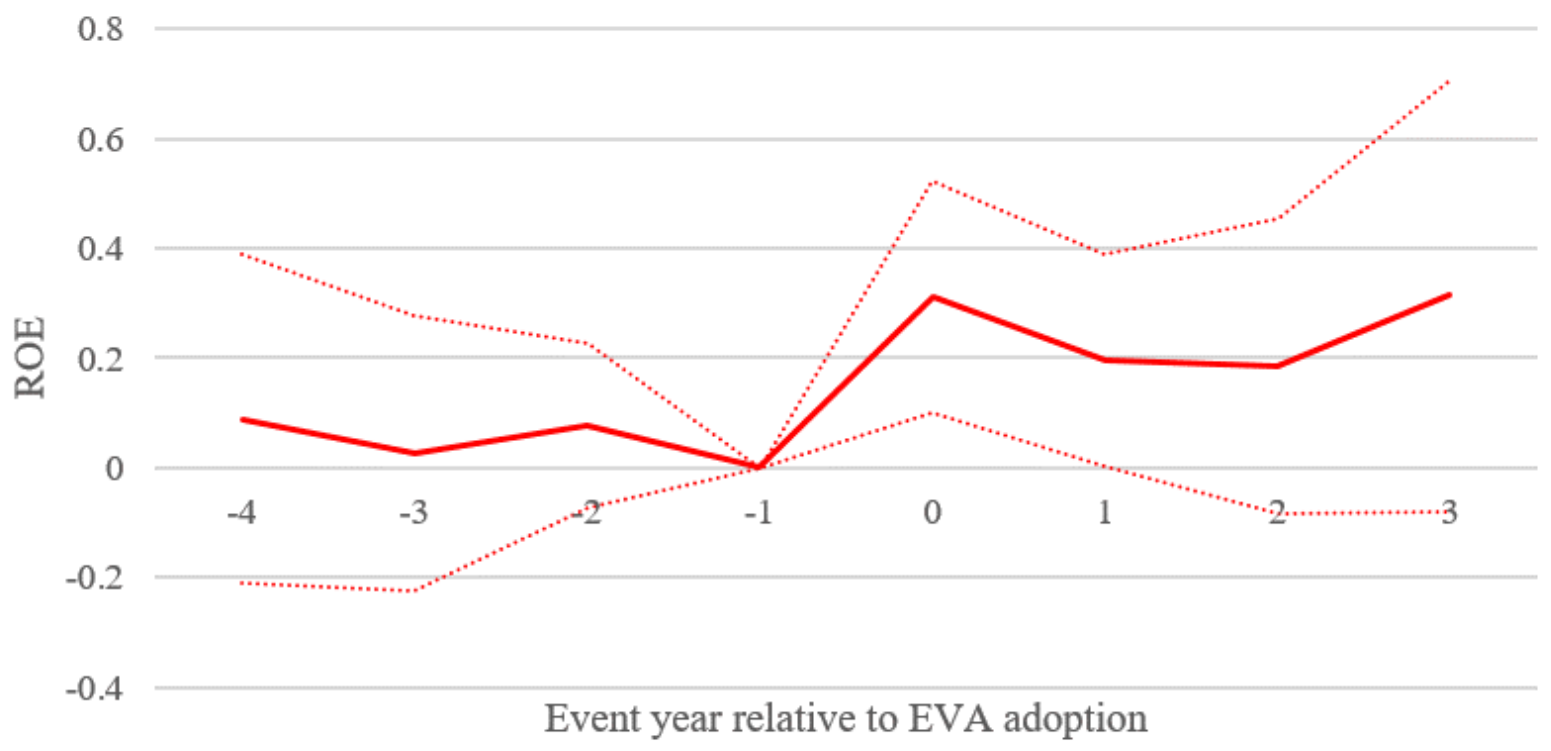

Panel B: With the province* year fixed effects

1

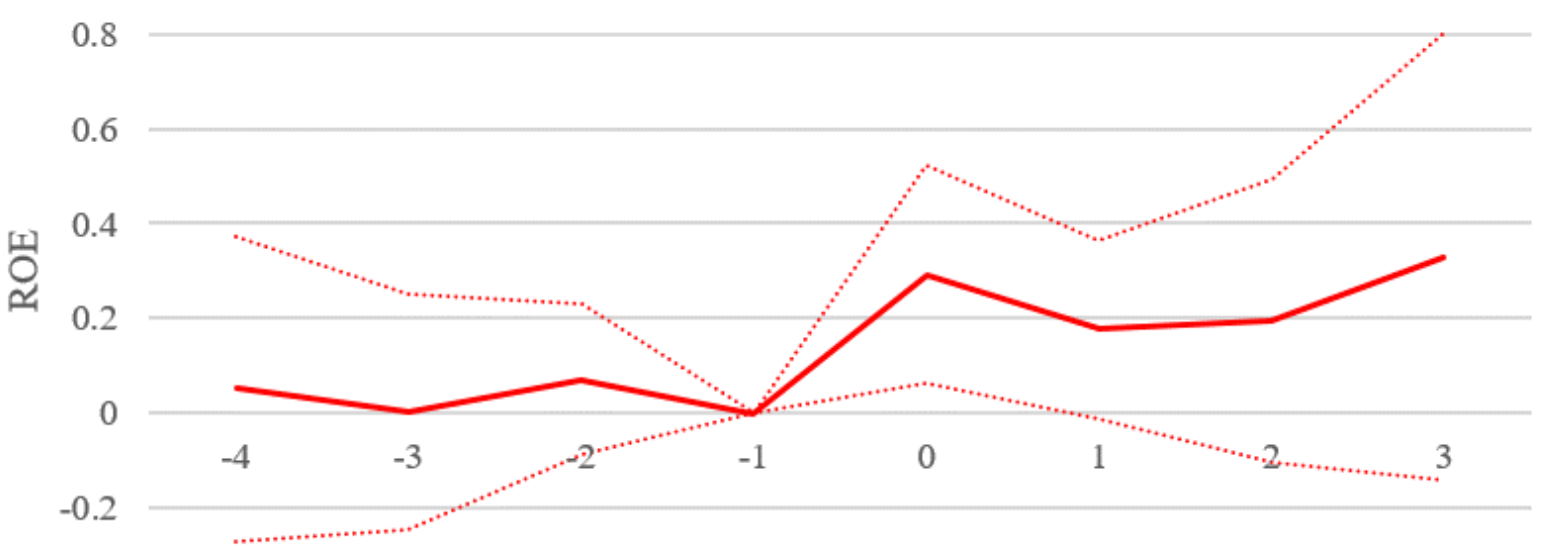

$-0.4$

Event year relative to EVA adoption 